\title{
Chapter 12 \\ Archaeobotany
}

\section{Introduction}

Archaeobotany is the study of plant remains from archaeological contexts, with aims to contribute to archaeological interpretations of past economies, foodways and in some cases environmental change. Archaeobotanical remains also provide evidence for the evolution of domesticated plants that have changed in the past as a result of human activities, in particular cultivation. As is most often the case, the present report will focus on seed and fruit remains (carpological analysis), which provides evidence mainly about food plants and agricultural systems. Other archaeobotanical datasets, such as wood charcoal and some charred parenchymatous remains (probably from tubers), are also present at Paithan and would repay future study. Archaeobotanical studies have a long history in India and have become increasingly systematic in terms of methods of recovery and sophistication of analytical and interpretative methodologies over the past few decades (Weber 2001; Fuller 2002). Nevertheless, the archaeobotanical record of India (and Pakistan) remains inconsistent. There are major variations between periods and regions that have been studied, with generally more evidence being available from the Neolithic and Chalcolithic periods, and often from regions that were foci of civilizations, such as the Indus and Ganges valleys, although the Southern Deccan is also well sampled (see Kajale 1991; Saraswat 1992; Fuller 2002, 2006a). Historical periods are generally more poorly represented, while Medieval and more recent times are almost entirely unsampled. Paithan, as a well-sampled site of Early Historic through Early Medieval times, is therefore of some significance. There are differences in the degree to which remains are counted and analysed quantitatively. In many published reports, only the presence of species is reported from individual samples or even site phases. A large body of research worldwide indicates that statistically significant quantitative patterns exist in archaeobotanical assemblages, structured by a combination of archaeological formation processes and past human activities, such as crop processing, agricultural prac- tices and in some cases dietary preferences (e.g. Jones 1991; Colledge 1998, 2001; Pearsall 2000; Stevens 2003; Wilkinson and Stevens 2003). One of the aims of this report is to show how quantification can contribute to our understanding of the Early Historic plant economy on the peninsula.

\section{Samples and their distribution}

Most samples were collected systematically in the 1998 and 1999 seasons and processed with a flotation machine that was set-up at the site. A few samples had been processed in 1997 by simple bucket flotation using the wash-over method (for details on various flotation methods, see Pearsall 2000). For many samples, initial sorting was carried out in the field, supervised by Peter Rowley-Conwy, and the separated seeds and non-wood material were then exported to the UK for further analysis. In addition, some unsorted flots were sorted in full in the UK. As such, the latter could be separated in a microscopy laboratory with rather more care. Seed density and diversity may have been affected by sampling method in these samples. As a result, sorted samples vary greatly in richness, and it is not possible to consider how sample richness might relate to past activity patterns; although it might repay further analysis to consider the impact of sampling and sorting procedures on data, it is beyond the scope of this interim report to do. Despite these concerns, the overall sample size from Paithan is considerable and allows us to consider patterns through time at the site and provides a firm basis for comparison to the rather more limited published Early Historic datasets from this region.

The raw data are presented in Table 12.1. The maximum seed count in one sample is 1,124 items, the minimum is 2 and the average is around 100 items per sample. Forty samples contain more than 30 items and 20 samples contain more than 70 . In terms of samples that are reliably phased on the basis of stratigraphic and artefactual evidence, the three main phases are fairly evenly represented by sample numbers, although the 
total seed counts are quite variable. We can therefore be more confident about the patterns in Period 1 and Period 3. A number of samples, especially from bucket flotation in 1997, come from contexts which could not be phased. They are included in the total site patterns and in a few cases contain well-preserved, identifiable remains. For most discussion, however, samples will be considered only where they are assigned to phases:

Period 1 (Pre-Satavahana, perhaps the 3rd century BC through to about the 1st century $\mathrm{BC}$ ): 17 samples and 2,529 seeds studied.

Period 2 (Satavahana period and later, probably 1st century $\mathrm{BC} / \mathrm{AD}-4$ th/5th century $\mathrm{AD}$ or perhaps earlier): 21 studied samples, but only 762 seeds identified.

Period 3 (construction of the earliest preserved Hindu temples on the site, probably 4th/5th century AD to 8th century AD or later): 17 samples and 1,128 seeds.

Period 4 (post-Medieval, 14th/15th to 17th century and later): only one archaeobotanical sample of this period has been studied. Those remaining in the Paithan archive would repay future analysis.

\section{General patterns in the evidence}

Broad patterns in the data can be illustrated by 'relative frequencies' and 'ubiquities', which are calculated for Periods 1-3 (based only on samples which were phased) and on site totals (including unphased samples). Relative frequency refers to the percentage of identified seeds (including indeterminate seeds but not indeterminate fragments) which are summed across all the samples for a phase. Ubiquity refers to the percent- age of samples in which a species is present. Thus, ubiquity is less prone to biases due to high versus low seed input into the record and preservation biases. It can be regarded as an estimate of recurrence of discard of species and for economic species recurrence of use. Relative frequency may be more useful for assessing how much of a species was used relative to another, but this may be heavily biased by numerous factors, especially differential preservation, which probably leads to higher rates of destruction for oily seeds as opposed to dry starchy seeds (like cereal grains and dried pulses), and differential rates of accidental loss during processing (e.g. more hulled cereals and podthreshing pulses versus free-threshing types). For weed seeds which are likely to be incidental inclusions in crop-processing waste, seed productivity may also be important, and thus, prolific seed producers such as Chenopodium may be over-represented in relation to smaller seed producers such as Convovulaceae or Malvaceae. Despite such biases, we expect assemblages prior to charring to have been structured by human activities, including the quantities of species used and processing practices, as the latter structure crop-chaffweed assemblages systematically (see e.g. Hillman 1984; Fuller 2002: 262-264; Stevens 2003; Harvey and Fuller 2005; Fuller and Weber 2005). Relative frequencies might therefore include more of a signal of activities, especially when considered on a sample-bysample basis, whereas ubiquity will be less informative except to indicate that taxa have been used.

In general terms, there is a higher occurrence of grain crops (cereals and pulses) during Paithan Period 1 than in later periods, with relative increases in the occurrence of rice, wheat and barley and winter pulses in Period 3. This is indicated by relative frequency (Fig.

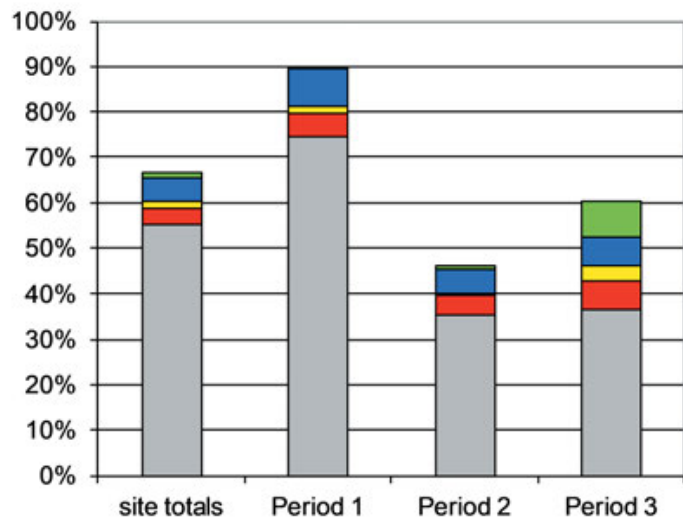

Fig. 12.1: Relative frequency of major crop groups.

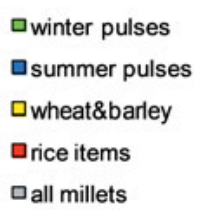

all millets 
12.1), where it can be seen that through all phases, millets dominate the archaeobotanical assemblage. This can be considered further through the ubiquity of some of the same crop groups together with some subdivisions of the millets (Fig. 12.2). In this, it can be seen that kodo millet (Paspalum scrobiculatum) is the most ubiquitous crop overall, followed by rice and the composite group of summer pulses. Kodo millet is also the dominant crop in terms of overall relative frequency, accounting for about $45 \%$ of all identified seeds. It can be noted, however, that the ubiquity of kodo millet declines through the three periods, whereas the small 'S/E/B' millets, which are mainly Brachiaria ramosa and Setaria italica, increase, as do African millets. Summer pulses show a similar trend and a Period 3 increase in winter pulses is also clear. This suggests an overall trend away from kodo millet cultivation towards a diverse range of millets, including the introduced African millets and Setaria italica. It is also worth noting the presence and persistence of the Southern Neolithic Ashmound millet, Brachiaria ramosa, as this is very much a relict and is, today, nearly extinct as a crop (Kimata et al. 2000) but was clearly a major staple in the earliest agriculture on the peninsula (Fuller et al. 2001, 2004). The decline of Brachiaria ramosa can therefore be hypothesized to post-date these Paithan samples. The trend towards more small millets in this long-embryo group is highlighted by a consideration of relative frequency (Fig. 12.3). Once again, increasing frequency is also seen in African millets and winter pulses, while the trend for summer pulses is less clear. With rice, wheat and barley, no single directional trend can be seen, but there is a decline in Period 2 and an increase that is more than a recovery in Period 3. On the whole, we might summarize the trends as indicating a move away from kodo millet dominance in Period
1 towards other millets and a further decline in kodo millet in Period 3 as other non-millet crops increased.

There is also a general tendency towards increasing cultivation of winter crops in the later phases of the site, seen especially in winter pulses. This is of interest because the predominant rainfall pattern in central Maharastra is the summer monsoon, and cultivation of winter crops poses some challenges and normally implies some form of artificial irrigation, as noted by Kajale (1988). While winter crops had been major staples in the region in the Chalcolithic (Kajale 1991; Fuller 2003c), there are indications that agriculture went into some decline after the Jorwe period. The particular emphasis on an increase in winter pulses may imply increasing double-cropping of the same lands. Pulses are naturally nitrogen-fixing plants and thus do not remove nitrates from the soil (Smartt 1990). Nitrates are one of the limiting nutrients for plant growth, and growing of legumes can help to replenish 'tired' soils. Thus, soils which were heavily and annually cropped for staple cereals in the summer might be planted with pulses in the winter to help replenish for use again the next year. This has two likely implications, which are not mutually exclusive: first, that cropping became increasingly continuous and fallow times were reduced between reuse of the same plot of land; and second, that cropping was expanded onto more marginal soils. In general the black regur soils of much of Maharastra are quite rich and thus move towards a regular rotation of cereals and pulses might imply use of locally poorer soils. Taken together, this evidence suggests moves to increased agricultural output, both through expansion (onto new lands and a wider range of soils) and intensification (by decreasing fallow periods and increasing repeated cropping on the same lands).

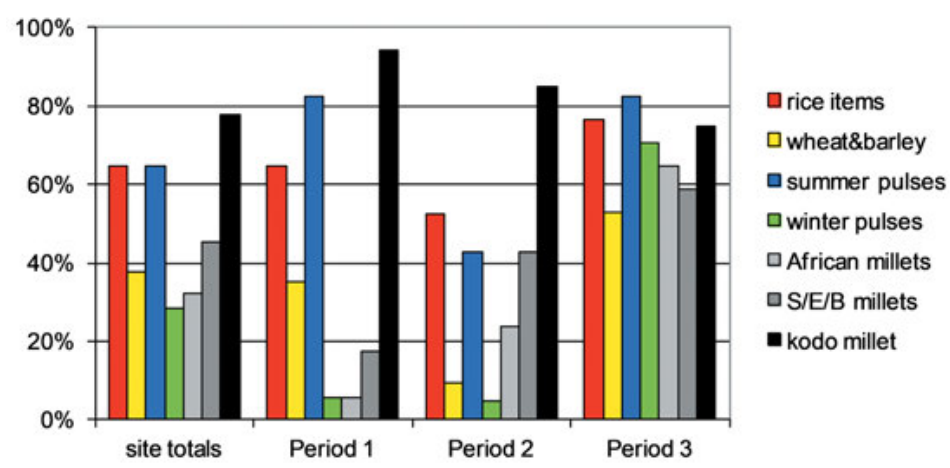

Fig. 12.2: Ubiquity of major crop groups and selected subdivisions of millets. 
Table 12.1a: Archaeobotanical data from Paithan. P: present; T: total.

\begin{tabular}{|c|c|c|c|c|c|c|c|c|c|c|c|c|c|c|c|c|c|c|}
\hline \multirow[t]{2}{*}{ Period } & \multirow[b]{2}{*}{$\begin{array}{l}\text { Site } \\
\text { total }\end{array}$} & \multirow[b]{2}{*}{ Freq. } & \multirow[b]{2}{*}{$\mathbf{P}$} & \multirow[b]{2}{*}{ Ubiquity } & \multicolumn{4}{|c|}{1} & \multicolumn{2}{|l|}{1} & \multicolumn{2}{|l|}{2} & \multicolumn{2}{|l|}{2} & \multirow{2}{*}{\multicolumn{2}{|c|}{$\begin{array}{l}3 \\
T\end{array}$}} & \multirow{2}{*}{\multicolumn{2}{|c|}{$\begin{array}{l}3 \\
P\end{array}$}} \\
\hline & & & & & & & $\mathbf{T}$ & & $\mathbf{P}$ & & $\mathbf{T}$ & & $\mathbf{P}$ & & & & & \\
\hline Pulses & & & & & $\begin{array}{l}\text { Pulse } \\
\text { items }\end{array}$ & e $\%$ & & & & & & & & & & & & \\
\hline $\begin{array}{l}\text { Vigna cf. aconitifolia } \\
\text { (whole) }\end{array}$ & 5 & $0.06 \%$ & 3 & $3.90 \%$ & 7 & 0.12 & 0 & $0 \%$ & 0 & $0 \%$ & 2 & $0 \%$ & 1 & $5 \%$ & 3 & $0 \%$ & 2 & $13 \%$ \\
\hline $\begin{array}{l}\text { Vigna cf. aconitifolia (coty- } \\
\text { ledon) }\end{array}$ & 1 & $0.01 \%$ & 1 & $1.30 \%$ & & & 1 & $0 \%$ & 1 & $6 \%$ & 0 & $0 \%$ & 0 & $0 \%$ & 0 & $0 \%$ & 0 & $0 \%$ \\
\hline $\begin{array}{l}\text { Vigna cf. aconitifolia (frag- } \\
\text { ment) }\end{array}$ & 1 & $0.01 \%$ & 1 & $1.30 \%$ & & & 0 & $0 \%$ & 0 & $0 \%$ & 1 & $0 \%$ & 1 & $5 \%$ & 0 & $0 \%$ & 0 & $0 \%$ \\
\hline Vigna cf. mungo (whole) & 4 & $0.05 \%$ & 3 & $3.90 \%$ & 12 & 0.20 & 0 & $0 \%$ & 0 & $0 \%$ & 0 & $0 \%$ & 0 & $0 \%$ & 3 & $0 \%$ & 2 & $13 \%$ \\
\hline $\begin{array}{l}\text { Vigna cf. mungo (cotyle- } \\
\text { don) }\end{array}$ & 8 & $0.10 \%$ & 6 & $7.79 \%$ & & & 0 & $0 \%$ & 0 & $0 \%$ & 2 & $0 \%$ & 1 & $5 \%$ & 4 & $0 \%$ & 4 & $25 \%$ \\
\hline Vigna cf. mungo (frags) & 0 & $0.00 \%$ & 0 & $0.00 \%$ & & & 0 & $0 \%$ & 0 & $0 \%$ & 0 & $0 \%$ & 0 & $0 \%$ & 0 & $0 \%$ & 0 & $0 \%$ \\
\hline Vigna cf. radiata (whole) & 10 & $0.12 \%$ & 7 & $9.09 \%$ & 29 & 0.50 & 0 & $0 \%$ & 0 & $0 \%$ & 2 & $0 \%$ & 2 & $10 \%$ & 8 & $1 \%$ & 5 & $31 \%$ \\
\hline $\begin{array}{l}\text { Vigna cf. radiata (cotyle- } \\
\text { don) }\end{array}$ & 19 & $0.23 \%$ & 13 & $16.88 \%$ & & & 4 & $0 \%$ & 3 & $18 \%$ & 5 & $1 \%$ & 3 & $15 \%$ & 8 & $1 \%$ & 6 & $38 \%$ \\
\hline Vigna cf. radiata (frags) & 0 & $0.00 \%$ & 0 & $0.00 \%$ & & & 0 & $0 \%$ & 0 & $0 \%$ & 0 & $0 \%$ & 0 & $0 \%$ & 0 & $0 \%$ & 0 & $0 \%$ \\
\hline Vigna sp. (whole) & 180 & $2.16 \%$ & 24 & $31.17 \%$ & 299 & 5.15 & 138 & $5 \%$ & 10 & $59 \%$ & 7 & $1 \%$ & 3 & $15 \%$ & 13 & $1 \%$ & 6 & $38 \%$ \\
\hline Vigna sp. (cotyledon) & 84 & $1.01 \%$ & 16 & $20.78 \%$ & & & 40 & $2 \%$ & 7 & $41 \%$ & 1 & $0 \%$ & 1 & $5 \%$ & 3 & $0 \%$ & 2 & $13 \%$ \\
\hline Vigna sp. (frag) & 35 & $0.42 \%$ & 12 & $15.58 \%$ & & & 10 & $0 \%$ & 5 & $29 \%$ & 0 & $0 \%$ & 0 & $0 \%$ & 11 & $1 \%$ & 3 & $19 \%$ \\
\hline $\begin{array}{l}\text { Vigna unguiculata (coty- } \\
\text { ledon) }\end{array}$ & 1 & $0.01 \%$ & 1 & $1.30 \%$ & & & 0 & $0 \%$ & 0 & $0 \%$ & 0 & $0 \%$ & 0 & $0 \%$ & 1 & $0 \%$ & 1 & $6 \%$ \\
\hline Macrotyloma (whole) & 3 & $0.04 \%$ & 3 & $3.90 \%$ & 23 & 0.39 & 1 & $0 \%$ & 1 & $6 \%$ & 1 & $0 \%$ & 1 & $5 \%$ & 1 & $0 \%$ & 1 & $6 \%$ \\
\hline Macrotyloma (cotyledon) & 13 & $0.16 \%$ & 3 & $3.90 \%$ & & & 11 & $0 \%$ & 2 & $12 \%$ & 0 & $0 \%$ & 0 & $0 \%$ & 2 & $0 \%$ & 1 & $6 \%$ \\
\hline Macrotyloma (frag) & 7 & $0.08 \%$ & 3 & $3.90 \%$ & & & 5 & $0 \%$ & 1 & $6 \%$ & 1 & $0 \%$ & 1 & $5 \%$ & 1 & $0 \%$ & 1 & $6 \%$ \\
\hline Lablab (whole) & 6 & $0.07 \%$ & 1 & $1.30 \%$ & 23 & 0.39 & 0 & $0 \%$ & 0 & $0 \%$ & 0 & $0 \%$ & 0 & $0 \%$ & 6 & $1 \%$ & 1 & $6 \%$ \\
\hline Lablab (cotyledon) & 8 & $0.10 \%$ & 4 & $5.19 \%$ & & & 5 & $0 \%$ & 2 & $12 \%$ & 2 & $0 \%$ & 1 & $5 \%$ & 0 & $0 \%$ & 0 & $0 \%$ \\
\hline Lablab (frag) & 9 & $0.11 \%$ & 5 & $6.49 \%$ & & & 1 & $0 \%$ & 1 & $6 \%$ & 2 & $0 \%$ & 1 & $5 \%$ & 2 & $0 \%$ & 1 & $6 \%$ \\
\hline Cajanus (whole) & 8 & $0.10 \%$ & 6 & $7.79 \%$ & 18 & 0.31 & 0 & $0 \%$ & 0 & $0 \%$ & 4 & $1 \%$ & 2 & $10 \%$ & 3 & $0 \%$ & 3 & $19 \%$ \\
\hline Cajanus (cotyledons) & 1 & $0.01 \%$ & 1 & $1.30 \%$ & & & 0 & $0 \%$ & 0 & $0 \%$ & 0 & $0 \%$ & 0 & $0 \%$ & 1 & $0 \%$ & 1 & $6 \%$ \\
\hline Cajanus (frags) & 9 & $0.11 \%$ & 2 & $2.60 \%$ & & & 0 & $0 \%$ & 0 & $0 \%$ & 9 & $1 \%$ & 2 & $10 \%$ & 0 & $0 \%$ & 0 & $0 \%$ \\
\hline Cicer (whole) & 12 & $0.14 \%$ & 6 & $7.79 \%$ & 36 & 0.62 & 0 & $0 \%$ & 0 & $0 \%$ & 3 & $0 \%$ & 1 & $5 \%$ & 9 & $1 \%$ & 5 & $31 \%$ \\
\hline Cicer (cotyledons) & 21 & $0.25 \%$ & 9 & $11.69 \%$ & & & 0 & $0 \%$ & 0 & $0 \%$ & 3 & $0 \%$ & 1 & $5 \%$ & 17 & $2 \%$ & 7 & $44 \%$ \\
\hline Cicer (frags) & 3 & $0.04 \%$ & 2 & $2.60 \%$ & & & 0 & $0 \%$ & 0 & $0 \%$ & 1 & $0 \%$ & 1 & $5 \%$ & 2 & $0 \%$ & 1 & $6 \%$ \\
\hline cf. Cicer (reticulate surface) & 3 & $0.04 \%$ & 1 & $1.30 \%$ & & & 0 & $0 \%$ & 0 & $0 \%$ & 3 & $0 \%$ & 1 & $5 \%$ & & $0 \%$ & 0 & $0 \%$ \\
\hline Lathyrus sativus (whole) & 4 & $0.05 \%$ & 3 & $3.90 \%$ & 7 & 0.12 & 0 & $0 \%$ & 0 & $0 \%$ & 0 & $0 \%$ & 0 & $0 \%$ & 3 & $0 \%$ & 2 & $13 \%$ \\
\hline $\begin{array}{l}\text { Lathyrus sativus (cotyle- } \\
\text { don) }\end{array}$ & 3 & $0.04 \%$ & 1 & $1.30 \%$ & & & 0 & $0 \%$ & 0 & $0 \%$ & 0 & $0 \%$ & 0 & $0 \%$ & 3 & $0 \%$ & 1 & $6 \%$ \\
\hline Lens (whole) & 48 & $0.58 \%$ & 14 & $18.18 \%$ & 71 & 1.22 & 0 & $0 \%$ & 0 & $0 \%$ & 0 & $0 \%$ & 0 & $0 \%$ & 38 & $3 \%$ & 9 & $56 \%$ \\
\hline Lens (cotyledon) & 12 & $0.14 \%$ & 5 & $6.49 \%$ & & & 0 & $0 \%$ & 0 & $0 \%$ & 0 & $0 \%$ & 0 & $0 \%$ & 7 & $1 \%$ & 4 & $25 \%$ \\
\hline Lens (frags) & 11 & $0.13 \%$ & 4 & $5.19 \%$ & & & 1 & $0 \%$ & 1 & $6 \%$ & 0 & $0 \%$ & 0 & $0 \%$ & 10 & $1 \%$ & 3 & $19 \%$ \\
\hline Pisum sativum (whole) & 2 & $0.02 \%$ & 2 & $2.60 \%$ & & & 0 & $0 \%$ & 0 & $0 \%$ & 0 & $0 \%$ & 0 & $0 \%$ & 0 & $0 \%$ & 0 & $0 \%$ \\
\hline Indet. large legume & 63 & $0.76 \%$ & 8 & $10.39 \%$ & & & 16 & $1 \%$ & 1 & $6 \%$ & 15 & $2 \%$ & 1 & $5 \%$ & 20 & $2 \%$ & 1 & $6 \%$ \\
\hline Millets & & & & & & & & & & & & & & & & & & \\
\hline Brachiria/Setaria caryopsis & 74 & $0.89 \%$ & 5 & $6.49 \%$ & & & 0 & $0 \%$ & 0 & $0 \%$ & 27 & $4 \%$ & 1 & $5 \%$ & 0 & $0 \%$ & 0 & $0 \%$ \\
\hline $\begin{array}{l}\text { Brachiaria ramosa/Setaria } \\
\text { italica }\end{array}$ & 269 & $3.23 \%$ & 16 & $20.78 \%$ & & & 5 & $0 \%$ & 3 & $18 \%$ & 24 & $3 \%$ & 4 & $20 \%$ & 111 & $10 \%$ & 3 & $19 \%$ \\
\hline $\begin{array}{l}\text { Brachiaria ramosa type } \\
\text { (w/o husk) }\end{array}$ & 67 & $0.80 \%$ & 11 & $14.29 \%$ & & & 0 & $0 \%$ & 0 & $0 \%$ & 13 & $2 \%$ & 2 & $10 \%$ & 39 & $3 \%$ & 6 & $38 \%$ \\
\hline B. ramosa (w/ husk) & 4 & $0.05 \%$ & 4 & $5.19 \%$ & & & 0 & $0 \%$ & 0 & $0 \%$ & 1 & $0 \%$ & 1 & $5 \%$ & 1 & $0 \%$ & 1 & $6 \%$ \\
\hline B. ramosa spikelets (silici- & 0 & $0.00 \%$ & 0 & $0.00 \%$ & & & 0 & $0 \%$ & 0 & $0 \%$ & 0 & $0 \%$ & 0 & $0 \%$ & 0 & $0 \%$ & 0 & $0 \%$ \\
\hline
\end{tabular}




\begin{tabular}{|c|c|c|c|c|c|c|c|c|c|c|c|c|c|c|c|c|}
\hline Echinochloa sp. caryopsis & 10 & $0.12 \%$ & 6 & $7.79 \%$ & 0 & $0 \%$ & 0 & $0 \%$ & 1 & $0 \%$ & 1 & $5 \%$ & 6 & $1 \%$ & 3 & $19 \%$ \\
\hline Eleusine coracana & 2 & $0.02 \%$ & 1 & $1.30 \%$ & 2 & $0 \%$ & 1 & $6 \%$ & 0 & $0 \%$ & 0 & $0 \%$ & 0 & $0 \%$ & 0 & $0 \%$ \\
\hline cf. Eleusine coracana & 4 & $0.05 \%$ & 3 & $3.90 \%$ & 2 & $0 \%$ & 1 & $6 \%$ & 0 & $0 \%$ & 0 & $0 \%$ & 0 & $0 \%$ & 0 & $0 \%$ \\
\hline Panicum sp. (small) & 5 & $0.06 \%$ & 2 & $2.60 \%$ & 0 & $0 \%$ & 0 & $0 \%$ & 0 & $0 \%$ & 0 & $0 \%$ & 0 & $0 \%$ & 0 & $0 \%$ \\
\hline $\begin{array}{l}\text { Panicum sp. (small imma- } \\
\text { ture) }\end{array}$ & 2 & $0.02 \%$ & 2 & $2.60 \%$ & 0 & $0 \%$ & 0 & $0 \%$ & 0 & $0 \%$ & 0 & $0 \%$ & 1 & $0 \%$ & 1 & $6 \%$ \\
\hline Paincum miliaceum & 4 & $0.05 \%$ & 2 & $2.60 \%$ & 0 & $0 \%$ & 0 & $0 \%$ & 0 & $0 \%$ & 0 & $0 \%$ & 4 & $0 \%$ & 2 & $13 \%$ \\
\hline Panicum cf. sumatrense & 27 & $0.32 \%$ & 10 & $12.99 \%$ & 2 & $0 \%$ & 2 & $12 \%$ & 4 & $1 \%$ & 2 & $10 \%$ & 14 & $1 \%$ & 3 & $19 \%$ \\
\hline $\begin{array}{l}\text { Panicum cf. sumatrense } \\
\text { (spikelet) }\end{array}$ & 1 & $0.01 \%$ & 1 & $1.30 \%$ & 0 & $0 \%$ & 0 & $0 \%$ & 0 & $0 \%$ & 0 & $0 \%$ & 0 & $0 \%$ & 0 & $0 \%$ \\
\hline Panicum sp. (immature) & 5 & $0.06 \%$ & 1 & $1.30 \%$ & 0 & $0 \%$ & 0 & $0 \%$ & 0 & $0 \%$ & 0 & $0 \%$ & 5 & $0 \%$ & 1 & $6 \%$ \\
\hline Paspalum scrobiculatum & 3,724 & $44.72 \%$ & 60 & $77.92 \%$ & 1,842 & $73 \%$ & 16 & $94 \%$ & 192 & $25 \%$ & 17 & $85 \%$ & 69 & $6 \%$ & 12 & $75 \%$ \\
\hline $\begin{array}{l}\text { Paspalum scrobiculatum } \\
\text { (w/ husk) }\end{array}$ & 4 & $0.05 \%$ & 3 & $3.90 \%$ & 3 & $0 \%$ & 2 & $12 \%$ & 0 & $0 \%$ & 0 & $0 \%$ & 0 & $0 \%$ & 0 & $0 \%$ \\
\hline $\begin{array}{l}\text { cf. Paspalum husk frags } \\
\text { (charred) }\end{array}$ & 121 & $1.45 \%$ & 2 & $2.60 \%$ & 31 & $1 \%$ & 1 & $6 \%$ & 0 & $0 \%$ & 0 & $0 \%$ & 0 & $0 \%$ & 0 & $0 \%$ \\
\hline Paspalum spikelet bases & 8 & $0.10 \%$ & 1 & $1.30 \%$ & 0 & $0 \%$ & 0 & $0 \%$ & 0 & $0 \%$ & 0 & $0 \%$ & 0 & $0 \%$ & 0 & $0 \%$ \\
\hline $\begin{array}{l}\text { cf. Paspalum rachis } \\
\text { segment }\end{array}$ & 1 & $0.01 \%$ & 1 & $1.30 \%$ & 0 & $0 \%$ & 0 & $0 \%$ & 0 & $0 \%$ & 0 & $0 \%$ & 0 & $0 \%$ & 0 & $0 \%$ \\
\hline Pennisetum glaucum & 75 & $0.90 \%$ & 9 & $11.69 \%$ & 2 & $0 \%$ & 1 & $6 \%$ & 8 & $1 \%$ & 1 & $5 \%$ & 58 & $5 \%$ & 3 & $19 \%$ \\
\hline Setaria italica type & 41 & $0.49 \%$ & 5 & $6.49 \%$ & 0 & $0 \%$ & 0 & $0 \%$ & 2 & $0 \%$ & 2 & $10 \%$ & 39 & $3 \%$ & 3 & $19 \%$ \\
\hline S. italica type w/ husk & 4 & $0.05 \%$ & 2 & $2.60 \%$ & 0 & $0 \%$ & 0 & $0 \%$ & 2 & $0 \%$ & 1 & $5 \%$ & 2 & $0 \%$ & 1 & $6 \%$ \\
\hline S. italica spikelet & 1 & $0.01 \%$ & 1 & $1.30 \%$ & 0 & $0 \%$ & 0 & $0 \%$ & 0 & $0 \%$ & 0 & $0 \%$ & 0 & $0 \%$ & 0 & $0 \%$ \\
\hline Setaria verticillata type & 35 & $0.42 \%$ & 9 & $11.69 \%$ & 0 & $0 \%$ & 0 & $0 \%$ & 6 & $1 \%$ & 2 & $10 \%$ & 26 & $2 \%$ & 6 & $38 \%$ \\
\hline S. verticillata type w/ husk & 4 & $0.05 \%$ & 4 & $5.19 \%$ & 0 & $0 \%$ & 0 & $0 \%$ & 2 & $0 \%$ & 2 & $10 \%$ & 1 & $0 \%$ & 1 & $6 \%$ \\
\hline Setaria cf. pumila & 19 & $0.23 \%$ & 3 & $3.90 \%$ & 0 & $0 \%$ & 0 & $0 \%$ & 0 & $0 \%$ & 0 & $0 \%$ & 0 & $0 \%$ & 0 & $0 \%$ \\
\hline Setaria cf. sphaceleata & 2 & $0.02 \%$ & 2 & $2.60 \%$ & 0 & $0 \%$ & 0 & $0 \%$ & 0 & $0 \%$ & 0 & $0 \%$ & 1 & $0 \%$ & 1 & $6 \%$ \\
\hline $\begin{array}{l}\text { Setaria/Brachiaria imma- } \\
\text { ture }\end{array}$ & 5 & $0.06 \%$ & 4 & $5.19 \%$ & 0 & $0 \%$ & 0 & $0 \%$ & 1 & $0 \%$ & 1 & $5 \%$ & 2 & $0 \%$ & 2 & $13 \%$ \\
\hline Sorghum bicolor & 44 & $0.53 \%$ & 16 & $20.78 \%$ & 0 & $0 \%$ & 0 & $0 \%$ & 13 & $2 \%$ & 4 & $20 \%$ & 22 & $2 \%$ & 8 & $50 \%$ \\
\hline S. bicolor cf. race bicolor & 3 & $0.04 \%$ & 3 & $3.90 \%$ & 0 & $0 \%$ & 0 & $0 \%$ & 1 & $0 \%$ & 1 & $5 \%$ & 1 & $0 \%$ & 1 & $6 \%$ \\
\hline S. bicolor cf. race durra & 4 & $0.05 \%$ & 3 & $3.90 \%$ & 0 & $0 \%$ & 0 & $0 \%$ & 0 & $0 \%$ & 0 & $0 \%$ & 4 & $0 \%$ & 3 & $19 \%$ \\
\hline Indet. small millet & 40 & $0.48 \%$ & 5 & $6.49 \%$ & 0 & $0 \%$ & 0 & $0 \%$ & 0 & $0 \%$ & 0 & $0 \%$ & 0 & $0 \%$ & 0 & $0 \%$ \\
\hline Indet. millet & 6 & $0.07 \%$ & 1 & $1.30 \%$ & 0 & $0 \%$ & 0 & $0 \%$ & 0 & $0 \%$ & 0 & $0 \%$ & 6 & $1 \%$ & 1 & $6 \%$ \\
\hline \multicolumn{17}{|l|}{ Big cereals } \\
\hline Oryza cf. sativa (grains) & 163 & $1.96 \%$ & 39 & $50.65 \%$ & 55 & $2 \%$ & 8 & $47 \%$ & 27 & $4 \%$ & 9 & $45 \%$ & 60 & $5 \%$ & 12 & $75 \%$ \\
\hline Oryza grain frags & 137 & $1.65 \%$ & 23 & $29.87 \%$ & 75 & $3 \%$ & 5 & $29 \%$ & 5 & $1 \%$ & 4 & $20 \%$ & 13 & $1 \%$ & 4 & $25 \%$ \\
\hline $\begin{array}{l}\text { Oryza husk fragments } \\
\text { (charred) }\end{array}$ & 3 & $0.04 \%$ & 3 & $3.90 \%$ & 0 & $0 \%$ & 0 & $0 \%$ & 0 & $0 \%$ & 0 & $0 \%$ & 0 & $0 \%$ & 0 & $0 \%$ \\
\hline $\begin{array}{l}\text { Oryza husk fragments } \\
\text { (silicified) }\end{array}$ & 0 & $0.00 \%$ & 0 & $0.00 \%$ & 0 & $0 \%$ & 0 & $0 \%$ & 0 & $0 \%$ & 0 & $0 \%$ & 0 & $0 \%$ & 0 & $0 \%$ \\
\hline Oryza spikelet bases & 12 & $0.14 \%$ & 1 & $1.30 \%$ & 12 & $0 \%$ & 1 & $6 \%$ & 0 & $0 \%$ & 0 & $0 \%$ & 0 & $0 \%$ & 0 & $0 \%$ \\
\hline Oryza sp. (small wild) & 6 & $0.07 \%$ & 2 & $2.60 \%$ & 3 & $0 \%$ & 1 & $6 \%$ & 0 & $0 \%$ & 0 & $0 \%$ & 3 & $0 \%$ & 1 & $6 \%$ \\
\hline $\begin{array}{l}\text { Hordeum vulgare (Grains/ } \\
\text { frags) }\end{array}$ & 56 & $0.67 \%$ & 14 & $18.18 \%$ & 33 & $1 \%$ & 6 & $35 \%$ & 1 & $0 \%$ & 1 & $5 \%$ & 1 & $0 \%$ & 1 & $6 \%$ \\
\hline Hordeum vulgare rachis & 1 & $0.01 \%$ & 1 & $1.30 \%$ & 0 & $0 \%$ & 0 & $0 \%$ & 0 & $0 \%$ & 0 & $0 \%$ & 0 & $0 \%$ & 0 & $0 \%$ \\
\hline Triticum sp. (grain) & 13 & $0.16 \%$ & 6 & $7.79 \%$ & 0 & $0 \%$ & 0 & $0 \%$ & 0 & $0 \%$ & 0 & $0 \%$ & 6 & $1 \%$ & 3 & $19 \%$ \\
\hline $\begin{array}{l}\text { Triticum cf. dicoccum } \\
\text { (grain) }\end{array}$ & 15 & $0.18 \%$ & 7 & $9.09 \%$ & 0 & $0 \%$ & 0 & $0 \%$ & 2 & $0 \%$ & 1 & $5 \%$ & 11 & $1 \%$ & 4 & $25 \%$ \\
\hline Triticum FT (grain) & 19 & $0.23 \%$ & 5 & $6.49 \%$ & 0 & $0 \%$ & 0 & $0 \%$ & 0 & $0 \%$ & 0 & $0 \%$ & 18 & $2 \%$ & 4 & $25 \%$ \\
\hline $\begin{array}{l}\text { Indet Hordeun/Triticum } \\
\text { (grain) }\end{array}$ & 27 & $0.32 \%$ & 5 & $6.49 \%$ & 1 & $0 \%$ & 1 & $6 \%$ & 0 & $0 \%$ & 0 & $0 \%$ & 0 & $0 \%$ & 0 & $0 \%$ \\
\hline $\begin{array}{l}\text { Culm node (large grass/ } \\
\text { cereal) }\end{array}$ & 6 & $0.07 \%$ & 4 & $5.19 \%$ & 0 & $0 \%$ & 0 & $0 \%$ & 2 & $0 \%$ & 1 & $5 \%$ & 4 & $0 \%$ & 3 & $19 \%$ \\
\hline
\end{tabular}


Table 12.1b: Archaeobotanical data from Paithan. P: present; T: total.

\begin{tabular}{|c|c|c|c|c|c|c|c|c|c|c|c|c|c|c|c|c|}
\hline \multirow[t]{2}{*}{ Period } & \multirow[b]{2}{*}{$\begin{array}{l}\text { Site } \\
\text { total }\end{array}$} & \multirow[b]{2}{*}{ Freq. } & \multirow[b]{2}{*}{$\mathbf{P}$} & \multirow[b]{2}{*}{$\begin{array}{l}\text { Ubiq- } \\
\text { uity }\end{array}$} & \multicolumn{2}{|l|}{1} & \multicolumn{2}{|l|}{1} & \multicolumn{2}{|l|}{2} & \multicolumn{2}{|l|}{2} & \multicolumn{2}{|l|}{3} & \multirow{2}{*}{\multicolumn{2}{|c|}{$\begin{array}{l}3 \\
\mathbf{P}\end{array}$}} \\
\hline & & & & & $\mathbf{T}$ & & $\mathbf{P}$ & & $\mathbf{T}$ & & $\mathbf{P}$ & & $\mathbf{T}$ & & & \\
\hline \multicolumn{17}{|l|}{ Other crops } \\
\hline Sesamum indicum & 225 & $2.70 \%$ & 151 & $19.48 \%$ & 6 & $0 \%$ & 1 & $6 \%$ & 165 & $22 \%$ & 5 & $25 \%$ & 7 & $1 \%$ & 4 & $25 \%$ \\
\hline cf. Sesamum radiatum type & 1 & $0.01 \%$ & 1 & $1.30 \%$ & 0 & $0 \%$ & 0 & $0 \%$ & 0 & $0 \%$ & 0 & $0 \%$ & 1 & $0 \%$ & 1 & $6 \%$ \\
\hline Linum usitatissimum & 1 & $0.01 \%$ & 1 & $1.30 \%$ & 0 & $0 \%$ & 0 & $0 \%$ & 0 & $0 \%$ & 0 & $0 \%$ & 1 & $0 \%$ & 1 & $6 \%$ \\
\hline cf. Linum frags. & 3 & $0.04 \%$ & 1 & $1.30 \%$ & 0 & $0 \%$ & 0 & $0 \%$ & 0 & $0 \%$ & 0 & $0 \%$ & 3 & $0 \%$ & 1 & $6 \%$ \\
\hline Carthamus tinctorius & 2 & $0.02 \%$ & 1 & $1.30 \%$ & 0 & $0 \%$ & 0 & $0 \%$ & 0 & $0 \%$ & 0 & $0 \%$ & 0 & $0 \%$ & 0 & $0 \%$ \\
\hline $\begin{array}{l}\text { cf. Carthamus tinctorius } \\
\text { (frags) }\end{array}$ & 6 & $0.07 \%$ & 2 & $2.60 \%$ & 3 & $0 \%$ & 1 & $6 \%$ & 0 & $0 \%$ & 0 & $0 \%$ & 0 & $0 \%$ & 0 & $0 \%$ \\
\hline $\begin{array}{l}\text { Cannabis sativa cf. subsp. } \\
\text { sativa }\end{array}$ & 1 & $0.01 \%$ & 1 & $1.30 \%$ & 0 & $0 \%$ & 0 & $0 \%$ & 0 & $0 \%$ & 0 & $0 \%$ & 1 & $0 \%$ & 1 & $6 \%$ \\
\hline Brassica cf. juncea & 8 & $0.10 \%$ & 1 & $1.30 \%$ & 0 & $0 \%$ & 0 & $0 \%$ & 8 & $1 \%$ & 1 & $5 \%$ & 0 & $0 \%$ & 0 & $0 \%$ \\
\hline Gossypium sp. & 25 & $0.30 \%$ & 121 & $15.58 \%$ & 2 & $0 \%$ & 2 & $12 \%$ & 3 & $0 \%$ & 3 & $15 \%$ & 16 & $1 \%$ & 6 & $38 \%$ \\
\hline Gossypium testa frags & 13 & $0.16 \%$ & 5 & $6.49 \%$ & 2 & $0 \%$ & 1 & $6 \%$ & 5 & $1 \%$ & 2 & $10 \%$ & 5 & $0 \%$ & 1 & $6 \%$ \\
\hline Abelmoschus sp. & 8 & $0.10 \%$ & 5 & $6.49 \%$ & 0 & $0 \%$ & 0 & $0 \%$ & 1 & $0 \%$ & 1 & $5 \%$ & 6 & $1 \%$ & 3 & $19 \%$ \\
\hline Cucumis cf. melo agrestis & 1 & $0.01 \%$ & 1 & $1.30 \%$ & 0 & $0 \%$ & 0 & $0 \%$ & 0 & $0 \%$ & 0 & $0 \%$ & 1 & $0 \%$ & 1 & $6 \%$ \\
\hline Cucumis melo/sativus & 2 & $0.02 \%$ & 2 & $2.60 \%$ & 0 & $0 \%$ & 0 & $0 \%$ & 1 & $0 \%$ & 1 & $5 \%$ & 1 & $0 \%$ & 1 & $6 \%$ \\
\hline $\begin{array}{l}\text { Cucurbitaceae: small } \\
\text { Melothria heterophylla }\end{array}$ & 7 & $0.08 \%$ & 4 & $5.19 \%$ & 0 & $0 \%$ & 0 & $0 \%$ & 0 & $0 \%$ & 0 & $0 \%$ & 6 & $1 \%$ & 3 & $19 \%$ \\
\hline Cucurbitaceae & 2 & $0.02 \%$ & 2 & $2.60 \%$ & 1 & $0 \%$ & 1 & $6 \%$ & 0 & $0 \%$ & 0 & $0 \%$ & 1 & $0 \%$ & 1 & $6 \%$ \\
\hline cf. Cuminum & 3 & $0.04 \%$ & 1 & $1.30 \%$ & 0 & $0 \%$ & 0 & $0 \%$ & 0 & $0 \%$ & 0 & $0 \%$ & 3 & $0 \%$ & 1 & $6 \%$ \\
\hline \multicolumn{17}{|l|}{ Tree fruits } \\
\hline Fruit/nut indet. frags & 12 & $0.14 \%$ & 7 & $9.09 \%$ & 1 & $0 \%$ & 1 & $6 \%$ & 6 & $1 \%$ & 2 & $10 \%$ & 3 & $0 \%$ & 3 & $19 \%$ \\
\hline Ziziphus sp. (wh+frags) & 35 & $0.42 \%$ & 101 & $12.99 \%$ & 4 & $0 \%$ & 2 & $12 \%$ & 3 & $0 \%$ & 2 & $10 \%$ & 22 & $2 \%$ & 4 & $25 \%$ \\
\hline Ficus sp. & 118 & $1.42 \%$ & 141 & $18.18 \%$ & 5 & $0 \%$ & 1 & $6 \%$ & 2 & $0 \%$ & 2 & $10 \%$ & 56 & $5 \%$ & 5 & $31 \%$ \\
\hline Emblica sp. & 2 & $0.02 \%$ & 2 & $2.60 \%$ & 0 & $0 \%$ & 0 & $0 \%$ & 1 & $0 \%$ & 1 & $5 \%$ & 1 & $0 \%$ & 1 & $6 \%$ \\
\hline cf. Vitaceae small & 1 & $0.01 \%$ & 1 & $1.30 \%$ & 0 & $0 \%$ & 0 & $0 \%$ & 1 & $0 \%$ & 1 & $5 \%$ & 0 & $0 \%$ & 0 & $0 \%$ \\
\hline cf. Acacia sp. & 2 & $0.02 \%$ & 2 & $2.60 \%$ & 0 & $0 \%$ & 0 & $0 \%$ & 1 & $0 \%$ & 1 & $5 \%$ & 1 & $0 \%$ & 1 & $6 \%$ \\
\hline cf. Prosopis sp. & 4 & $0.05 \%$ & 2 & $2.60 \%$ & 2 & $0 \%$ & 1 & $6 \%$ & 2 & $0 \%$ & 1 & $5 \%$ & 0 & $0 \%$ & 0 & $0 \%$ \\
\hline Indet fruit seed/nutlet & 1 & $0.01 \%$ & 0 & $0.00 \%$ & 0 & $0 \%$ & 0 & $0 \%$ & 0 & $0 \%$ & 0 & $0 \%$ & 0 & $0 \%$ & 0 & $0 \%$ \\
\hline \multicolumn{17}{|l|}{$\begin{array}{l}\text { Weedy grasses (excluding } \\
\text { millet genera) }\end{array}$} \\
\hline Alopecurus sp. & 1 & $0.01 \%$ & 1 & $1.30 \%$ & 0 & $0 \%$ & 0 & $0 \%$ & 0 & $0 \%$ & 0 & $0 \%$ & 1 & $0 \%$ & 1 & $6 \%$ \\
\hline Coix caryopsis & 12 & $0.14 \%$ & 1 & $1.30 \%$ & 0 & $0 \%$ & 0 & $0 \%$ & 12 & $2 \%$ & 1 & $5 \%$ & 0 & $0 \%$ & 0 & $0 \%$ \\
\hline cf. Coix caryopsis(?) & 1 & $0.01 \%$ & 1 & $1.30 \%$ & 0 & $0 \%$ & 0 & $0 \%$ & 1 & $0 \%$ & 1 & $5 \%$ & 0 & $0 \%$ & 0 & $0 \%$ \\
\hline $\begin{array}{l}\text { Dactyloctenium cf. aegyp- } \\
\text { tium }\end{array}$ & 1 & $0.01 \%$ & 1 & $1.30 \%$ & 0 & $0 \%$ & 0 & $0 \%$ & 0 & $0 \%$ & 0 & $0 \%$ & 0 & $0 \%$ & 0 & $0 \%$ \\
\hline Digitaria sp. & 31 & $0.37 \%$ & & $10.39 \%$ & 0 & $0 \%$ & 0 & $0 \%$ & 5 & $1 \%$ & 2 & $10 \%$ & 23 & $2 \%$ & 5 & $31 \%$ \\
\hline Eleusine indica & 3 & $0.04 \%$ & 2 & $2.60 \%$ & 2 & $0 \%$ & 1 & $6 \%$ & 0 & $0 \%$ & 0 & $0 \%$ & 1 & $0 \%$ & 1 & $6 \%$ \\
\hline Ischaemum cf. rugosum & 21 & $0.25 \%$ & 7 & $9.09 \%$ & 0 & $0 \%$ & 0 & $0 \%$ & 3 & $0 \%$ & 2 & $10 \%$ & 18 & $2 \%$ & 5 & $31 \%$ \\
\hline $\begin{array}{l}\text { cf. Lolium temulentum } \\
\text { (large Hordeae) }\end{array}$ & 2 & $0.02 \%$ & 1 & $1.30 \%$ & 0 & $0 \%$ & 0 & $0 \%$ & 0 & $0 \%$ & 0 & $0 \%$ & 2 & $0 \%$ & 1 & $6 \%$ \\
\hline $\begin{array}{l}\text { cf. Pennisetum sp. small } \\
\text { wild }\end{array}$ & 2 & $0.02 \%$ & 1 & $1.30 \%$ & 0 & $0 \%$ & 0 & $0 \%$ & 0 & $0 \%$ & 0 & $0 \%$ & 0 & $0 \%$ & 0 & $0 \%$ \\
\hline cf. Stipa(?) & 1 & $0.01 \%$ & 1 & $1.30 \%$ & 0 & $0 \%$ & 0 & $0 \%$ & 1 & $0 \%$ & 1 & $5 \%$ & 0 & $0 \%$ & 0 & $0 \%$ \\
\hline $\begin{array}{l}\text { Urochloa/Braciahia eruci- } \\
\text { forme }\end{array}$ & 20 & $0.24 \%$ & 4 & $5.19 \%$ & 0 & $0 \%$ & 0 & $0 \%$ & 0 & $0 \%$ & 0 & $0 \%$ & 14 & $1 \%$ & 1 & $6 \%$ \\
\hline Indet small grass & 46 & $0.55 \%$ & 6 & $7.79 \%$ & 0 & $0 \%$ & 0 & $0 \%$ & 2 & $0 \%$ & 2 & $10 \%$ & 19 & $2 \%$ & 1 & $6 \%$ \\
\hline Aizooaceae & 1 & $0.01 \%$ & 1 & $1.30 \%$ & 0 & $0 \%$ & 0 & $0 \%$ & 1 & $0 \%$ & 1 & $5 \%$ & 0 & $0 \%$ & 0 & $0 \%$ \\
\hline Aizooaceae: Trianthema & 35 & $0.42 \%$ & 5 & $6.49 \%$ & 1 & $0 \%$ & 1 & $6 \%$ & 5 & $1 \%$ & 2 & $10 \%$ & 3 & $0 \%$ & 2 & $13 \%$ \\
\hline $\begin{array}{l}\text { Aizooaceae: Zaleya decan- } \\
\text { dra }\end{array}$ & 84 & $1.01 \%$ & & $29.87 \%$ & 0 & $0 \%$ & 0 & $0 \%$ & 25 & $3 \%$ & 6 & $30 \%$ & 28 & $2 \%$ & 6 & $38 \%$ \\
\hline
\end{tabular}




\begin{tabular}{|c|c|c|c|c|c|c|c|c|c|c|c|c|c|c|c|c|}
\hline Amaranthaceae & 2 & $0.02 \%$ & 2 & $2.60 \%$ & 0 & $0 \%$ & 0 & $0 \%$ & 0 & $0 \%$ & 0 & $0 \%$ & 0 & $0 \%$ & 0 & $0 \%$ \\
\hline Apiaceae & 1 & $0.01 \%$ & 1 & $1.30 \%$ & 0 & $0 \%$ & 0 & $0 \%$ & 0 & $0 \%$ & 0 & $0 \%$ & 1 & $0 \%$ & 1 & $6 \%$ \\
\hline Asteraceae & 19 & $0.23 \%$ & 3 & $3.90 \%$ & 17 & $1 \%$ & 1 & $6 \%$ & 0 & $0 \%$ & 0 & $0 \%$ & 1 & $0 \%$ & 1 & $6 \%$ \\
\hline Boraginaceae type & 3 & $0.04 \%$ & 1 & $1.30 \%$ & 3 & $0 \%$ & 1 & $6 \%$ & 0 & $0 \%$ & 0 & $0 \%$ & 0 & $0 \%$ & 0 & $0 \%$ \\
\hline Brassicaceae & 26 & $0.31 \%$ & 7 & $9.09 \%$ & 1 & $0 \%$ & 1 & $6 \%$ & 0 & $0 \%$ & 0 & $0 \%$ & 13 & $1 \%$ & 3 & $19 \%$ \\
\hline Capparaceae type & 1 & $0.01 \%$ & 1 & $1.30 \%$ & 0 & $0 \%$ & 0 & $0 \%$ & 0 & $0 \%$ & 0 & $0 \%$ & 0 & $0 \%$ & 0 & $0 \%$ \\
\hline Caryophyllaceae & 10 & $0.12 \%$ & 1 & $1.30 \%$ & 0 & $0 \%$ & 0 & $0 \%$ & 0 & $0 \%$ & 0 & $0 \%$ & 2 & $0 \%$ & 1 & $6 \%$ \\
\hline $\begin{array}{l}\text { Chenopodiaceae: Cheno- } \\
\text { podium } \mathrm{sp.}\end{array}$ & 5 & $0.06 \%$ & 3 & $3.90 \%$ & 0 & $0 \%$ & 0 & $0 \%$ & 0 & $0 \%$ & 0 & $0 \%$ & 0 & $0 \%$ & 0 & $0 \%$ \\
\hline $\begin{array}{l}\text { Commelinaceae: Com- } \\
\text { melina sp. }\end{array}$ & 9 & $0.11 \%$ & 7 & $9.09 \%$ & 1 & $0 \%$ & 1 & $6 \%$ & 5 & $1 \%$ & 3 & $15 \%$ & 3 & $0 \%$ & 3 & $19 \%$ \\
\hline Cyperaceae: cf. Carex & 2 & $0.02 \%$ & 2 & $2.60 \%$ & 0 & $0 \%$ & 0 & $0 \%$ & 0 & $0 \%$ & 0 & $0 \%$ & 0 & $0 \%$ & 0 & $0 \%$ \\
\hline Cyperaceae: Cyperus & 1 & $0.01 \%$ & 1 & $1.30 \%$ & 0 & $0 \%$ & 0 & $0 \%$ & 1 & $0 \%$ & 1 & $5 \%$ & 0 & $0 \%$ & 0 & $0 \%$ \\
\hline Cyperaceae: Fimbristylis & 10 & $0.12 \%$ & 1 & $1.30 \%$ & 0 & $0 \%$ & 0 & $0 \%$ & 0 & $0 \%$ & 0 & $0 \%$ & 0 & $0 \%$ & 0 & $0 \%$ \\
\hline Cyperaceae & 7 & $0.08 \%$ & 4 & $5.19 \%$ & 0 & $0 \%$ & 0 & $0 \%$ & 0 & $0 \%$ & 0 & $0 \%$ & 0 & $0 \%$ & 0 & $0 \%$ \\
\hline Euphorbiaceae type & 6 & $0.07 \%$ & 4 & $5.19 \%$ & 0 & $0 \%$ & 0 & $0 \%$ & 0 & $0 \%$ & 0 & $0 \%$ & 0 & $0 \%$ & 0 & $0 \%$ \\
\hline Leguminosae small & 109 & $1.31 \%$ & 192 & $24.68 \%$ & 12 & $0 \%$ & 1 & $6 \%$ & 1 & $0 \%$ & 1 & $5 \%$ & 24 & $2 \%$ & 5 & $31 \%$ \\
\hline Lamiaceae & 2 & $0.02 \%$ & 2 & $2.60 \%$ & 0 & $0 \%$ & 0 & $0 \%$ & 0 & $0 \%$ & 0 & $0 \%$ & 1 & $0 \%$ & 1 & $6 \%$ \\
\hline $\begin{array}{l}\text { Malvaceae (large) CROP?/ } \\
\text { below }\end{array}$ & 44 & $0.53 \%$ & 151 & $19.48 \%$ & 0 & $0 \%$ & 0 & $0 \%$ & 8 & $1 \%$ & 5 & $25 \%$ & 35 & $3 \%$ & 9 & $56 \%$ \\
\hline $\begin{array}{l}\text { Malvaceae (large) cf. } \\
\text { Hibiscus }\end{array}$ & 23 & $0.28 \%$ & 3 & $3.90 \%$ & 0 & $0 \%$ & 0 & $0 \%$ & 11 & $1 \%$ & 1 & $5 \%$ & 12 & $1 \%$ & 2 & $13 \%$ \\
\hline $\begin{array}{l}\text { Malavaceae (small) cf. } \\
\text { Malva }\end{array}$ & 21 & $0.25 \%$ & 101 & $12.99 \%$ & 3 & $0 \%$ & 1 & $6 \%$ & 5 & $1 \%$ & 2 & $10 \%$ & 10 & $1 \%$ & 4 & $25 \%$ \\
\hline Papavaraceae type & 2 & $0.02 \%$ & 1 & $1.30 \%$ & 0 & $0 \%$ & 0 & $0 \%$ & 0 & $0 \%$ & 0 & $0 \%$ & 0 & $0 \%$ & 0 & $0 \%$ \\
\hline Poaceae indet. & 4 & $0.05 \%$ & 2 & $2.60 \%$ & 0 & $0 \%$ & 0 & $0 \%$ & 0 & $0 \%$ & 0 & $0 \%$ & 0 & $0 \%$ & 0 & $0 \%$ \\
\hline $\begin{array}{l}\text { Polygonacaeae: cf. Polygo- } \\
\text { num sp. }\end{array}$ & 1 & $0.01 \%$ & 1 & $1.30 \%$ & 0 & $0 \%$ & 0 & $0 \%$ & 0 & $0 \%$ & 0 & $0 \%$ & 0 & $0 \%$ & 0 & $0 \%$ \\
\hline Portulaceae type & 4 & $0.05 \%$ & 1 & $1.30 \%$ & 0 & $0 \%$ & 0 & $0 \%$ & 0 & $0 \%$ & 0 & $0 \%$ & 4 & $0 \%$ & 1 & $6 \%$ \\
\hline $\begin{array}{l}\text { Rubiaceae mericarp, } \\
\text { Spermacoce cf. hispida }\end{array}$ & 4 & $0.05 \%$ & 2 & $2.60 \%$ & 0 & $0 \%$ & 0 & $0 \%$ & 0 & $0 \%$ & 0 & $0 \%$ & 3 & $0 \%$ & 2 & $13 \%$ \\
\hline Rubiaceae cf. Rubia sp. & 2 & $0.02 \%$ & 2 & $2.60 \%$ & 0 & $0 \%$ & 0 & $0 \%$ & 0 & $0 \%$ & 0 & $0 \%$ & 1 & $0 \%$ & 1 & $6 \%$ \\
\hline Solanaceae: Solanum sp. & 4 & $0.05 \%$ & 3 & $3.90 \%$ & 2 & $0 \%$ & 1 & $6 \%$ & 0 & $0 \%$ & 0 & $0 \%$ & 1 & $0 \%$ & 1 & $6 \%$ \\
\hline $\begin{array}{l}\text { Schrophulariaceae: cf. } \\
\text { Verbascum }\end{array}$ & 4 & $0.05 \%$ & 3 & $3.90 \%$ & 0 & $0 \%$ & 0 & $0 \%$ & 0 & $0 \%$ & 0 & $0 \%$ & 4 & $0 \%$ & 3 & $19 \%$ \\
\hline Indet large seeds & 14 & $0.17 \%$ & 6 & $7.79 \%$ & 0 & $0 \%$ & 0 & $0 \%$ & 2 & $0 \%$ & 1 & $5 \%$ & 2 & $0 \%$ & 2 & $13 \%$ \\
\hline Indet small seeds/sclerotia & 73 & $0.88 \%$ & & $10.39 \%$ & 0 & $0 \%$ & 0 & $0 \%$ & 3 & $0 \%$ & 1 & $5 \%$ & 32 & $3 \%$ & 3 & $19 \%$ \\
\hline Indet & 39 & $0.47 \%$ & 3 & $3.90 \%$ & 37 & & 1 & $6 \%$ & 1 & & 1 & $5 \%$ & 1 & & 1 & $6 \%$ \\
\hline Indet testa frags & 39 & $0.47 \%$ & 5 & $6.49 \%$ & 0 & & 0 & $0 \%$ & 0 & & 0 & $0 \%$ & 0 & & 0 & $0 \%$ \\
\hline Indet. fragments & 1,330 & $15.97 \%$ & 151 & $19.48 \%$ & 122 & & 2 & $12 \%$ & 10 & & 1 & $5 \%$ & 5 & & 1 & $6 \%$ \\
\hline $\begin{array}{l}\text { Large frags (cf. paren- } \\
\text { chyma) }\end{array}$ & 94 & $1.13 \%$ & 4 & $5.19 \%$ & 0 & & 0 & $0 \%$ & 63 & & 1 & $5 \%$ & 22 & & 2 & $13 \%$ \\
\hline Dung fragments & 1 & $0.01 \%$ & 1 & $1.30 \%$ & 1 & & 1 & $6 \%$ & 0 & & 0 & $0 \%$ & 0 & & 0 & $0 \%$ \\
\hline Total items & 8,327 & & 77 & &, 529 & & & & 762 & & & & 128 & & & \\
\hline No. samples & 78 & & & & 17 & & & & 21 & & & & 17 & & & \\
\hline
\end{tabular}




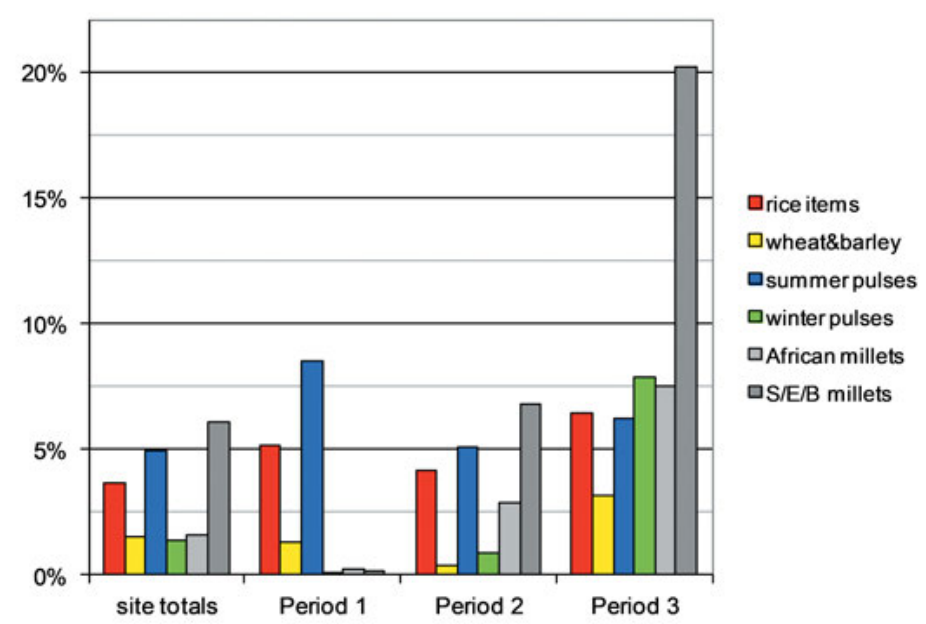

Fig. 12.3: Relative frequency of major crop groups.

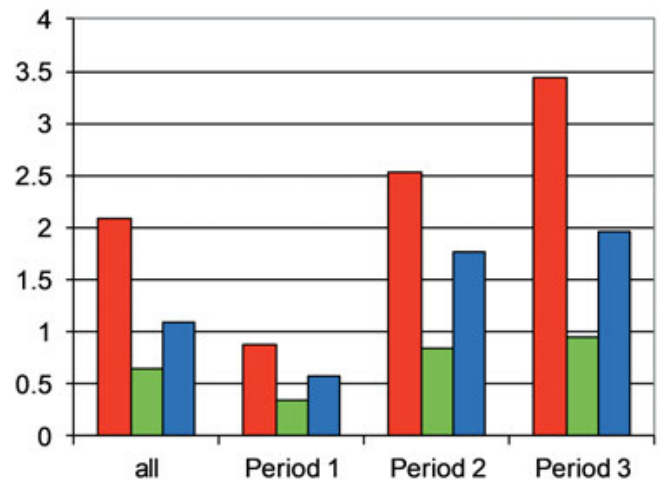

aShannon_H

口Simpson_1-D

a Menhinick

Fig. 12.4: Comparative diversity indices.

Overall, in terms of staple crop production, this might be interpreted as some tendency towards agricultural diversification. Measured merely in terms of the number of cereal/pulse species, there is directional change: from 13 taxa in Period 1 to 18 taxa in Period 2 and 22 in Period 3 (this count includes Setaria verticillata, assumes the presence of both Brachiaria ramosa and Setaria italica throughout and groups together sorghum subdivisions but separates free-threshing and diococcum-type wheat grains). This increase in diversity is not reflected in the weed flora, of which each period has 38 identifiable species present (although the total for all periods is 43, indicating that there were some minor changes in the presence of weed species). In biological terms, diversity is often considered to include not just the number of species but also how evenly distributed they are. In other words, an assemblage with ten species but in which only one or two of these account for most individuals is less diverse than an assemblage with ten species that are all found in similarly low frequencies. To measure this, three simple indices have been drawn from the ecologists' toolkit (Krebs 1985: 519ff). These include the Simpson index and the Shannon index, which are in common use amongst paleontologists and archaeozoologists. The Shannon index represents entropy on a scale from 0 (when a single species represents all individuals) to higher numbers as more species are encountered and are more evenly distributed. The Simpson index represents evenness with an index between 0 and 1 , by calculating a ratio of dominance (for each species the number of individuals of the species is divided by the total of all individuals squared, and then summed across all species). The Menhinick richness index takes 
into account the number of species and sample size as an attempt to correct for influence of sample size (i.e. that larger samples normally contain more taxa). These indices were calculated using the program PAST (Hammer et al. 2001). By these measures, the increase in diversity is clear (Fig. 12.4).

In the subsequent sections of this report, discussion is focussed around particular quantitative aspects of occurrence, issues of identification and significance of the species in terms of the economy at Paithan. The evidence from Paithan is situated in relation to the archaeobotanical record for South Asia as a whole. Table 12.1 presents the raw data.

\section{Limitations of the interim report}

There is still further work to be done on the archaeobotanical assemblage at Paithan. This includes preparing a comprehensive set of representative illustrations for all taxa, systematic measurements on many taxa, rechecking and refining someidentifications especially of small millets and putting further efforts into identifying some unknown seed types. Of particular importance is refining the identification of weed seeds to genus and/or species level. At present, available reference collection materials are inadequate, and unlike many world regions, good seed atlases are not available for southern India. In the present report, a comprehensive discussion of the weed taxa recovered is not provided.

\section{Cereals}

Cereals are the mainstays of most world agricultural economies today as they were in the past. These are cultivated grasses in which production is focussed on the seed, which is a dry, hard grain that is readily storable and high in carbohydrates. Cereal grains, once mature, are not directly edible but require preparation through pulverisation (grinding), which makes flours for breads or gruels, or through boiling or steaming whole, as is familiar for rice, or boiling and fermenting to make beers. Paithan has a rich record for cereals and includes a wide range of species, including most of those known to have been cultivated in India in ancient times. Cropping in general and cereals in particular are often divided into two main seasonal groups in South Asia (see e.g. Kajale 1988; Weber
1991): the winter cereals (wheat and barley), or rabi cereals, and summer (monsoon) millets (a wide range of species, including sorghum), or kharif crops, as well as rice, which is probably most often a kharif crop, although winter varieties exist and may have already been available in the past. For the most part, these seasonalities are constrained by physiology and genetics of the crops themselves, as flowering (and subsequent seed production) is normally triggered by changes in day-length (Willcox 1992). Thus, winter crops are long-day plants that flower as a result of days getting longer after the shortest day (21 December), leading to harvests in February or March, while summer crops are short-day plants that flower as days shorten towards the end of summer. In modern agriculture, exceptions are found, and these are usually 'photoperiod neutral' plants, i.e. plants in which sensitivity to day-length has been deactivated through plant breeding. Thus, there are winter sorghums and pearl millets and summer wheats and barleys (in Europe and in the Himalayas). How long ago these alternative season varieties evolved is unknown, although in many cases, these alternative states may exist in different wild populations, for example, in sorghum and rice. Wild rices in southern regions, such as Indonesia or Sri Lanka, are often photoperiod neutral and not tied to the summer, whereas those further north in south China or the Ganges and Orissa are (Jennings 1966). The same is true of Southern African sorghums, both domesticated and wild. Thus, it is possible that winter varieties were already available to the inhabitants of Paithan, and at present, we just do not know. However, since the establishment of millet and sorghum agriculture in Southern Africa is rather later - probably closer to the time that Paithan was founded (Marshall and Hildebrandt 2002) - it seems likely that the sorghum varieties available at Paithan would have been predominantly, if not entirely, tied to summer cultivation. This was probably also the case with early indica rices, prior to the diffusion of tropical japonica varieties from the Malaysia region. In the case of summer wheats and barleys in the Himalayas, in all likelihood, the evolution of these varieties was necessary for agricultural settlement and may be hypothesized to have occurred by the start of the Kashmir Neolithic (Fuller 2006a: 36 ), but such forms are unlikely to have ever spread to southern India. 
Table 12.2: The presence/absence of cereal crops on peninsular Indian sites of Iron Age or Early Historic date. Sources: Cooke et al. (2005), Kajale (1974, 1977b, 1982, 1984, 1989, 1994), Fuller et al. (2004), Fuller (unpublished data) (Piklihal), Vishnu-Mittre (1968), Vishnu-Mittre and Gupta (1968a,b) and Vishnu-Mittre et al. (1971, 1984). (IA = Iron Age; IV = Hallur period IV; EH = Early Historic).

\begin{tabular}{|c|c|c|c|c|c|c|c|c|c|c|c|c|c|c|c|}
\hline & Period & Site & 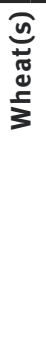 & 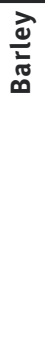 & $\stackrel{\underline{u}}{\alpha}$ & 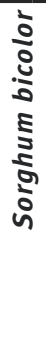 & 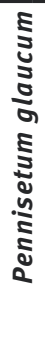 & 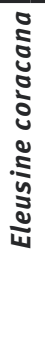 & 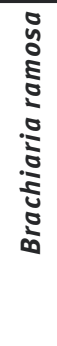 & 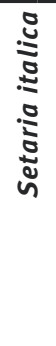 & 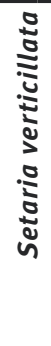 & 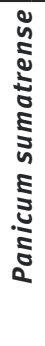 & 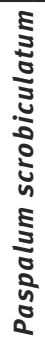 & 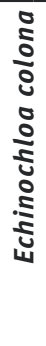 & 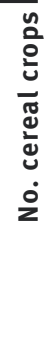 \\
\hline \multirow[t]{6}{*}{800 вс } & $\mathrm{IA}$ & Adam Cave & - & - & + & - & - & $-?$ & $+?$ & + & $+?$ & - & - & - & 5 \\
\hline & IA & Bhagimohari & - & + & + & - & - & - & - & - & - & - & - & - & 2 \\
\hline & IA & Bhokardan & + & - & + & + & - & $-?$ & $+?$ & - & $?$ & - & - & - & 4 \\
\hline & IA & Naikund & + & - & - & - & - & - & - & - & - & - & - & - & 1 \\
\hline & IA & Veerapuram & - & - & + & - & - & - & - & - & - & - & + & - & 2 \\
\hline & IV/IA & Hallur & - & - & $+?$ & - & - & + & + & - & + & - & - & - & 4 \\
\hline \multirow[t]{13}{*}{$300 \mathrm{BC}-?$} & $\mathrm{EH}$ & Piklihal & - & - & - & + & - & - & + & - & - & + & + & - & 4 \\
\hline & $\mathrm{EH}$ & Veerapuram & - & - & + & - & - & - & - & - & - & - & + & - & 2 \\
\hline & $\mathrm{EH}$ & Adam Cave & + & + & + & - & - & - & - & - & - & - & - & - & 3 \\
\hline & $\mathrm{EH}$ & Bhatkuli & - & - & - & + & - & - & - & - & - & - & - & - & 1 \\
\hline & $\mathrm{EH}$ & Bhokardan & + & - & - & + & - & $-?$ & $?$ & $?$ & $?$ & - & - & - & 2 \\
\hline & $\mathrm{EH}$ & Dangwada & + & - & + & - & - & - & - & - & - & - & - & - & 2 \\
\hline & $\mathrm{EH}$ & Kaundinyapura & - & - & + & - & - & - & - & - & - & - & - & - & 1 \\
\hline & $\mathrm{EH}$ & Nevasa & + & + & + & + & + & + & $?$ & - & $?$ & - & + & - & 7 \\
\hline & $\mathrm{EH}$ & Paunar & - & - & + & + & - & - & - & - & - & - & - & - & 2 \\
\hline & $\mathrm{EH}$ & Ter & + & + & + & - & - & - & - & - & - & - & + & - & 4 \\
\hline & $\mathrm{EH}$ & Kodumanal & - & - & + & - & - & - & + & - & - & + & - & - & 3 \\
\hline & $\mathrm{EH}$ & Mangudi & - & - & + & - & - & - & + & - & - & - & - & + & 3 \\
\hline & $\mathrm{EH}$ & Perur & - & - & + & - & - & + & + & - & + & + & + & + & 7 \\
\hline $300-0$ вс & & Paithan I & - & + & + & - & + & + & + & $+?$ & - & - & + & - & 7 \\
\hline$A D 0-400$ & & Paithan II & + & + & + & + & + & - & + & + & + & + & + & + & 11 \\
\hline \multirow[t]{2}{*}{ AD $400-700$} & & Paithan III & + & + & + & + & + & - & + & + & + & + & + & + & 11 \\
\hline & & Total sites & 9 & 7 & 18 & 8 & 4 & 4 & 10 & 4 & 5 & 5 & 9 & 4 & \\
\hline
\end{tabular}

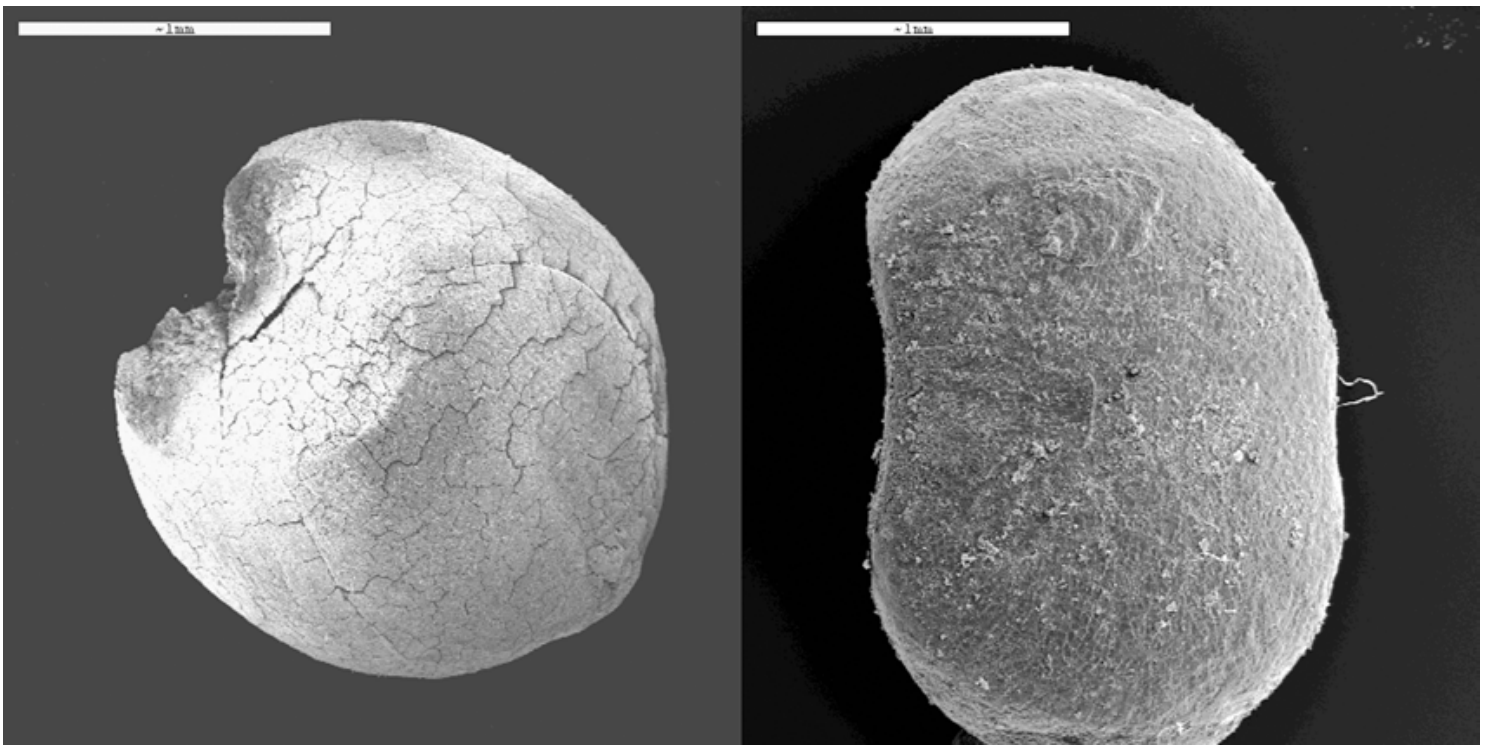

Fig. 12.5: Scanning electron micrograph of charred Paspalum scrobiculatum (kodo millet) from Paithan; dorsal view (left) and ventral view (right). 
In comparison to other peninsular sites of Iron Age or Early Historic date, Paithan has the most diverse range of cereal species (Table 12.2). This may, however, merely reflect the impact of a large-scale flotation program rather than any real difference in agricultural diversity.

Kodo millet, Paspalum scrobiculatum (Fig. 12.5), is by far the dominant plant in the Paithan archaeobotanical assemblage; it occurs in $80 \%$ of the samples and accounts for $44 \%$ of all the seeds identified. As discussed above, its unrivalled dominance in Period 1 declines through subsequent phases and sees replacement by other millets, including African millets and especially Brachiaria ramosa and/or Setaria italica. This trend is of interest since kodo millet is not a major crop in the region today, although it is known (Kimata 1989; Kobayashi and Kimata 1989), and does not appear to have been a crop in the region during Chalcolithic times (Kajale 1991; Fuller 2002). It is present as only a few seeds in the later Southern Neolithic in Karnataka, which may not represent use as a crop (Fuller et al.2004). All of this implies that during the late Iron Age and through the Satavahana period, kodo millet was a major crop in this region. Indeed, kodo millet is known from several other sites of the Iron Age or Early Historic period on the peninsula, and this period may represent the apogee of cultivation of this species (Table 12.3). Based on the current archaeobotanical evidence, we might point towards the Ganges Chalcolithic (e.g. Narhan Culture) as a possible locus of domestication of this crop. Presumably, this species was first known as a weed of cultivated rice and is still today a pernicious weed of rice (Moody 1989; Galinato et al. 1999). It may then have been recognized as a useful fall back or supplement food and began to be cultivated on poorer non-rice soils. This would make kodo millet a true secondary domesticate in the Vavilovian sense, as postulated for several Indian millets by Kimata et al. (2000). Subsequently, it may have spread to the Deccan at the same period as rice, but in the drier savannah zone, it was found to be particularly well suited.

This species is drought-tolerant, does well on poor soils and has a short growing season of 3 to 4 months, thereby being a low-labour demanding crop (Watt 1889-1893; De Wet et al. 1983). It also provides a relatively nutritious grain (FAO 1995; Weber and Fuller 2008). One of its drawbacks however, is that it is prone to fungal infection especially if it gets wet during grain maturation, and such infected grains are toxic for people and in animal fodder (FAO 1995). Frequency of this would have varied with climatic conditions, and realization of this could have contributed to decreased popularity over the course of the Early Historic period, which may have been a time of increasing monsoons between $300 \mathrm{BC}$ and $\mathrm{AD} 100$ (see e.g. increased Oxygen18 Isotope levels in the Arabian sediment profile of Staubwasser et al. 2003).

Rice, Oryza sativa (Fig. 12.6) is the world's most productive crop today and a widespread staple food in Asia and South Asia. Its origins have been reviewed elsewhere (Fuller 2006a: 39-41; 2006b; 2007: 911-915),
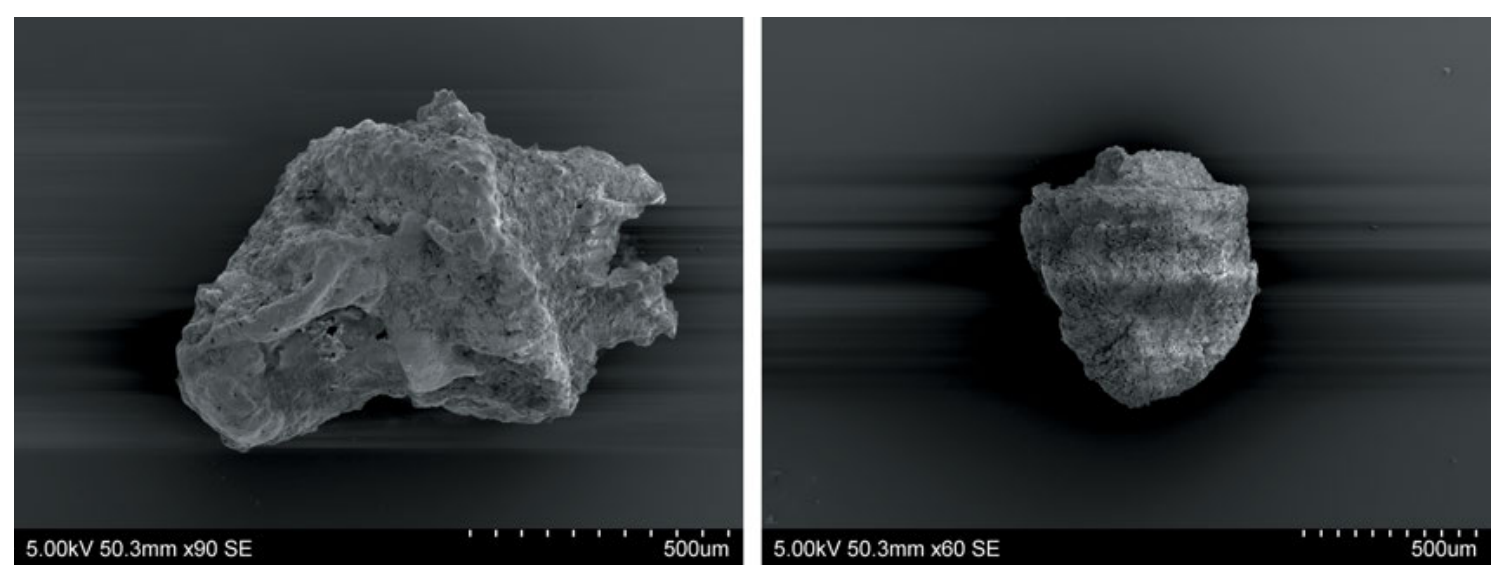

Fig. 12.6: Rice spikelet base from context 721; lateral view (left) and ventral view (right). Notice the indented scar indicative of domesticated/non-shattering morphotype. 
Table 12.3: The occurrence of kodo millet in South Asian archaeology.

\begin{tabular}{|c|c|c|c|c|c|}
\hline Site & Period & $\begin{array}{l}\text { Paspalum } \\
\text { ubiquity/comments }\end{array}$ & Dominant cereal(s) & Others & Reference \\
\hline Kuntasi, Saurashtra & Mature Harappan & Probable Paspalum & $\begin{array}{l}\text { Panicum sumatrense, } \\
\text { Setaria spp.(?) }\end{array}$ & $\begin{array}{l}\text { Wheat, barley, } \\
\text { many Coix for } \\
\text { beads }\end{array}$ & $\begin{array}{l}\text { Kajale } 1996 a \\
\text { (preliminary report } \\
\text { only) }\end{array}$ \\
\hline Kurugodu & $\begin{array}{l}\text { Neolithic IIIA } \\
(1750-1550 \text { BC) }\end{array}$ & $\begin{array}{l}\text { One grain, one } \\
\text { sample } \\
\text { (of four) }\end{array}$ & $\begin{array}{l}\text { Brachiaria ramosa, } \\
\text { Setaria verticillata }\end{array}$ & Wheat, barley & $\begin{array}{l}\text { Fuller et al. } 2001 \text {, } \\
\text { 2004; revised dating: } \\
\text { Fuller et al. } 2007\end{array}$ \\
\hline Rojdi, Saurashtra & $\begin{array}{l}\text { Period C, Late } \\
\text { Harappan (2000- } \\
1700 \mathrm{BC})\end{array}$ & $1 \%$ (of 254 samples) & $\begin{array}{l}\text { Panicum sumatrense, } \\
\text { Setaria spp.(?) }\end{array}$ & $\begin{array}{l}\text { Sorghum, } \\
\text { Echinochloa } \\
\text { (weedy?) }\end{array}$ & Weber 1991 \\
\hline Rupar, Punjab & $\begin{array}{l}\text { Late Harappan/Baran } \\
(2000-1600 \text { BC?) }\end{array}$ & $?$ & Wheat & & $\begin{array}{l}\text { Vishnu-Mittre and } \\
\text { Savithri } 1979\end{array}$ \\
\hline Senuwar & $\begin{array}{l}\text { Period IB, Late } \\
\text { Neolithic (2000- } \\
1300 \text { BC) }\end{array}$ & $\begin{array}{l}2 \% \text { (of } 42 \text { ), absent } \\
\text { from earlier period }\end{array}$ & Rice, barley & $\begin{array}{l}\text { Wheat, sorghum, } \\
\text { Setaria pumila }\end{array}$ & Saraswat 2004 \\
\hline $\begin{array}{l}\text { Daimabad, Maha- } \\
\text { rashtra }\end{array}$ & $\begin{array}{l}\text { Jorwe (1500-1100 } \\
\text { BC) }\end{array}$ & $\begin{array}{l}\text { Absent from earlier } \\
\text { levels, as are rice and } \\
\text { sorghum }\end{array}$ & $\begin{array}{l}\text { Wheat, barley, } \\
\text { Brachiaria ramosa(?)/ } \\
\text { Setaria italica }\end{array}$ & Sorghum, rice & $\begin{array}{l}\text { Kajale 1977a; Vishnu- } \\
\text { Mittre et al. } 1986\end{array}$ \\
\hline $\begin{array}{l}\text { Imlidh-Khurd, Uttar } \\
\text { Pradesh }\end{array}$ & $\begin{array}{l}\text { Period II, Narhan } \\
\text { Culture (1300-800 } \\
\text { BC) }\end{array}$ & $?$ & Rice, wheat, barley & Setaria pumila & Saraswat 1993 \\
\hline Malhar, Uttar Pradesh & $\begin{array}{l}\text { Period II, Early Iron } \\
\text { Age (1600(?)-800 } \\
\text { BC) }\end{array}$ & $5.5 \%$ (of 18$)$ & Rice, wheat, barley & Sorghum, Eleusine & Tewari et al. 2000 \\
\hline Narhan, Uttar Pradesh & $\begin{array}{l}\text { Chalcolithic-Iron Age } \\
\text { (c. } 1300-200 \mathrm{BC} \text { ) }\end{array}$ & $\begin{array}{l}23 \% \text { (of } 26 \text { samples), } \\
\text { absent from later } \\
\text { period }\end{array}$ & Rice, wheat, barley & Pearl millet & Saraswat et al. 1994 \\
\hline Hallur, Karnataja & $\begin{array}{l}\text { Neolithic IIIB } \\
(1550-1350 \text { BC) }\end{array}$ & $\begin{array}{l}12.5 \% \text { ( } 1 \text { of } 8 \\
\text { samples; } 2 \% \text { fre- } \\
\text { quency) }\end{array}$ & $\begin{array}{l}\text { Brachiaria ramosa, } \\
\text { Setaria verticillata }\end{array}$ & $\begin{array}{l}\text { Wheat, pearl } \\
\text { millet, Panicum } \\
\text { sumatrense, wild } \\
\text { Oryza sp. }\end{array}$ & $\begin{array}{l}\text { Fuller et al. } 2001 \text {, } \\
\text { 2004; revised dating: } \\
\text { Fuller et al. } 2007\end{array}$ \\
\hline Magha, Uttar Pradesh & Black and Red ware & $?$ & Rice & Echinochloa sp. & $\begin{array}{l}\text { Vishnu-Mittre et al. } \\
1984\end{array}$ \\
\hline $\begin{array}{l}\text { Hulaskhera, Uttar } \\
\text { Pradesh }\end{array}$ & $\begin{array}{l}\text { Iron Age (800-300 } \\
\text { BC) }\end{array}$ & $\begin{array}{l}17 \% \text { (of } 6 \text { samples), } \\
\text { mis-reported as } \\
\text { 'Eleusine' }\end{array}$ & Barley, rice & Rare wheat & Chanchala 1992 \\
\hline Perur, Tamil Nadu & $\begin{array}{l}\text { Early Historic/Late } \\
\text { Megalithic ( } 300 \\
\text { BC-300 AD) }\end{array}$ & $\begin{array}{l}20 \% \text { (of } 10 \text { samples, } \\
\text { frequency } 9 \% \text { and } \\
26 \% \text { ) }\end{array}$ & Rice, Eleusine coracana & $\begin{array}{l}\text { Panicum } \\
\text { sumatrense, } \\
\text { Echinochoa cf. } \\
\text { colona }\end{array}$ & Cooke et al. 2005 \\
\hline $\begin{array}{l}\text { Veerapuram, } \\
\text { Andhra Pradesh } \\
\end{array}$ & $500 \mathrm{BC}-400 \mathrm{AD}$ & $\begin{array}{l}14 \% \text { (of } 21 \text { samples, } \\
\text { but high frequency) }\end{array}$ & Rice, kodo millet(?) & Barley & Kajale 1984 \\
\hline Hallur, Karnataka & $800-200$ в С & $\begin{array}{l}\text { One of two samples } \\
\text { studied of this } \\
\text { period, low } \\
\text { Frequency }(9.6 \%) ; \\
\text { also preserved by } \\
\text { mineralization with } \\
\text { metal tools }\end{array}$ & $\begin{array}{l}\text { Brachiaria ramosa, } \\
\text { Setaria verticillata }\end{array}$ & $\begin{array}{l}\text { Panicum } \\
\text { sumatrense, } \\
\text { Eleusine } \\
\text { coracana, rice }\end{array}$ & $\begin{array}{l}\text { Fuller 1999; Fuller et } \\
\text { al. 2004; Vishnu-Mit- } \\
\text { tre 1971; for dating: } \\
\text { Fuller et al. } 2007\end{array}$ \\
\hline Charda, Uttar Pradesh & $\begin{array}{l}\text { Period IIA, 600-200 } \\
\text { BC }\end{array}$ & $9 \%$ (of 11 samples) & Rice, barley & $\begin{array}{l}\text { Wheat, a small } \\
\text { millet }\end{array}$ & Chanchala 2002 \\
\hline
\end{tabular}




\begin{tabular}{|c|c|c|c|c|c|}
\hline $\begin{array}{l}\text { Saunphari, Uttar } \\
\text { Pradesh }\end{array}$ & 1000 BC-AD 300 & $?$ & Rice, barley, wheat & & Chanchala 2004 \\
\hline $\begin{array}{l}\text { Hulaskhera, Uttar } \\
\text { Pradesh }\end{array}$ & $\begin{array}{l}\text { Early Historic } \\
(300 \text { BC-AD 300) }\end{array}$ & $\begin{array}{l}83 \% \text { (of } 23 \\
\text { samples), mis- } \\
\text { reported as 'Eleu- } \\
\text { sine') }\end{array}$ & Kodo millet, barley, rice & $\begin{array}{l}\text { Rare wheat, pearl } \\
\text { millet }\end{array}$ & Chanchala 1992 \\
\hline Manji, Uttar Pradesh & $\begin{array}{l}\text { Early Historic } \\
(300 \text { BC-AD 300) }\end{array}$ & $\begin{array}{l}50 \% \text { (of } 4 \text { samples), } \\
\text { mis-reported as } \\
\text { 'Eleusine') }\end{array}$ & Barley, wheat, rice & $\begin{array}{l}\text { Rare Setaria cf. } \\
\text { italica }\end{array}$ & Chanchala 2000-2001 \\
\hline Sanghol & $\begin{array}{l}\text { Early Historic } \\
(300 \text { BC-AD 300) }\end{array}$ & $\begin{array}{l}\text { ?, mis-reported as } \\
\text { 'Eleusine' }\end{array}$ & Rice, barley, wheat & $\begin{array}{l}\text { Sorghum, Setaria } \\
\text { sp. }\end{array}$ & $\begin{array}{l}\text { Pokharia and Saraswat } \\
1999\end{array}$ \\
\hline Balathal, Rajasthan & $\begin{array}{l}\text { Early Historic } \\
(300 \text { BC-AD } 300)\end{array}$ & $?$ & $\begin{array}{l}\text { Barley, wheat, rice, } \\
\text { kodo millet(?) }\end{array}$ & $\begin{array}{l}\text { Panicum, Setaria, } \\
\text { Coix }\end{array}$ & Kajale 1996a \\
\hline $\begin{array}{l}\text { Nevasa, } \\
\text { Maharashtra }\end{array}$ & $\begin{array}{l}\text { Early Historic } \\
(150 \text { BC-AD 200) }\end{array}$ & $?$ & Barley, wheat, rice & $\begin{array}{l}\text { Pearl millet, } \\
\text { sorghum, } \\
\text { Eleusine(?) }\end{array}$ & $\begin{array}{l}\text { Anonymous, in } \\
\text { Sankalia } \\
\text { et al. 1960: 529-30; } \\
\text { Kajale 1977b }\end{array}$ \\
\hline $\begin{array}{l}\text { Ter (Thair), } \\
\text { Maharashtra }\end{array}$ & $\begin{array}{l}\text { Early Historic } \\
(200 \text { BC-AD 400) }\end{array}$ & Large quantities & Rice, kodo millet(?) & Wheat, barley & $\begin{array}{l}\text { Vishnu-Mittre } \text { et al. } \\
1971\end{array}$ \\
\hline Piklihal, Karnataka & Early Historic & $\begin{array}{l}\text { One grain in one } \\
\text { sample (of two) }\end{array}$ & $\begin{array}{l}\text { Brachiaria ramosa, } \\
\text { Panicum sumatrense }\end{array}$ & Sorghum & $\begin{array}{l}\text { Fuller, unpublished } \\
\text { data; dating: Fuller et } \\
\text { al. } 2007\end{array}$ \\
\hline $\begin{array}{l}\text { Paithan, } \\
\text { Maharashtra }\end{array}$ & $400 \mathrm{BC}-\mathrm{AD} 700$ & $\begin{array}{l}78 \% \text { (in } 77 \text { samples, } \\
\text { declining over dura- } \\
\text { tion of site from } 94 \% \\
\text { to } 75 \% \text { ) }\end{array}$ & $\begin{array}{l}\text { Kodo millet, } \\
\text { Brachiaria ramosa/ } \\
\text { Setaria italica, rice }\end{array}$ & $\begin{array}{l}\text { Wheat, barley, } \\
\text { sorghum, pearl } \\
\text { millet, Panicum } \\
\text { sumatrense, } \\
\text { Eleusine coracana }\end{array}$ & This report \\
\hline
\end{tabular}

but there is now a strong case for one of several domestication events for Asian rice in northern South Asia, probably the Gangetic region, while separate processes of domestication are inferred for Yangtze river basin of China (Crawford 2006; Fuller 2007). Available evidence suggests that rice became a crop in parts of peninsular India during the Iron Age (Kajale 1989, 1991; Fuller 2006a: 53), with the earliest few finds from the latest level at Inamgaon in Maharashtra, dated to 1200-900 BC (Kajale 1988). The Iron Age adoption of rice was accompanied by some changes in ceramic repertoire that suggest the influence of northern Indian food traditions (Fuller 2005: 769). It is therefore no surprise that rice was a consistent find at Paithan. It has a high ubiquity of c. $65 \%$ of samples, which is essentially constant through all phases. In terms of absolute numbers and relative frequencies, however, rice is quitelow, with its total relative frequency of c. $3 \%$. While this is about twice the total frequency of wheat and barley, it is less than the frequency of summer pulses or winter pulses (when taxa are grouped) and much less than the total frequency of millets, which is over $60 \%$. Given that recovery and sorting biases might be expected to favour large seeds (like rice, wheat and pulses), these numbers are suggestive. Rice was widely available, but somehow special, and does not appear to have been the staple crop, but perhaps a high-status or specialuse cereal alongside the staple millets and pulses. This is how we would expect the traditional diet of the Deccan to have been until quite recent times, until the spread of artificial irrigation. Rice is a thirsty crop, and without major capital investments (landesque intensification, sensu Brookfield 1984; Blaikie and Brookfield 1987: 9; also Kirch 1994: 19), it is unlikely to have been produced on as large a scale as monsoon-adapted dry crops like millets and summer pulses.

Rice is highly diverse, with a wide range of landraces known in India as well as several varieties of wild weedy rice that may occur as weeds of cultivation. Varieties in India include both the conventional subspecies indica, with likely origins in northern India, and japonica of East Asian origin. Grain morphometric evidence suggests that japonica rices were introduced to the northwestern subcontinent, as at Pirak, in the first half of the 2nd millennium $\mathrm{BC}$, together with other evidence for diffusion from China (Fuller 2006a: 36; Fuller and Qin 2009). It is therefore of interest to know which subspecies are most likely represented by the Paithan 


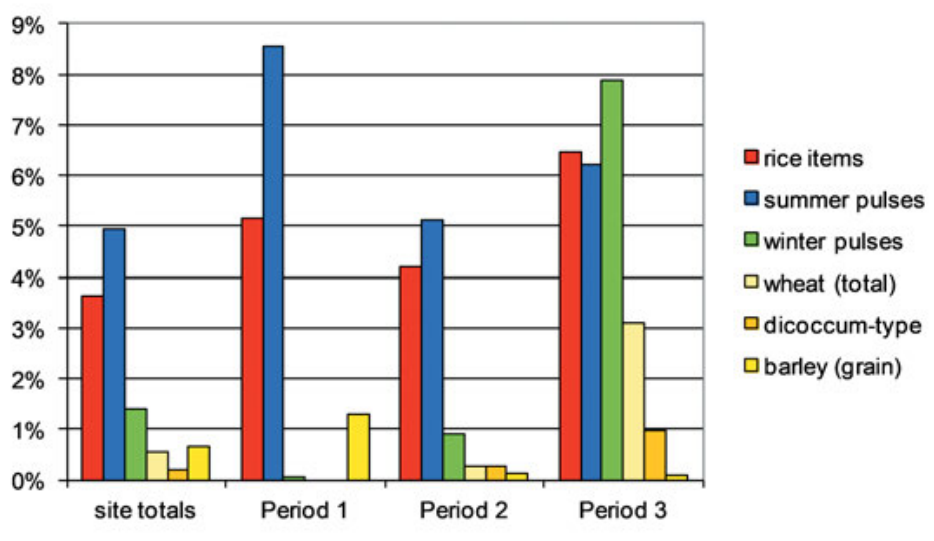

Fig. 12.7: Comparison of the frequency of wheat and barley with other taxa.

finds, and detailed metrical analysis may allow this in the future. In addition, the presence of apparent wild rices with noticeably smaller and thinner grains must also be noted, some of which may have had long use as occasional foodstuffs in South India, or perhaps occurred as weeds of pulse or millet cultivation, as indicated by small quantities of probable Oryza granulata grains from Late Neolithic Hallur in Karnataka (2nd millennium BC) (Fuller 2003c: 378, n.2). In addition, other thin and flattened grains are likely to represent immature grains, implying that crops did not ripen evenly and that early harvests included some ill-formed grains. A full morphometric analysis of the Paithan rices in the context of the wider context of grain shape variation in archaeobotanical materials in South Asia is warranted.

\section{Wheat and barley}

The major winter cereals of South Asia have their origins in South-West Asia and have been transmitted to India via the Indus region, where they were the staple crops of the Harappan civilization (Fuller and Madella 2001; Fuller 2006a: 20-35). In Maharashtra, they were widespread and important cereals of the Deccan Chalcolithic (Kajale 1991; Fuller 2003c: 372-374), with the more drought-tolerant barley in particular dominating the archaeobotanical record at Inamgaon (Kajale 1988). Further south, in the Southern Neolithic, these cereals were occasional and of low frequency, suggesting that they may have had some special status (Fuller et al. 2004; Fuller 2005), and they might have been cultivated in small, garden-like plots, where they could be more carefully tended and watered (Fig. 12.7). At Paithan, these species are fairly widespread, with a combined ubiquity of over $40 \%$ but with very low frequency. However, the patterns in wheat and barley differ. In Period 1, only barley is recorded, and this shows a significant subsequent decline into Periods 2 and 3. Wheat first occurs in Period 2 and shows a major rise into Period 3. The latter increase is mirrored in the winter pulses, which suggests a general increase in winter-cropping; this perhaps implies an increase in the control over water supply to provide irrigation through the winter. This may be related to an overall pattern of agricultural intensification, diversification and expansion aimed at increasing overall productivity (as noted in the general discussion, above).

The evidence from Paithan implies a significant difference from the regional pattern in the Chalcolithic period. In addition, in more recent times, it is freethreshing bread wheats that are most prominent, with barley significantly less so. Glumed wheats, namely emmer (Triticum dicoccum), were reported from the region in the 19th century (Watt 1889-1893; Fuller 2006a: 22-24), and it is therefore of interest to know the relative proportions of different winter cereal types through time. Distinguishing the glume wheat emmer from free-threshing wheat can only definitively be done on the basis of chaff remains, although grains tend to be clearly distinct, and on this basis, some plumper grains have been assigned to the free-threshing category and others to the emmer-type category (Figs 12.812.10). This suggests that there is a fairly even split between emmer and free-threshing wheat at Paithan, at least in Period 3, where there are sufficient numbers. 


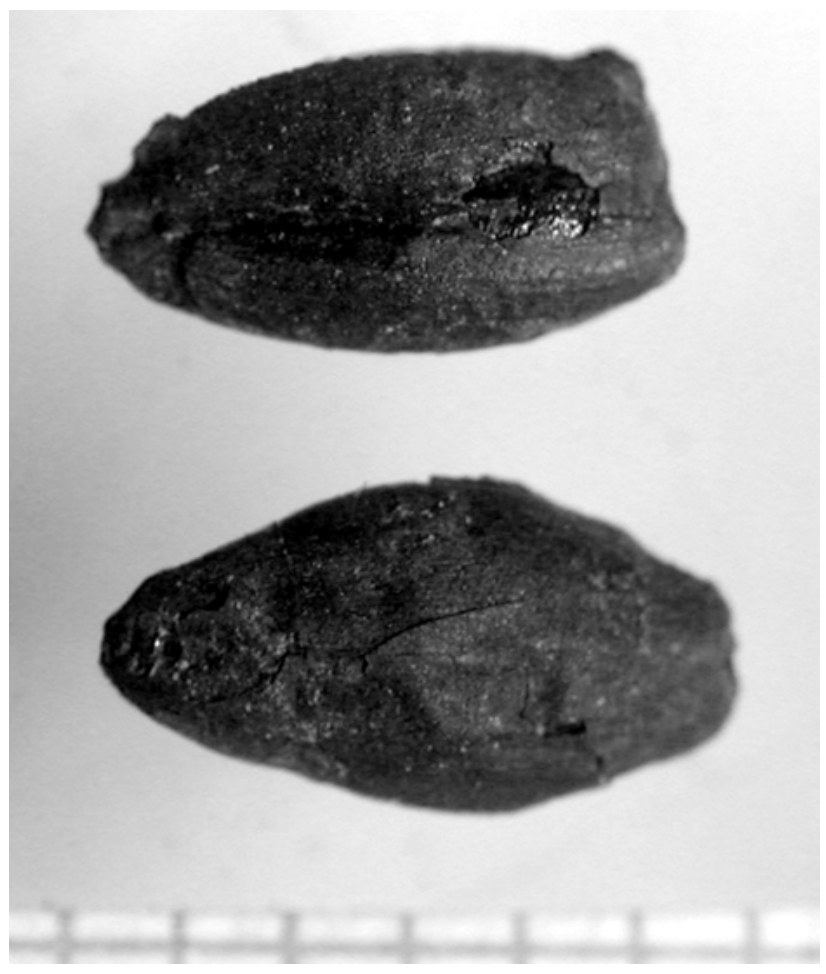

Fig. 12.8: Grains of barley (Hordeum vulgare), hulled variety, from context 721; ventral view (above) and dorsal view (below).

It should be noted that no attempt here is made to identify Triticum sphaerococcum, 'Indian shot wheat'. Although T.sphaerococcum has been widely reported in South Asian archaeobotany, its identification as a distinct genotype group of hexaploid breadwheats on the basis of grain remains is dubious (Fuller 2002: 273277; 2006a: 23). No clear criteria exist for recognizing this species from grain remains. The reported criteria of some authors contradict each other and if found in Neolithic Europe would fit with known free-threshing tetraploids (cf. Maier 1996). Given the impact of carbonization, which tends to make grains more spherical through differential shrinkage of length, and the potential wide range of variability of grain shapes

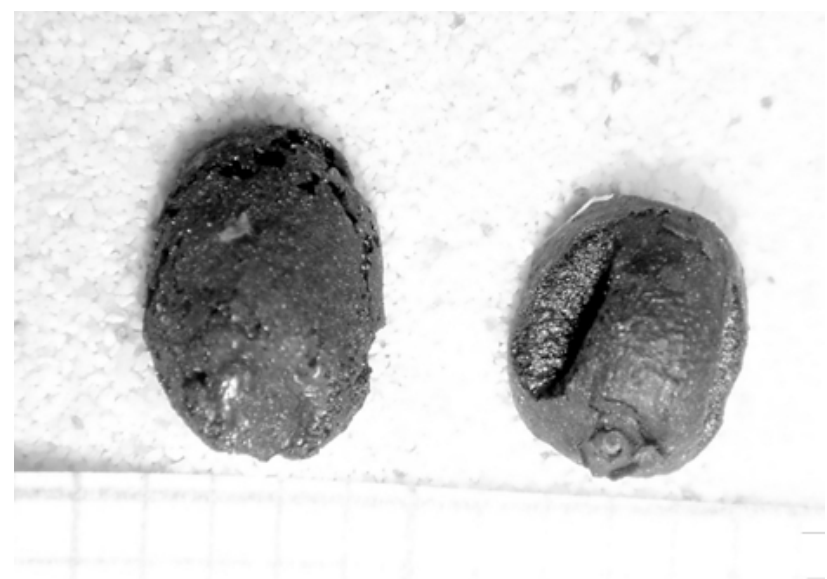

Fig. 12.9: Grains of free-threshing wheat (Triticum aestivun/ durum) from context 1036; dorsal view.

within both bread wheat and durum wheat, it is premature and misleading to refer archaeological material to 'Triticum sphaerococcum' until more systematic metrical studies of populations have been carried out on both modern and archaeological Indian wheats. A definitive identification would also be aided by the recovery of charred rachis remains, which have proved elusive in the Paithan samples.

\section{African millets (sorghum, pearl millet and finger millet) (Figs 12.11-12.13)}

These three cereals (Hindi jowar, bajra and ragi), which were brought into cultivation in three different parts of Africa (Fuller 2003b; cf. Marshall and Hildebrand 2002), are of widespread importance in South Asia today, and especially on the Indian peninsula (FAO 1995; Possehl 1986). These species are on the whole fairly minor at Paithan, although both sorghum and pearl millet show major increases in frequency in Period 3. This may suggest that the beginning of the process by which these species rose to prominence in
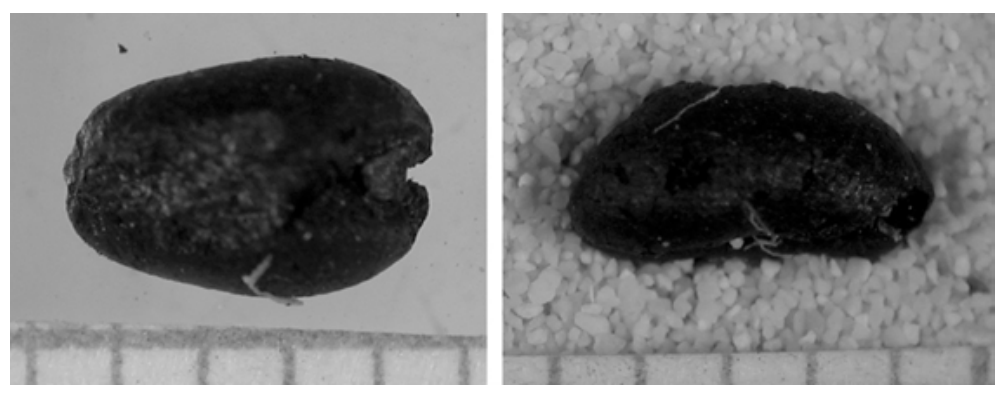

Fig. 12.10: Grain of emmer wheat type (Triticum diococcum) from context 919; dorsal view (left) and lateral view (right). 

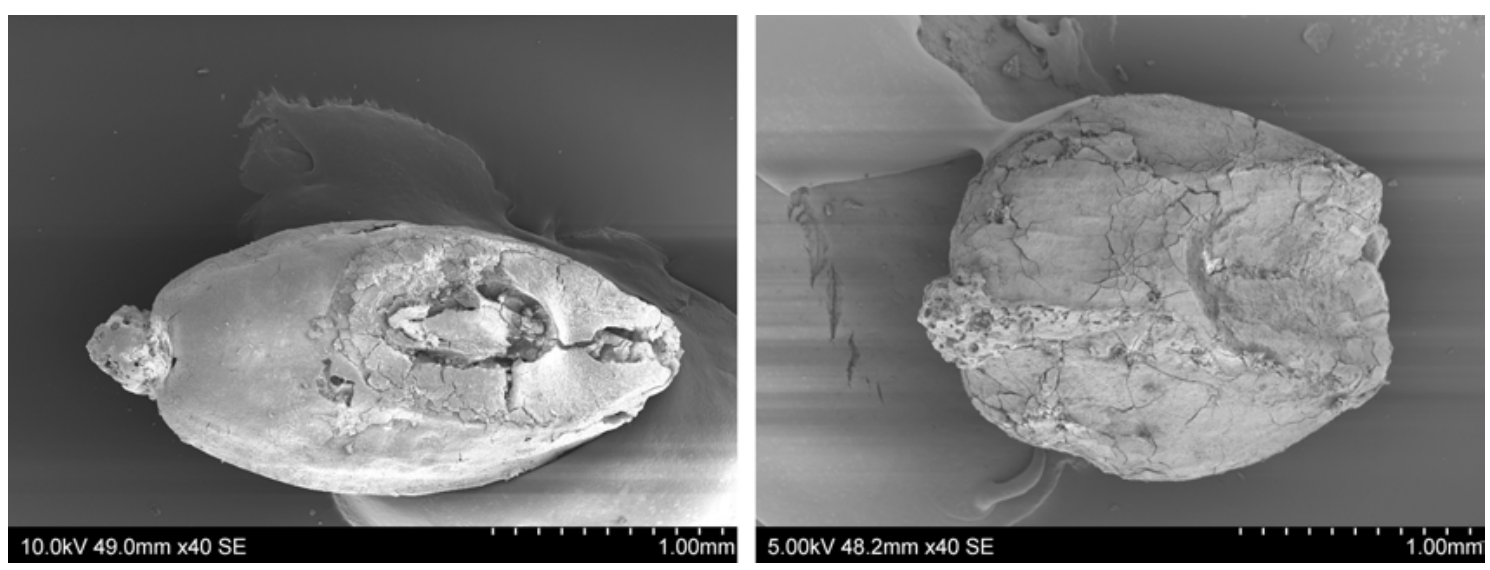

Fig. 12.11: Pearl millet grain (Pennisetum glaucum), narrow grain type, from context 930; dorsal view (left) and dorsal view (right).
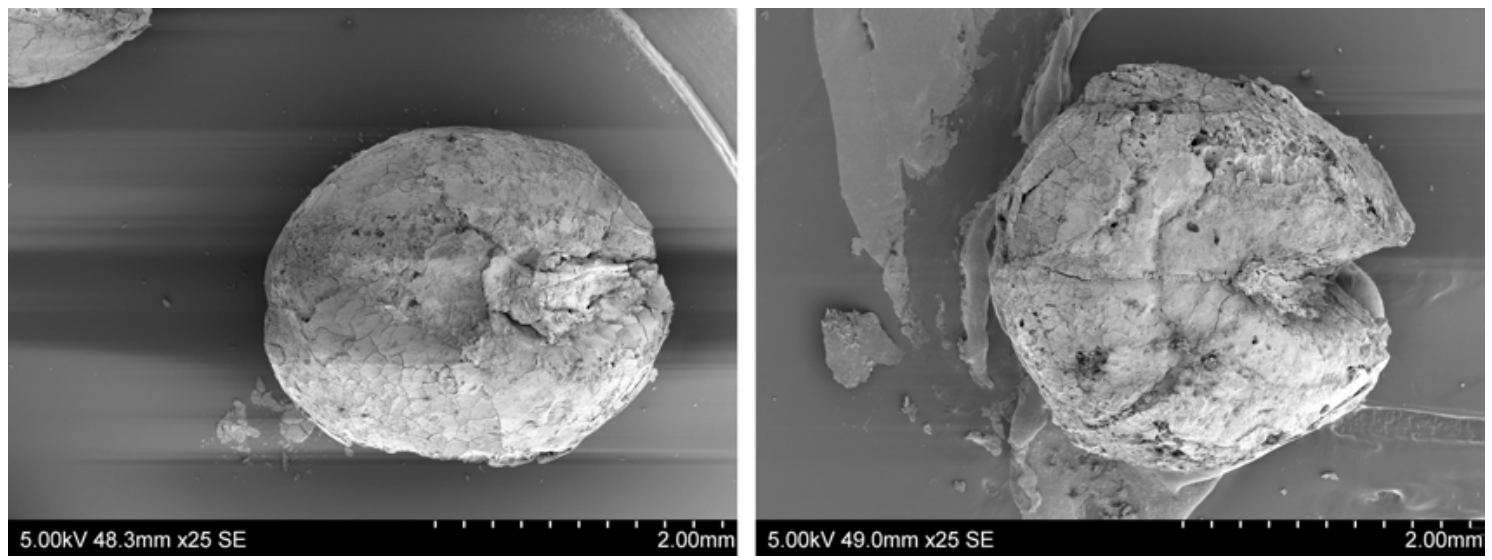

Fig. 12.12: Sorghum (Sorghum bicolor) of race bicolor type from context 930; dorsal view (right). Sorghum of race durra type from context 1092; dorsal view (right).

South India began only in the 3rd or 4th century. Some years ago, Possehl (1986) postulated that the introduction of these species from Africa may have been fundamental to the development of double-cropping in the greater Indus region and especially Gujarat, and paved the way for the development of agriculture in peninsular India. Subsequently, systematic archaeobotanical work in Gujarat suggested that the African millets were added to cultivation based on indigenous millets, especially Panicum sumatrense (Weber 1991, 1998), and research in South India established the primacy of a suite of native crops with Brachiaria ramosa and Setaria verticillata millets (Fuller et al. 2004). What is intriguing about the evidence from Paithan is that it implies that even though these species were introduced already in the Chalcolithic period (see Fuller 2003b), they may have remained fairly minor crops for the first two millennia or so that they were in India. The reasons for this are not immediately apparent. In general terms, they have a similar ecology and season- ality to the indigenous millets and have an advantage in being free-threshing (true of pearl millet and finger millet, and advanced durra type sorghums; see Reddy 2003; Fuller and Weber 2005), and this implies fewer crop-processing stages and labour needed to take them from the field to the plate. Nevertheless, cultural preference may have operated against them in favour of the traditional small millets, or else the persistent husks of the small millets may have been favoured for the advantages that the husks provide in storage as extra protection against fungus and to some extent against insects. In this regard, it is of interest to note that earlier finds of sorghum in Periods 1 and 2 - when referable to variety - appear to be hulled bicolor type sorghums, whilst the free-threshing larger-grained durra is present only in Period 3. It should also be noted that recent research suggests that a local trajectory of evolution from bicolor to durra sorghum took place in the Middle Nile Valley (Nubia) in the early centuries $\mathrm{AD}$, and thus, it may be that this free-threshing form 
became available by diffusion from Africa only in the 3rd century or so (see Clapham and Rowley-Conwy 2007; Shinnie and Anderson 2004: 366).

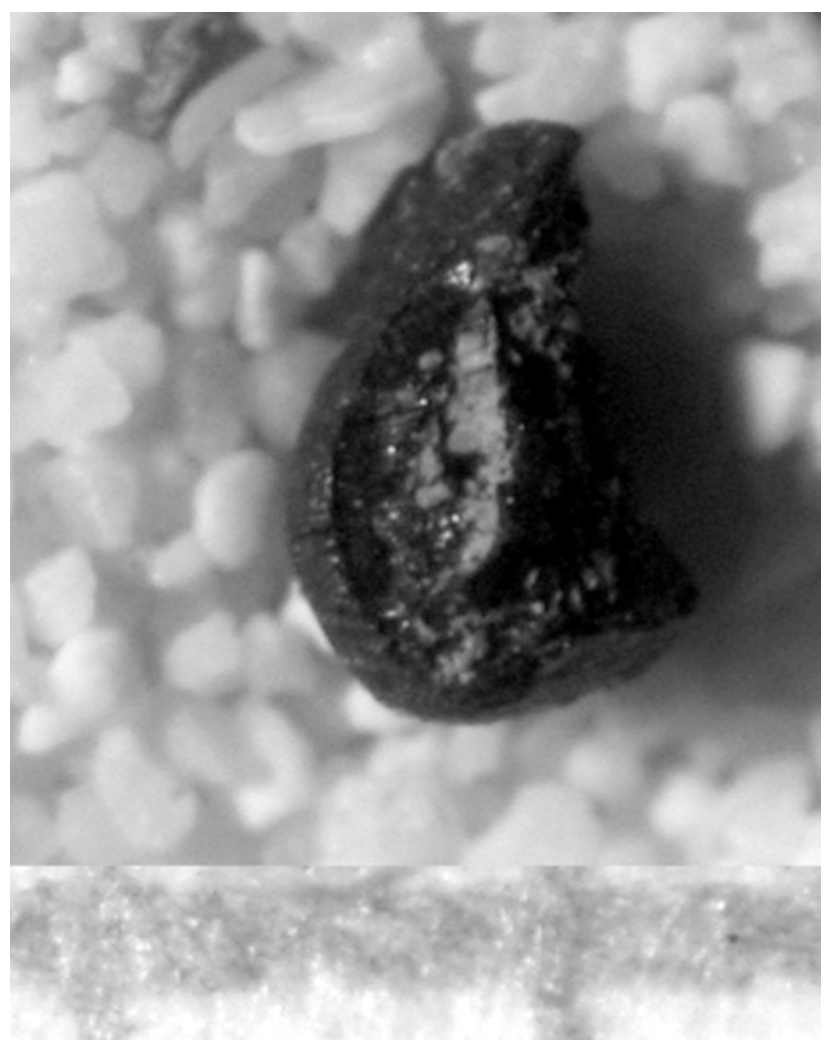

Fig. 12.13: Finger millet (Eleusine coracana), fragmented, from context 721; basal view of embryo. Approximately half of the grain is preserved.

There have been recent concerns over identification criteria for distinguishing these cereals (see Fuller 2003b for a review). While some reports of sorghum on the basis of ceramic and mudbrick impressions appear to have been in error, most reports on charred macroremains appear valid, and specimens from Paithan are well preserved and readily recognizable. This is also true of pearl millet. Finger millet appears to have been the most widely mis-reported. Clear grains, with characteristic globular-angular shapes and minute surface warts, were recovered only from one sample in Period 1 at Paithan (Fig. 12.13). Previously, the author has found one distinct specimen from Iron Age Hallur (Fuller et al. 2004) and ten from Early Historic Perur in Tamil Nadu (Cooke et al. 2005). These extremely small numbers raise the question as to whether there is some inherent preservation bias acting against this species. Compared to other cereals, it has a distinctively thicker pericarp, which is somewhat sticky and oily in appearance. It is conceivable that this lends itself more readily to destruction by fire. At present, there is so little good archaeobotanical evidence for this species, from either East Africa or India, that its early cultivation remains truly obscure.

\section{The Chinese millets (broomcorn millet and common foxtail millet) (Figs 12.14 and 12.15)}

These two species, Panicum miliaceum and Setaria italica, are both widespread in India today, and the latter, in particular, is a major crop in South India. At Paithan, there are only a few occurrences of broomcorn millet in Periods 2 and 3, while Setaria italica is confirmed for both of these periods and probably in significant proportions, having a ubiquity of $10-20 \%$. A complicating factor is that charred grains of Setaria italica are very difficult to separate from grains of the indigenous Brachiaria ramosa, even their rugose husk patterns are similar, although the rugae are slightly coarser in B. ramosa, which has grains that tend to be somewhat flatter and with a relatively larger hilum. These distinctions, however, are made more problematic by the distortions introduced by charring.

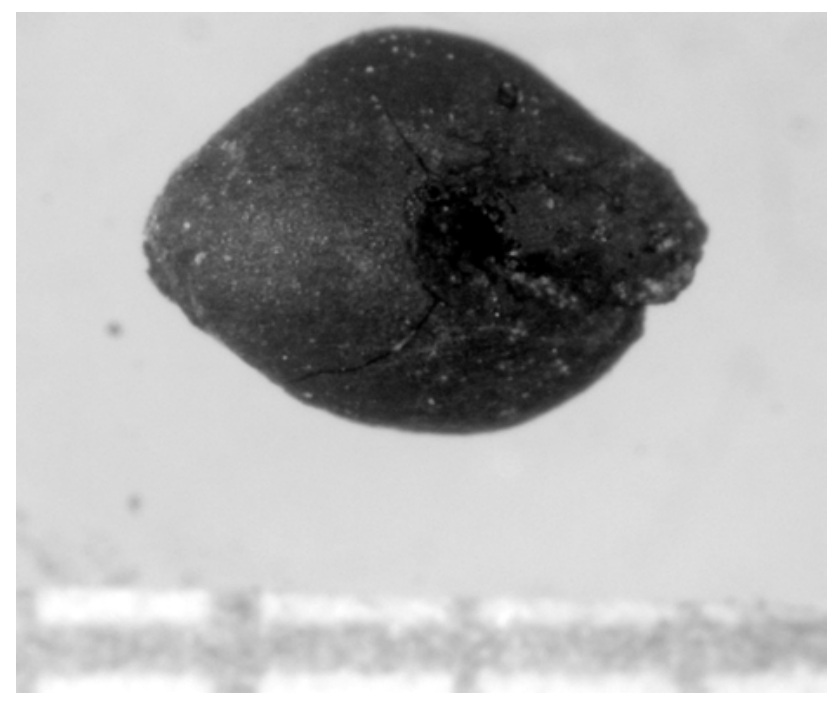

Fig. 12.14: Grain of common broomcorn millet (Panicum miliaceum) from context 1128; dorsal view.

Further re-examination of this material is warranted; only for a few samples has the author attempted these divisions, and thus for many samples, only a $B$. ramosa/S. italica category is counted. As will be seen, this accounts for about $10 \%$ of all seed finds in Period 3 , indicating major significance. Future work needs to focus on determining the relative contribution of these 

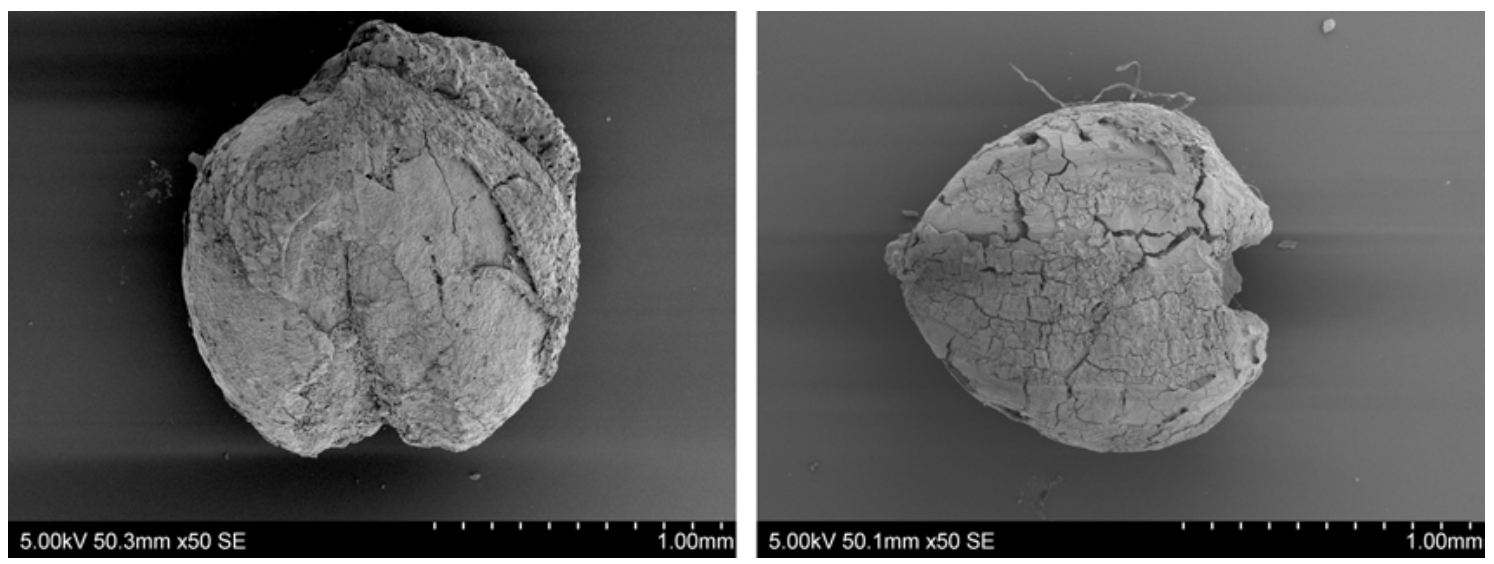

Fig. 12.15: Grain of common foxtail millet (Setaria italica) from context 1135; dorsal view (left) and ventral view (right), both with adhering lemma. Notice on ventral view the indentation of charred away hilum which is relatively short compared to overall grain length (in contrast to Brachiaria ramosa).

two species, as at some stage, there must have been a transition from prehistoric dominance of Brachiaria ramosa, the native crop of the Southern Neolithic and probably the Deccan Chalcolithic (Fuller 2003b, 2006a; Fuller et al. 2004; Cooke et al. 2005), to recent historical dominance by Setaria italica, with Brachiaria persisting in cultivation only in isolated peripheral pockets, where it is maintained apparently for ritual uses (Kimata et al. 2000). This transition amongst the small millets represents a major, still undocumented, change in the history of Indian agriculture.

Foxtail and Broomcorn millets are associated with the earliest agriculture in North China in the Yellow River basin (Crawford 2006), and both species appear to have been domesticated there. Nevertheless, recent genetic studies on modern foxtail millet varieties suggest more than one domestication centre, and a distinctive wild race found today in Afghanistan and northern Pakistan may have given rise independently to some domesticated landraces (Fukunaga et al. 2002, 2006). This being the case, it need not surprise us that Setaria italica reports, for example at Rojdi A (Weber 1991), predate those of Panicum miliaceum or other potential Chinese imports, which appear mainly after 1900 вC (Fuller 2006a: 36). Nevertheless, the identification challenge of separating $S$. italica and B. ramosa needs to be tackled more widely.

\section{The Indian small millets (little millet, browntop millet, sawa millet and other Setaria spp.) (Fig. 12.16)}

There is a wide range of small millets cultivated in South Asia today, and many of these were domesticated somewhere on the subcontinent (see Fuller 2006a: 18). At least five of these were present at Paithan, including kodo millet (see above) and the other genera discussed here (Panicum, Brachiaria, Echinochloa and Setaria). One difficulty with all of these species is that they are wild components of the flora in India and occur as weeds of other crops (including other millets and rice), but they are also known in cultivated or domesticated forms. For the archaeobotanist, we do not yet have clear and unambiguous means for determining whether finds of these represent domesticated crops or weeds. For early periods, such as the Southern Neolithic, this has been inferred on the basis of high relative frequency and ubiquity of occurrence (see Fuller 2003c; Fuller et al. 2004), but at an agriculturally diverse site such as Paithan, this is somewhat more problematic. Nevertheless, these species are likely to have been cultivars, and most of them (with the exception of Brachiaria ramosa) can be found in cultivation in Maharashtra today (Kimata 1989; Kobayashi and Kimata 1989; Kimata and Sakamoto 1992). B. ramosa was the staple cereal of the Southern Neolithic (Fuller et al.2004), and it may also have been cultivated in the Neolithic Ganges, Gujarat and Maharashtra, although difficulties with precise identification and determining whether it might be present in the wild form, as a weed, raise interpretative problems. Its presence at Paithan, as well as Early Historic Tamil Nadu (Cooke et al. 2005), indicates that it was more widespread in the past than today (cf. Kimata et al. 2000; Kingwell-Banham and Fuller 2014). As noted in the discussion of $S$. italica (above), determining the timing and regions in which this crop declined remains an important issue. In the Southern Neolithic, the recurrent presence of Setaria 

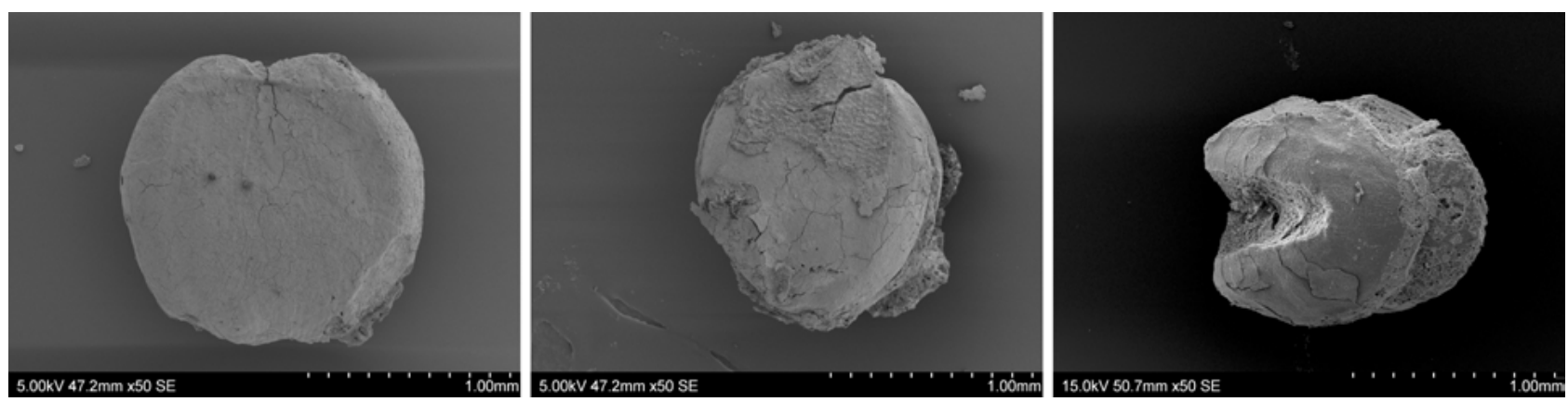

Fig. 12.16: Grain of browntop millet (Brachiaria ramosa) from context 1127; ventral view (left) showing adhering palea (centre) and dorsal view (right). Notice (left) faint traces of hilum, which is relatively long compared to overall grain length (1/4-1/3 length).

verticillata has been interpreted as having been a co-staple with Brachiaria (Fuller et al. 2004). It is not clear whether this species was ever domesticated, but it may have been a tolerated and consumed weed. Its co-occurrence at Paithan in some quantity in Period 3, together with B. ramosa and S. italica, suggests that this continued to be the case into Medieval times. Panicum sumatrense was the staple cereal of Protohistoric Saurashtra (Weber 1991: 84-85) and was also cultivated at Harappa (Weber 1999). The process and timing by which it spread to the peninsula remain unclear, but it persists as a widespread minor cereal today. The early history of sawa millet (Echinochoa colona) remains obscure. It may be, like kodo millet, a secondary domestication of an early rice or millet weed. Early finds of probable weedy type include those from the Southern Neolithic (Fuller et al. 2004) and Rojdi Phase C (Weber 1991).

\section{Pulses}

As already noted above, pulses are important in crop rotations because they are nitrogen-fixing plants
(Smartt 1990; Zohary and Hopf 2000: 92). They can generally be grown on most soils except those which are waterlogged. In general, those pulses native to the tropics (India or Africa) have a monsoon-adapted seasonality, while those that spread in prehistory from the Near East (including lentil, pea, chickpea and grasspea) are winter crops. They are important also in human nutrition as sources of protein and thus complement the carbohydrate-rich cereals. Indeed, in much of India today, pulses are probably the main protein source for vegetarians, and in the form of dhal, they are a regular part of Indian meals. Pulses can also be made into flour, a key ingredient in many distinctive southern Indian food products, such as dosa, idli and vadai. It is noticeable that archaeologically, pulses are a prominent part of the archaeobotanical evidence in peninsular India already in prehistory, in many cases occurring in equal or greater quantity than cereals (Fuller et al. 2004; Fuller and Harvey 2006). This is a notable contrast from the quantitative frequency of pulses in other world regions, such as the Near East, Europe or the Indus Valley. It can be hypothesized that this resulted from the fact that the distinctive impor-

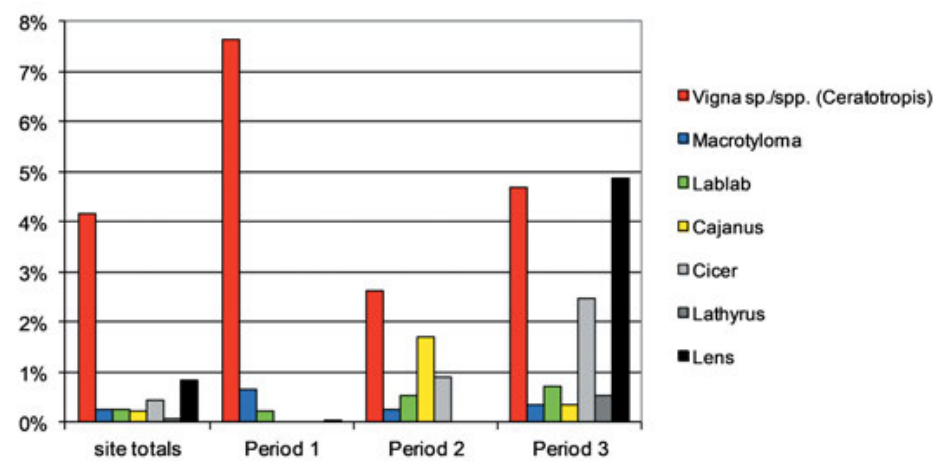

Fig. 12.17: Relative frequency of pulses. 
Table 12.4: The presence/absence of pulse crops on peninsular Indian sites of Iron Age or Early Historic date. Sources as for Table 12.2. (IA = Iron Age; IV = Hallur period IV; EH = Early Historic).

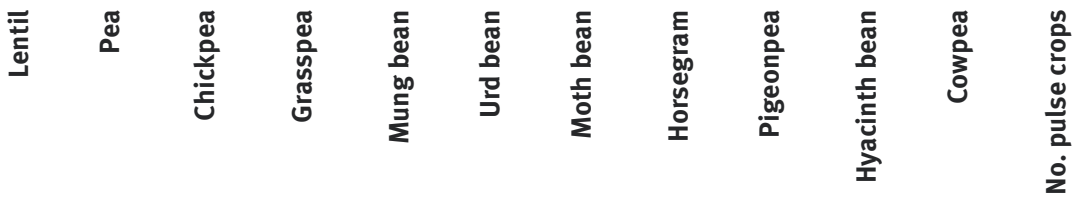

\begin{tabular}{|c|c|c|c|c|c|c|c|c|c|c|c|c|c|c|}
\hline & Period & Site & & & & & & & & & & I & & 운 \\
\hline \multirow[t]{6}{*}{$800 \mathrm{BC}$} & IA & Adam Cave & - & - & - & + & - & + & - & + & - & + & - & 4 \\
\hline & IA & Bhagimohari & + & + & - & + & $+?$ & + & - & + & + & + & - & 8 \\
\hline & IA & Bhokardan & + & + & + & + & - & + & - & - & + & + & - & 7 \\
\hline & IA & Naikund & + & + & - & - & - & + & - & - & - & - & - & 3 \\
\hline & IA & Veerapuram & - & - & + & - & - & + & - & + & - & + & - & 4 \\
\hline & $\mathrm{IV} / \mathrm{IA}$ & Hallur & - & - & - & - & + & + & - & + & - & + & - & 4 \\
\hline \multirow[t]{13}{*}{$300 \mathrm{BC}-?$} & $\mathrm{EH}$ & Piklihal & - & - & + & + & + & - & - & + & - & + & - & 5 \\
\hline & $\mathrm{EH}$ & Veerapuram & - & - & + & - & - & - & - & + & - & + & - & 3 \\
\hline & $\mathrm{EH}$ & Adam Cave & + & + & - & + & + & + & - & - & - & + & - & 5 \\
\hline & $\mathrm{EH}$ & Bhatkuli & - & - & + & - & - & - & - & - & - & - & - & 1 \\
\hline & $\mathrm{EH}$ & Bhokardan & + & + & + & + & + & + & - & - & + & + & - & 8 \\
\hline & $\mathrm{EH}$ & Dangwada & + & - & - & + & - & - & - & - & - & - & - & 2 \\
\hline & $\mathrm{EH}$ & Kaundinyapura & - & + & - & + & - & - & - & - & - & - & - & 2 \\
\hline & $\mathrm{EH}$ & Nevasa & + & + & + & + & + & + & - & + & + & + & - & 8 \\
\hline & $\mathrm{EH}$ & Paunar & - & - & - & - & - & - & - & - & - & - & - & 0 \\
\hline & $\mathrm{EH}$ & Ter & + & + & - & + & + & + & - & + & - & - & - & 6 \\
\hline & $\mathrm{EH}$ & Kodumanal & - & - & - & - & + & + & - & + & - & + & + & 5 \\
\hline & $\mathrm{EH}$ & Mangudi & - & - & - & - & - & - & - & - & - & - & - & 0 \\
\hline & $\mathrm{EH}$ & Perur & - & - & - & - & + & + & - & + & - & + & + & 5 \\
\hline $300-0 \mathrm{BC}$ & & Paithan I & + & $?$ & - & - & + & - & + & + & - & + & - & 5 \\
\hline AD $0-400$ & & Paithan II & - & $?$ & + & - & + & + & + & + & + & + & - & 7 \\
\hline \multirow[t]{2}{*}{ AD $400-700$} & & Paithan III & + & $?$ & + & + & + & + & + & + & + & + & + & 10 \\
\hline & & Total sites & 10 & 8 & 9 & 11 & 12 & 14 & 3 & 13 & 6 & 15 & 3 & \\
\hline
\end{tabular}

tance of pulses, and especially pulse flours, associated with southern Indian foods had already developed on the Indian peninsula and that this distinctive pulse preparation style, which often involves dry-roasting, led to more frequent carbonization (Fuller and Harvey 2006). The relative frequency of pulses at Paithan is illustrated in Fig. 12.17. A comparative table on the presence of pulses on the Indian peninsula during Iron Age and Early Historic times is shown in Table 12.4. As with cereals, Paithan provides evidence for a wider range of pulses than other sites, a likely reflection of more extensive sampling.

\section{Mung and urd beans (Figs 12.18 and 12.19)}

An important group of related pulses are those of the genus Vigna, subgenus Ceratotropis, which is focussed in Asia (Tomooka et al. 2003). This includes two closely related species of particular importance in India, the mung bean (or green gram), $V$. radiata, and urd bean (or black gram), V. mungo. The scientific names of these species have, unfortunately, caused a degree of confusion (see Verdcourt 1971; Fuller 2002: 334, n.6; Fuller and Harvey 2006). These two species had separate origins from distinct wild progenitors, and current evidence suggests that they had non-overlapping origins, with a suggested epicentre of early urd cultivation in Gujarat/north-west Maharashtra and two early centres of mung cultivation in the Eastern Harappan zone and the South Indian Neolithic (Fuller and Harvey 2006; Fuller 2007). Distinguishing these species may prove difficult, especially if charred seeds are whole (with the cotyledons still together), but the seed coat and hilum have been destroyed by charring. If preserved, the hilum clearly distinguishes these taxa, with a much larger, protruding hilum in $V$. mungo and a smaller hilum in $V$. radiata that is flush with the seed surface, but very few such examples are available from Paithan, as was also true in the Southern Neolithic (Fuller et al. 2004). The criteria used in this study are those of Fuller etal. (2004) and Fuller and Harvey (2006), with a focus on plumule length (visible on split cotyledons) 
to overall seed length. These species have been widely recovered from archaeological sites throughout India.

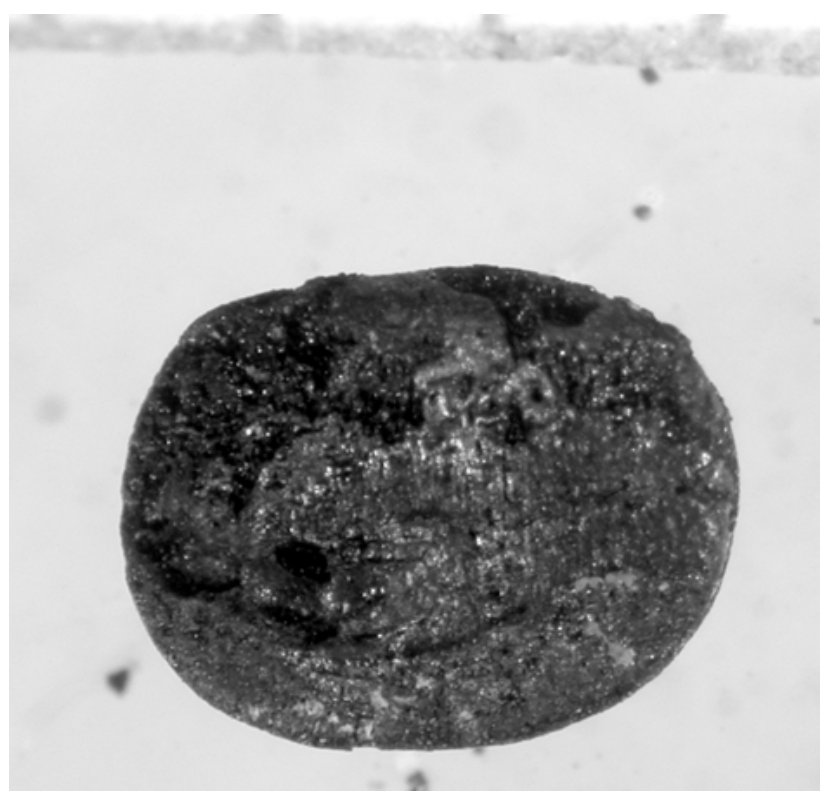

Fig. 12.18: Interior view of the cotyledon of mung bean (Vigna radiata) from context 1150 . Notice the relatively long plumule.

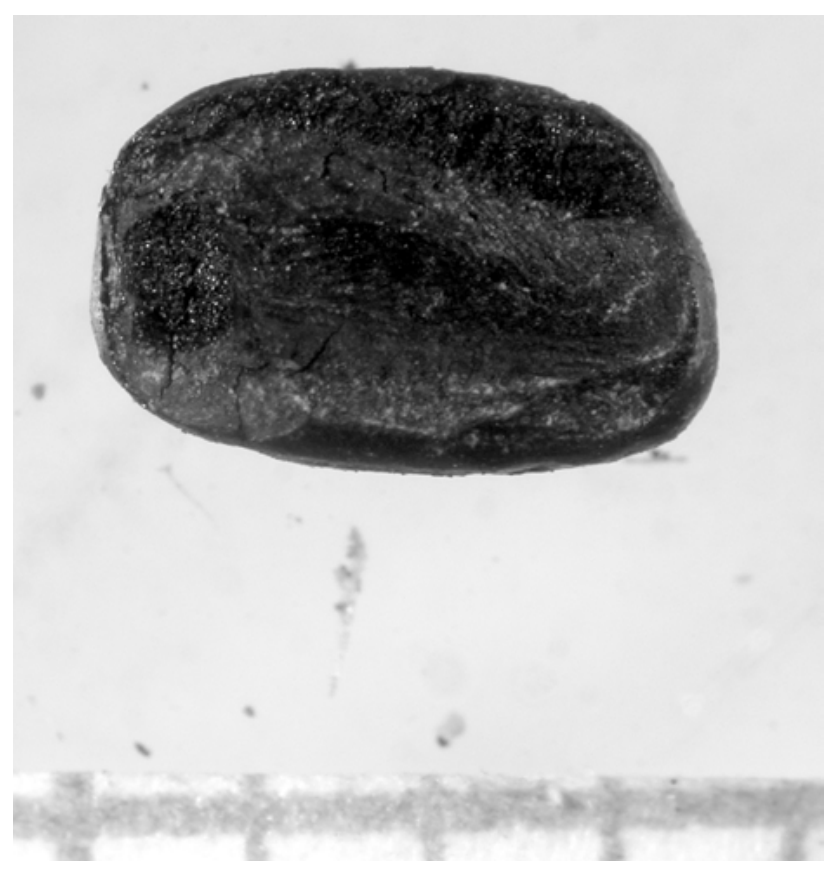

Fig. 12.19: Interior view of the cotyledon of urd bean (Vigna mungo) from context 1150 . Notice the shorter, half-seed-length plumule.

At Paithan, the Indian Vigna species dominate the pulse assemblage (Fig. 12.17). This is not unexpected as mung bean is one of the most frequent and ubiquitous pulses in Neolithic South India and Chalcolithic Maharashtra (Kajale 1988, 1991; Fuller et al.
2004), while urd is also prominent on the northern peninsula. Despite the Early Historic date of Paithan, Vigna specimens from the site can contribute to our understanding of the domestication process in pulse species. As with cereals, the domestication syndrome in pulses is expected to include grain size increase as well as a shift to non-dehiscent pods and loss of seed dormancy. While the latter two traits must have evolved early, it has been suggested that seed size increase did not and that this is a recurrent feature of pulses (Fuller and Harvey 2006; Fuller 2007). It may have required more intensive cultivation regimes, such as ard-ploughing, resulting in deeper burial of planted seeds to select for seed size increase. This assumes an unconscious mechanism, but it is also possible that farmers eventually took the conscious decision to select those crops that produced bigger seeds. Evidence for this lag time in size increase comes from the fact that early pulses, such as Vigna measured from Southern Neolithic sites, are small and within the size range of modern wild populations (which have been corrected for shrinkage due to charring), but that at later sites, particularly of Iron Age or Early Historic date, larger seeds, which would fit within the range of modern domesticated crops, are present. Some measurements from Paithan Vigna (on an initial representative assemblage rather than all examples) illustrates this in comparison to Southern Neolithic measurements (Fig. 12.20).

Moth bean, Vigna aconitifolia (Fig. 12.21), is another closely related pulse crop domesticated in South Asia. It can be distinguished from V. radiata and V. mungo by its minute hilum, which lies in a slight depression; it also has a distinctively short plumule length visible on split cotyledons. Unfortunately, it has not been adequately mapped in terms of its wild and weedy distribution, although it is not considered native to southern India (Cooke 1903-1908; Gamble 1935; Saldanha 1984) and thus may be a northern or central Indian domesticate (cf. Tomooka et al. 2003). In addition, early archaeological finds span from Harayana, including Harappan Burthana Tigrana and Late Harappan Mitathal, through the middle Ganges, at several sites in the 1300-600 BC horizon (Narhan, Imlidih-Khurd Period II, Raja-Nala-Ka-Tila Period II, Senuwar Period II, Kharadih Period II and Saunphari; see Chanchala 2004; Saraswat 2005). Together, these archaeological finds suggest a north Indian origin. Finds on the peninsula are lacking (see Table 12.4), and it may be that 


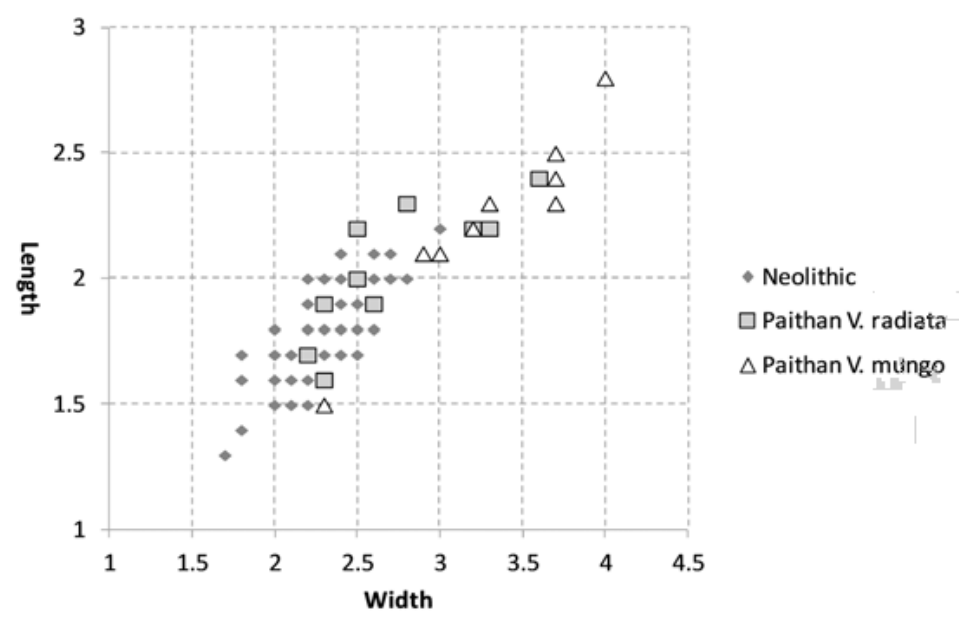

Fig. 12.20: Comparison of measurements of Paithan Vigna with samples from Neolithic contexts in southern India.

the appearance of this species at Paithan indicates its initial spread to the south.

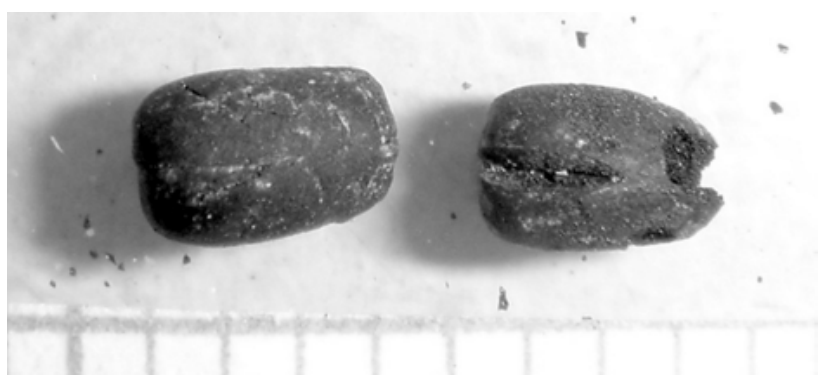

Fig. 12.21: Moth beans (Vigna aconitifolia) from context 1136.

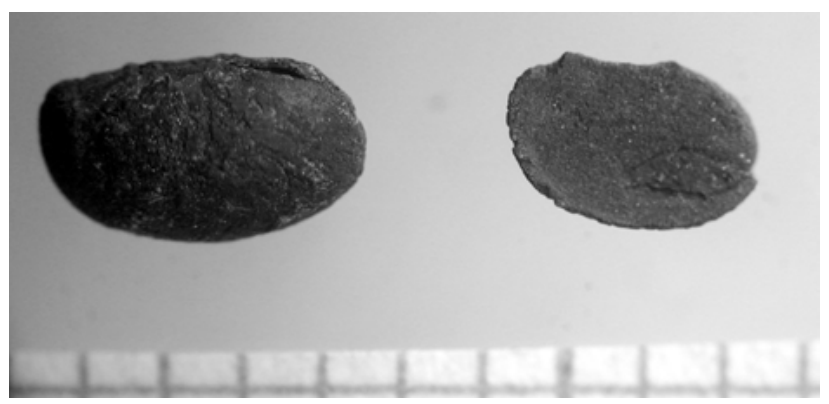

Fig. 12.22: Horsegram (Macrotyloma uniflorum) from context 467; complete seed (left) and interior of split cotyledon (right).

Cowpea (Vigna unguiculata), Hindi lobiya, is represented by a single unambiguous specimen from Period 3. This species is native to Africa and was most likely brought into cultivation in the West African savannah woodland transition, perhaps within modern Ghana (Vaillancourt and Weeden 1992; Ng 1995; Fuller 2003b: 241; D’Andrea et al. 2007). This author's previous review of crops of African origin in South Asia accepted two
Chalcolithic reports of Vigna unguiculata at Hulas and Daimabad (Fuller 2003b), although in neither case is the evidence unambiguous. More recently, additional finds have been reported from the Late Chalcolithic/ Iron Age Ganges at Kharadih and Raja-Nala-Ka-Tila in Uttar Pradesh (Saraswat 2005), while those of Early Historic Sanghol are unambiguous (Pokharia and Saraswat 1999).

Horsegram (Macrotyloma uniflorum (Lam.) Verdcourt) (Fig. 12.22), known in Hindi as kulthi, is one of the most widespread pulses (grain legumes) of modern and ancient India. It is grown as a small shrub throughout the semi-arid or savannah regions of South Asia. It is highly droughtresistant and yields a crop in 3-4 months. It is thought to be native to a region with such a climate, although very little botanical research on wild populations has been carried out. A limited herbarium survey by the author indicates wild populations in Rajasthan, such as around Mount Abu, a few north peninsular finds and several in the Southern Deccan, all in the drier semi-arid savannah zone (Fuller and Harvey 2006). Archaeologically, horsegram is one of the most widely reported pulses in prehistoric/protohistoric India (cf. Fuller and Harvey 2006), and it is the most widespread pulse find in peninsular India in Iron Age or Early Historic times (Table 12.4). Its seeds are distinctly rectangular-trapezoidal with a sharp edge. It is a pod-threshing pulse, and as such, seeds may be more prone to loss during processing. Its flat seed shape may also provide for preservation bias under charring, as seems to be the case with lentils. Archaeobotanical finds indicate that it was cultivated from Southern India 

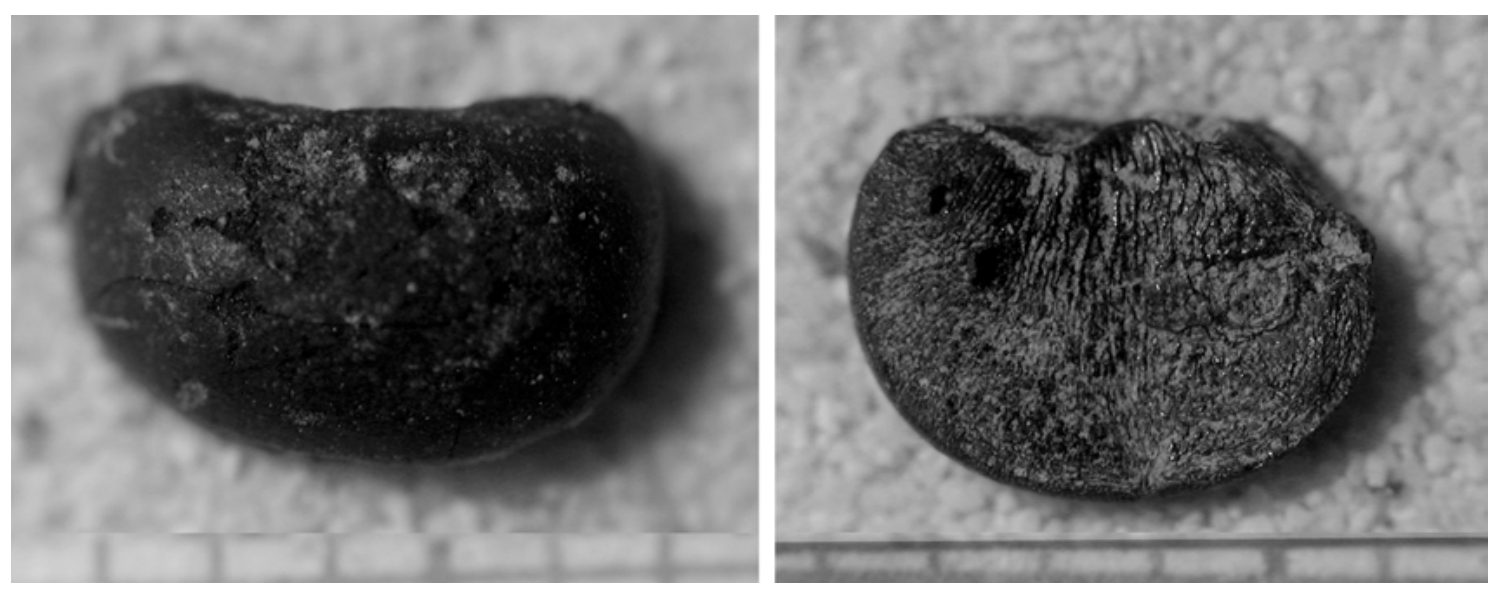

Fig. 12.23: Pigeonpea (Cajanus cajan) from context 1036; lateral view (left) and interior view of split cotyledon (right).

to Haryana and the middle Gangetic basin by 2200 BC. While this species has been suggested to be part of the indigenous Southern Neolithic package (Fuller 2002: 296; Fuller et al. 2004), current archaeological evidence might suggest independent domestication(s) in northern/western India (Fuller \& Murphy 2018).

\section{Hyacinth bean}

Finds of Lablab purpureus (Hindi sem) in India are earlier than any available from Africa, although it is generally regarded as originating in Africa (Fuller 2003b; Fuller and Harvey 2006). Early finds in Africa include early-centuries-AD finds in Nubia (Clapham and Rowley-Conwy 2007) and in Southern Africa (Smith and Jacobson 1995). By contrast, Lablab appears to have arrived in India relatively early, probably in the first half of the 2nd millennium. Out of 90 sites with evidence for pulses, Lablab has been reported from 19, of which 15 are on the peninsula (Fuller and Harvey 2006). It appears that this crop became widespread in peninsular India by c. $1500 \mathrm{BC}$, with an early direct AMS date of с. 1600 вс (Fuller and Harvey 2006; Fuller et al. 2007). A few earlier finds may come from the Eastern Harappan zone, with reports from Late Harappan Sanghol and Mahorana, but dating evidence is inadequate to place these securely much earlier than 1700-1500 вс. In Africa, this species is grown mainly as a pulse, for its dried seeds, whilst in India, it has both pulse and green vegetable varieties, the latter being grown for its green pods, which are harvested before seed maturation as a vegetable (Smartt 1990). The latter variety presumably evolved in India and predominates more towards the north and east and also occurs further east into South-East Asia and China. The form at Paithan was presumably a pulse type.

\section{Pigeonpea Cajanus cajan (Hindi toor dhal and arhar) (Fig. 12.23)}

This is a major pulse throughout India and often a staple dhal variety. Nevertheless, it has only been reported from relatively few sites in India to date, including Tuljapur Garhi, Peddamudiyam and Sanganakallu, all from the Deccan in roughly the mid-2nd millennium BC, with similar age finds from Gopalpur in Orissa (Fuller et al. 2004; Fuller and Harvey 2006; Harvey et al. 2006). It is a rare find at Paithan, as on other sites where it occurs, and it may be that there are persistent preservation biases working against this species.

\section{Winter pulses (chickpea, grasspea, pea, lentil)(Figs 12.24 and 12.25)}

Cicer arietinum (Hindi chana), Lathyrus sativus (Hindi khesari), Pisum sativum (Hindi matar), Lens culinaris (Hindi masur) - these four pulse species have their origins in the Near East in the same general regions as wheat and barley (Smartt 1990; Zohary and Hopf 2000). While they spread east to South Asia in prehistory, the earliest evidence for these species comes from the Early and particularly the Mature Harappan period (Fuller and Madella 2001). All species were present in Maharashtra in the Chalcolithic period, but they appear to have been less favoured and largely absent further south (Kajale 1991; Fuller 2005). They remain 
frequent finds on the northern peninsula through the Iron Age and Early Historic periods. As already discussed, one aspect of their importance lies in nitrogen-fixation, which allows them to be cropped in the winter on soils that have already been used for cereals or other crops in the summer; their use in this way can help to maintain soil fertility.

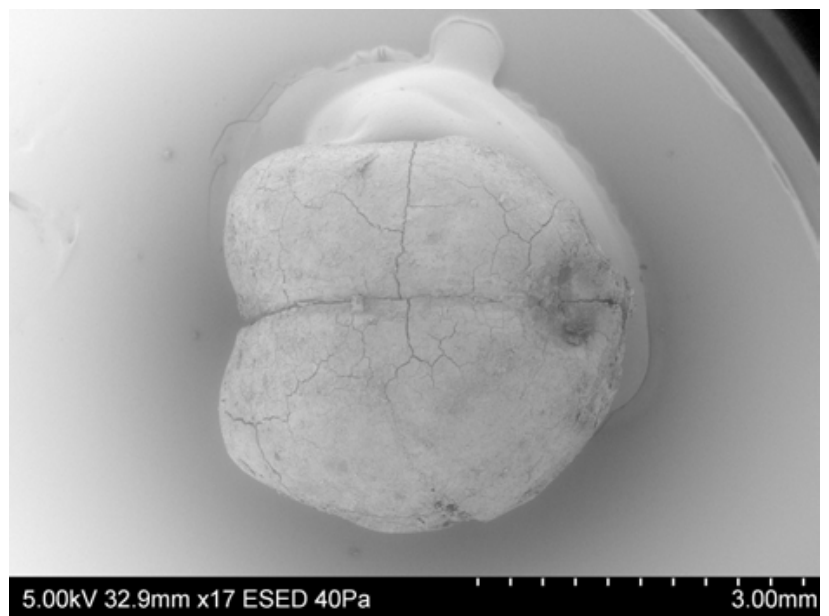

Fig. 12.24: An example of chickpea (Cicer arietinum); ventral view.

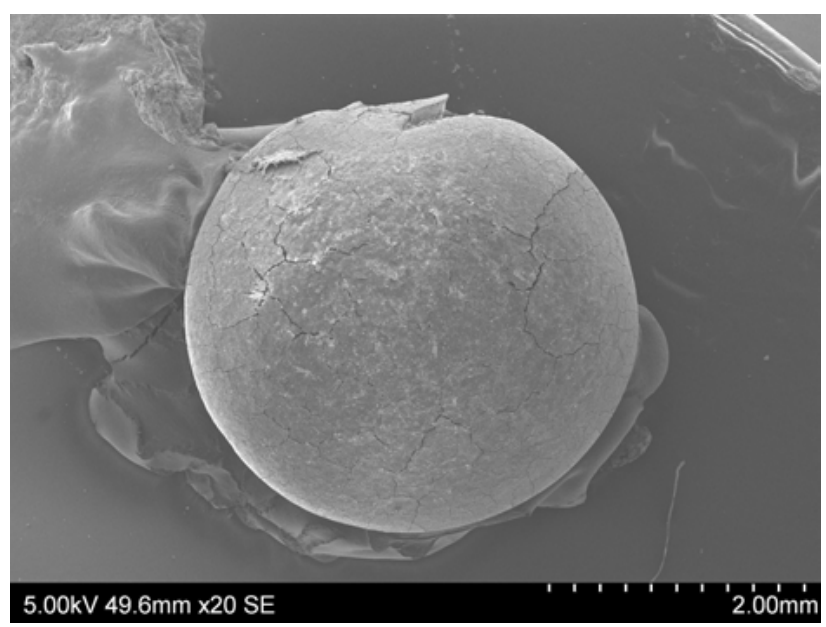

Fig. 12.25: An example of lentil (Lens culinaris); lateral view.

\section{Some other field crops}

There is a range of other crops at Paithan, and the section below will include five oilseed/fibre crops of particular note. In addition to these, there is evidence for probable brown mustard (Brassica juncea) cultivation (Fig. 12.26) and possible cucurbit cultivation, including possible melons or cucumbers (which can be difficult to distinguish on charred seeds). There are also a few tree fruits, including the ubiquitous Ziziphus, emblic myrobalan (Phyllanthus emblica) and fig seeds (not necessarily of a cultivated species) (Fig. 12.27). Possible okra seeds (Abelmoschus sp.) deserve note and further investigation in order to determine whether domesticated versus wild progenitor species might be involved. Also worthy of further investigation are Solanum seeds, listed in this report under weeds (as there are numerous weed taxa in this genus), in relation to the possible presence of eggplants (Solanum melongena), for which clear archaeobotanical identification criteria are not yet available. It should also be noted that there is evidence of probable 'mouse cucumber', Melothria heterophylla (Fig. 12.28), a wild species throughout India and much of South-East Asia that is eaten (from wild or weedy plants) but not cultivated. The Melothria-type seeds had been previously referred to as 'cf. Cucumis prophetarum' in reports on the Southern Neolithic (Fuller et al. 2004: Fig. 6H), which testifies to the fact that the gamut of cucurbitaceae species in South Asia, both wild and domesticated, still requires further comparative study.

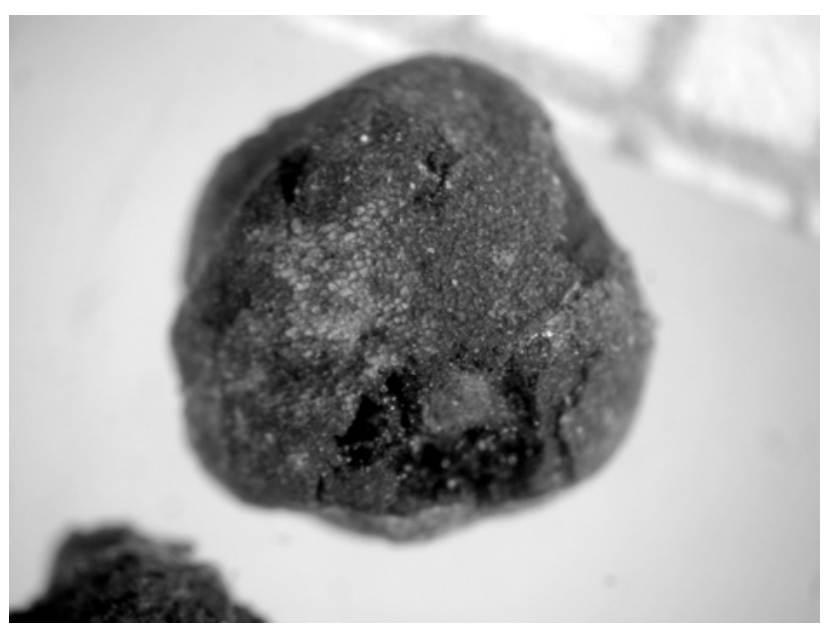

Fig. 12.26: Seed of mustard (Brassica cf. juncea) from context 985, with part of seed coat cell pattern visible.

Sesame (Sesamum indicum L. syn. S. orientale L.) (Fig. 12.29) is an oilseed crop of global importance. This crop is widely cultivated in South Asia through Burma, and somewhat more patchily eastwards. It is now firmly established that sesame has a South Asian origin (Bedigian and Harlan 1986; Bedigian 1998, 2003; Fuller 2003a), although details about when, and more precisely where, and the ecological circumstances of domestication require research. Origins in the greater Indus region seem likely. At present, the earliest archaeological evidence comes from the mature 
urban phase of the Harappan civilization (2500-2000 BC), at which time sesame would appear to have been an important oilseed crop (Fuller and Madella 2001; Fuller 2003a). Finds are nevertheless few, probably owing to the low preservation potential of oily seeds, and include finds from Miri Qalat (Tengberg 1999) and Harappa (Vats 1940: 467; Weber 1999, 2003) and Late Harappan Sanghol. In the case of Miri Qalat, sesame is absent from earlier levels, back to $4000 \mathrm{BC}$, indicating that it is likely to have been introduced to this site during the Harappan period. South Asian finds from the 2nd millennium BC and later are fairly numerous, especially from the Middle Ganges region, including Imlidh-Khurd Period II, Narhan, Kharaidih Period II, Senuwar Period II and Raj-Nala-Ka-Tila Period II (Saraswat 2004, 2005). The cultivation of this species can be considered widespread in the subcontinent by c. 1000 BC.

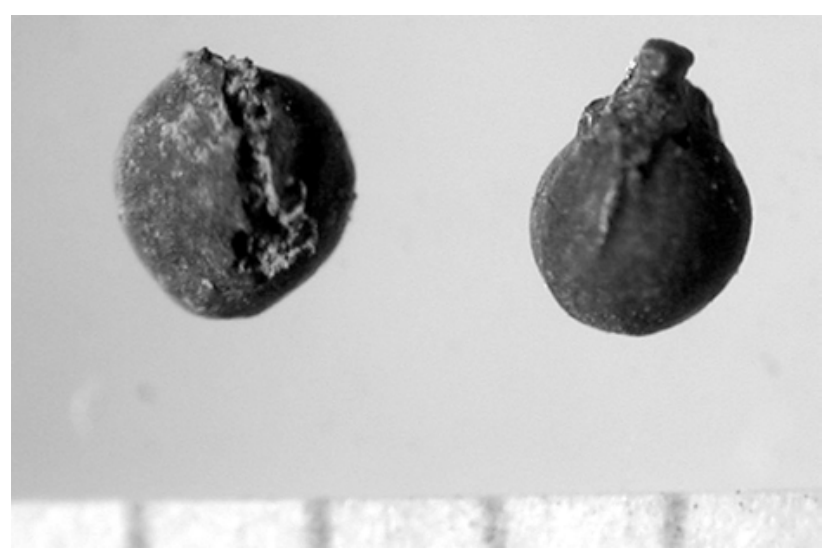

Fig. 12.27: Seeds of fig type (Ficus sp.) from context 619.

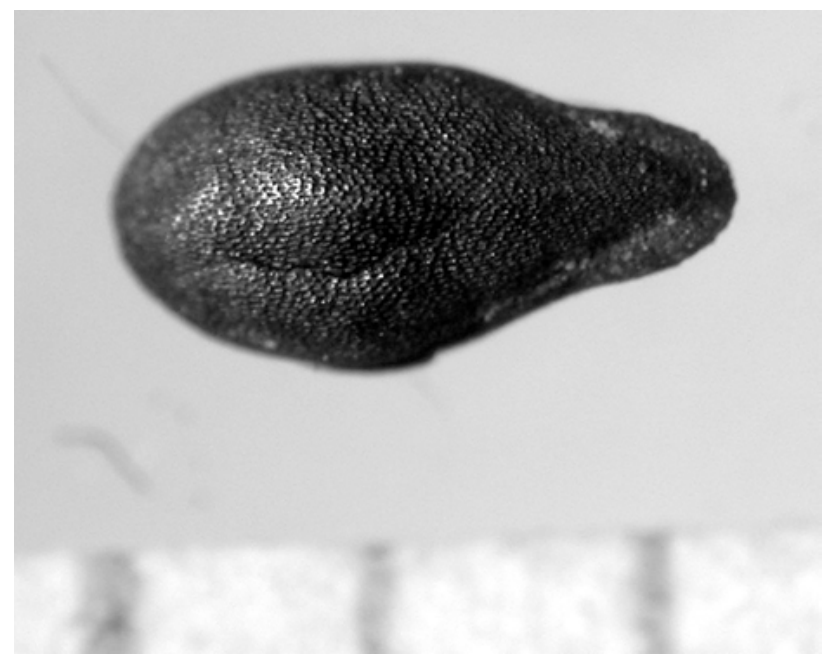

Fig. 12.28: Seed of mouse cucumber (Melothria cf. heterophylla, family Cucurbitaceae) from context 1116 .

As an oilseed, there are strong biases against preservation by charring; thus, it is not surprising that findcounts are low. At Paithan, some 67 seeds $(<1 \%$ by frequency) have been recovered from 12 samples (16\% ubiquity), suggesting fairly widespread use. Unfortunately, a large number of these come from unphased samples. In phased samples, Sesamum increased in ubiquity and frequency through Periods 2 (Satavahana) and 3 (Early Medieval) (Fig. 12.30).

Sesame grows best in well-drained soils with longwarm growing seasons and is highly drought-resistant. It generally has similar climatic requirements to cotton and is well suited to savannah environments. It is a short-day plant growing to maturity more quickly through the summer (Griffee 2001; Burden 2005).

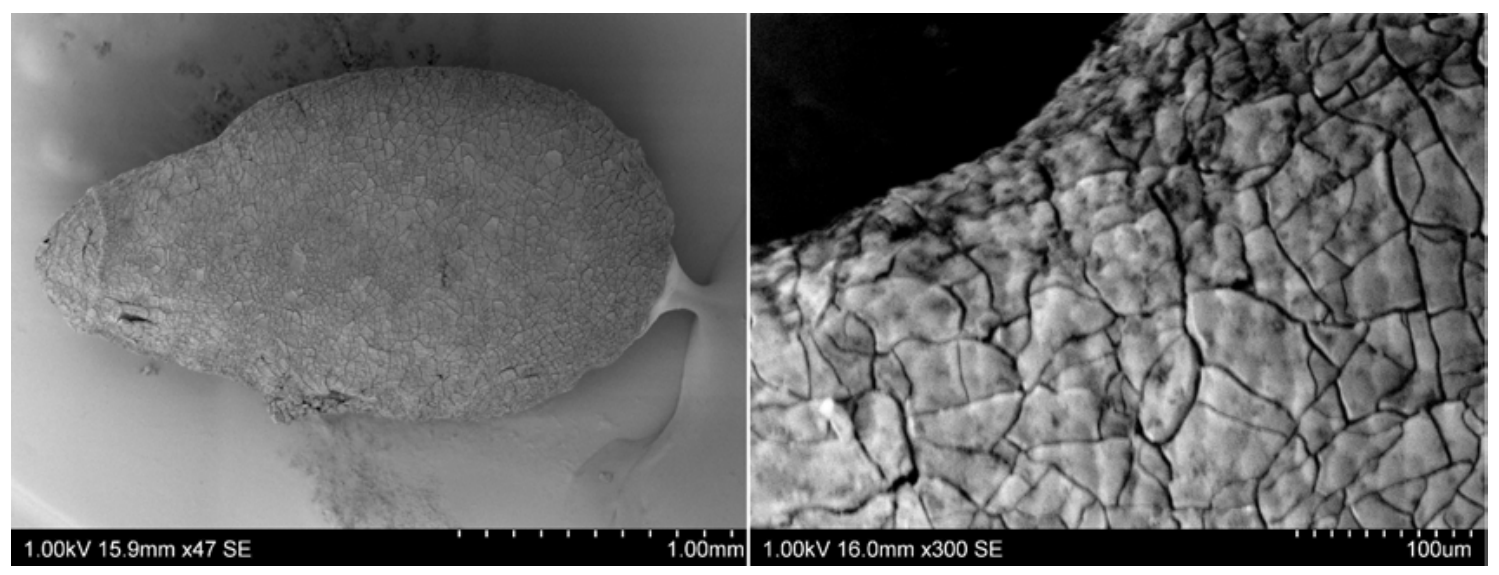

Fig. 12.29: Sesame seed (Sesamum indicum) from context 930, whole seed (left) and detail of seed coat (right). 


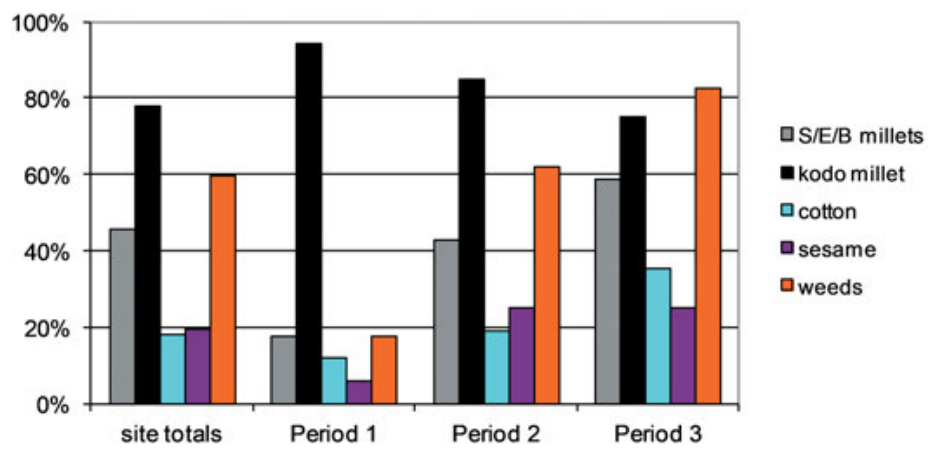

Fig. 12.30: Ubiquity of selected crop types and weeds.

Cotton (Gossypium sp.) is represented by charred whole seeds, seed fragments and sometimes a minute funicular 'cap' structure (Fig. 12.31). Although identification at species level seems impossible on the basis of preserved anatomical features, it is fairly safe to presume that these early cottons represent the indigenous species tree cotton (G. arboreum).

Cotton is grown primarily for its uniqueseed hairs that are readily spun and turned into threads and textiles. However, cotton seeds can also be pressed for oil once the fibre is removed, and with refining, this is edible. The pressed seed cakes also make a traditional fodder (Rehm and Epsig 1991: 343). There are four cotton species that are cultivated for their seed fibres today, including two of New World origin ( $G$. hirsutum and G. barbadense), which have become of global importance in the past 300 years. Indigenous to the Old World are tree cotton (G. arboreum) and short-staple cotton (G. herbaceum) (Wendel 1995). Tree cotton, G. arboreum L., is now considered most likely to be of South Asian origin (Zohary and Hopf 2000; Fuller 2002), and its early use is probably represented by finds at Mehrgarh in Pakistan in the 6th millennium BC (Costantini 1983; Moulherat et al. 2002). Archaeological evidence for cotton in South Asia is fairly extensive (see Table 12.5; Fig. 12.32). Cotton is presumed to have been an important 'cash crop' of the Indus region during the Harappan civilization, and several sites have yielded finds of cotton seeds or possible textile remains, including Harappa and Mohenjo-daro (see Weber 1999; Fuller and Madella 2001). During this era, cotton was unknown in Mesopotamia or Egypt, where textile production was focussed on flax (Zohary and Hopf 2000). Beyond the Harappan zone, cotton appears to have spread only in the post-urban period, including Late Harappan era finds on the eastern and south-eastern zones of the Harappan civilization, and from the mid to late 2nd millennium $\mathrm{BC}$, finds are reported from a number of sites in the middle Ganges region. The earliest hard evidence from South India is that from the later levels at Hallur, Karnataka, which produced a direct AMS date of c. 950 BC (Fuller et al. 2007).

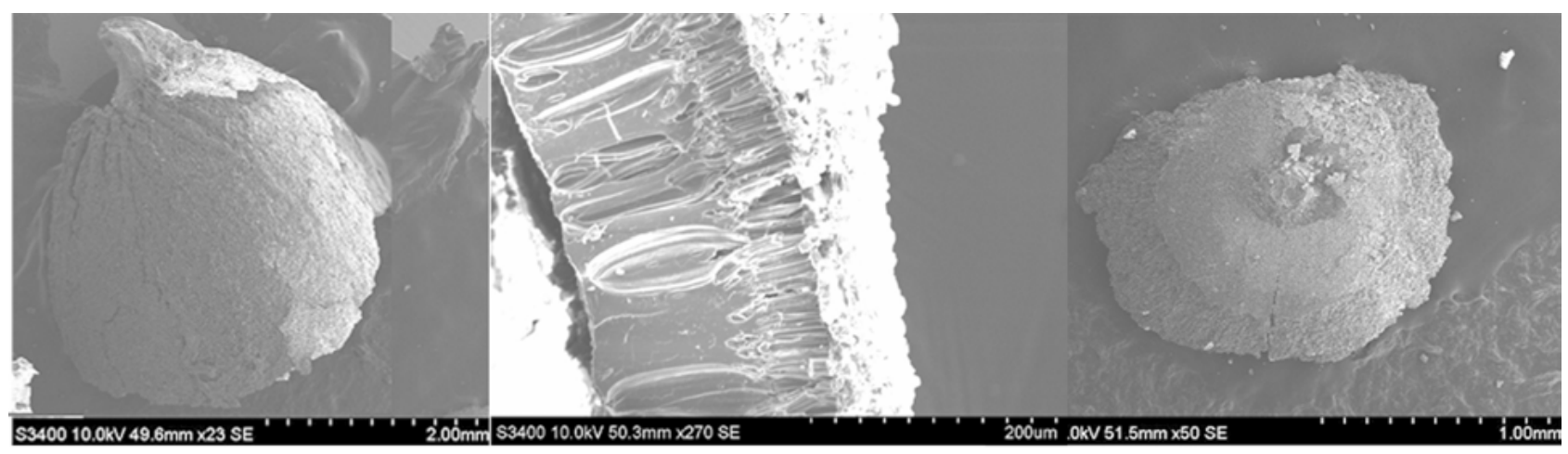

Fig. 12.31: Cotton (Gossypium sp.) remains from context 930, including fragmented seed (left), cross-section of seed coat (centre) and funicular cap from inferior seed (right). 
Table 12.5: Archaeobotanical and textile remains of cotton from South Asia.

\begin{tabular}{|c|c|c|c|}
\hline Site & Evidence & Period & Reference(s) \\
\hline Mehrgarh, Baluchistan & $\begin{array}{l}\text { Seeds (uncharred); } \\
\text { mineralized thread in } \\
\text { copper bead }\end{array}$ & Ceramic Neolithic, $6000-4500$ BC & $\begin{array}{l}\text { Costantini 1983; } \\
\text { Costantini and Biasini 1985: 24; } \\
\text { Moulherat et al. } 2002\end{array}$ \\
\hline Mohenjo-daro & Cloth & Mature Harappan, $2600-2000$ BC & Gulati and Turner 1929 \\
\hline Balakot, Sindh & $\begin{array}{l}\text { Malavaceae pollen type, } \\
\text { comparable to Gos- } \\
\text { sypium }\end{array}$ & Mature Harappan, $2500-2000$ BC & $\begin{array}{l}\text { McKean 1983; } \\
\text { also mentioned in Dales } 1986\end{array}$ \\
\hline Harappa & Seed(s)/imprints & $\begin{array}{l}\text { Mature Harappan(?), 2600-1900 } \\
\text { BC }\end{array}$ & $\begin{array}{l}\text { Weber 1999: } 818 \\
\text { Vats 1940: } 466\end{array}$ \\
\hline Kunal & Seed(s) & $\begin{array}{l}\text { Mature Harappan, ?2500-2000 BC, } \\
\text { perhaps equivalent to Harappa } 3 C(?), \\
2200-1900 \text { ВС }\end{array}$ & Saraswat and Pokharia 2003 \\
\hline Banawali & Seed(s) & $\begin{array}{l}\text { Mature Harappan (?=Harappa 3C), } \\
2200-1900 \text { BC }\end{array}$ & $\begin{array}{l}\text { Saraswat et al. 2000; } \\
\text { Saraswat } 2002\end{array}$ \\
\hline Sanghol & Seed(s) & Late Harappan, 1900-1400 в С & Saraswat 1997 \\
\hline Hulas & Seed(s) & Late Harappan, $1800-1300$ в & Saraswat 1993 \\
\hline Kanmer, Kacchh & Seed(s) & Late Harappan, 2000-1700 в С & Pokharia in Kharakwal et al. 2007 \\
\hline $\begin{array}{l}\text { Imlidh-Khurd, Gorakhpur, } \\
\text { Uttar Pradesh }\end{array}$ & Seed(s) & Period II, 1300-800 BC & Saraswat 2005 \\
\hline Waina, Ballia, Uttar Pradesh & Seed(s) & Period I, $1600-800$ в C & Saraswat 2005 \\
\hline $\begin{array}{l}\text { Sringaverapura, Dist Alla- } \\
\text { habad, Uttar Pradesh }\end{array}$ & Fibres & Late Ochre-Coloured Pottery, $1200-700$ BC & Saraswat 1986 \\
\hline $\begin{array}{l}\text { Hallur, Upper Tungabhadra, } \\
\text { Karnataka }\end{array}$ & Seeds and fragments & $\begin{array}{l}\text { Early Iron Age, AMS direct date: 950-900 } \\
\text { BC }\end{array}$ & $\begin{array}{l}\text { Fuller et al. 2004; } \\
\text { for dating: Fuller et al. } 2007\end{array}$ \\
\hline $\begin{array}{l}\text { Sanghol, Ludhiana Dist., } \\
\text { Indian Punjab }\end{array}$ & Seed(s) & Early Historic, Kushana, 200 BC-AD 300 & Pokharia and Saraswat 1999 \\
\hline Hund, Peshwar Dist., Pakistan & Seeds and fragments & $\begin{array}{l}\text { Kushana through Mughal (all periods), } 200 \\
\text { BC-AD } 1600\end{array}$ & $\begin{array}{l}\text { Fuller, unpublished data; } \\
\text { Cooke } 2002\end{array}$ \\
\hline Kausambi & Seed(s) & NBP horizon, 550-250 BC & Chanchala 1995 \\
\hline Nevasa (1954-1956 season) & Seed(s) & Early Historic, 250 BC-AD 250 & $\begin{array}{l}\text { Anonymous, in Sankalia et al. 1960: } \\
529-530\end{array}$ \\
\hline $\begin{array}{l}\text { Kodumanal, Coimbatore Dist., } \\
\text { Tamil Nadu }\end{array}$ & Seeds and fragments & $\begin{array}{l}\text { Early Historic/Late Megalithic, } 300 \text { BC-AD } \\
300\end{array}$ & Cooke et al. 2005 \\
\hline $\begin{array}{l}\text { Perur, Coimbatore Dist., Tamil } \\
\text { Nadu }\end{array}$ & Seed and fragments & $\begin{array}{l}\text { Early Historic/Late Megalithic, } 300 \text { BC-AD } \\
300\end{array}$ & Cooke et al. 2005 \\
\hline $\begin{array}{l}\text { Mangudi, Madurai Dist., Tamil } \\
\text { Nadu }\end{array}$ & Seed and fragments & $\begin{array}{l}\text { Early Historic/Late Megalithic, } 300 \text { BC-AD } \\
300\end{array}$ & Cooke et al. 2005 \\
\hline Ufalda, Garhwal, Uttaranchal & Seeds and fragments & Early Historic(?), AD 0-600 & Fuller, unpublished data \\
\hline $\begin{array}{l}\text { Singh-Bhagwantpur, Rupna- } \\
\text { gar Dist., Indian Punjab }\end{array}$ & Seed(s) & Medieval, AD 800-1100 & Vishnu-Mittre et al. 1984 \\
\hline Mangali Luduwala, Haryana & Seed(s) & Sub-recent, AD 1500-1900 & Willcox 1992 \\
\hline
\end{tabular}




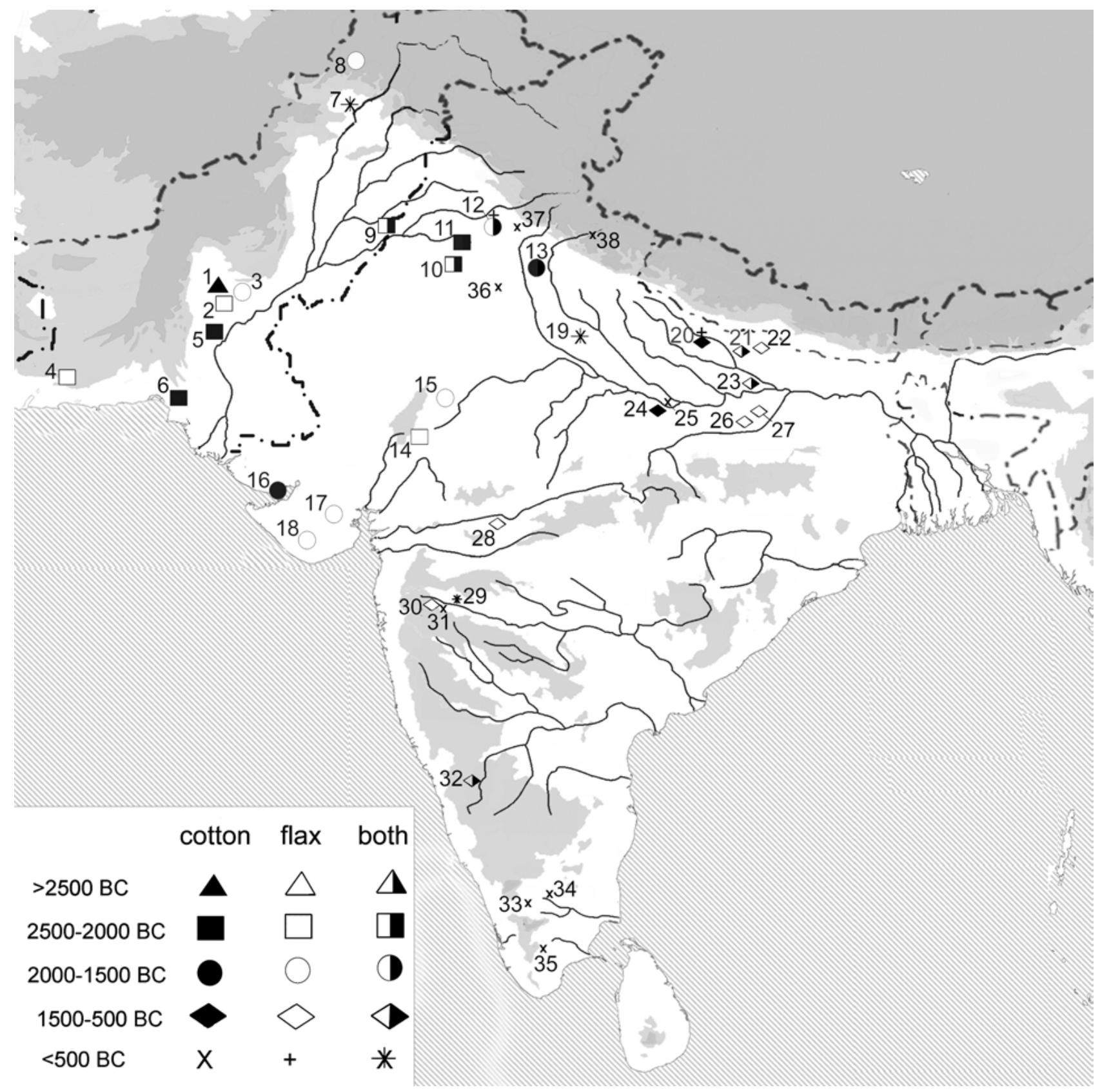

Fig. 12.32: The distribution of archaeological finds of cotton and flax seed in South Asia, indicated by broad time horizons. Sites numbered with data references: 1. Mehrgarh (Moulherat et al. 2002); 2. Nausharo (Costantini 1990); 3. Pirak (Costantini 1979); 4. Miri Qalat (Tengberg 1999); 5. Mohenjo-daro (Gulati and Turner 1929); 6. Balakot (McKean 1983); 7. Hund (Fuller, unpublished data); 8. Loebanhr 3 (Constantini 1987); 9. Harappa (Weber 1999, 2003); 10. Kunal (Saraswat and Pokharia 2003); 11. Banawali (Saraswat 2002); 12. Sanghol (indicating Late Harappan and Early Historic evidence) (Saraswat 1997; Pokharia and Saraswat 1999); 13. Hulas (Saraswat 1993); 14. Balathal (Kajale 1996b); 15. Ojiyana (Pokharia 2008); 16. Kanmer (Pokharia 2007); 17. Babor Kot (Reddy 1994, 2003); 18. Rojdi (Weber 1991); 19. Hulaskhera (see Chanchala 1992, plate 5, 24, interpreted by the present author as cotton seed fragment); 20. Charda (Saraswat 1993; Chanchala 2002); 21. Imlidh-Khurd (Saraswat 2005); 22. Narhan (Saraswat et al. 1994); 23. Waina (Saraswat 2005); 24. Sringaverapura (Saraswat 1986); 25. Kausambi (Chanchala 1995); 26. Senuwar (Saraswat 2004); 27. Raja-Nala-Ka-Tila (Saraswat 2005); 28. Navdatoli (Vishnu-Mittre 1961); 29. Paithan (this report); 30. Daimabad (Kajale 1977a); 31. Nevasa (Sankalia et al. 1960: 529-530); 32. Hallur (Fuller et al. 2004); 33. Perur (Cooke et al. 2005); 34. Kodumanal (Cooke et al. 2005); 35. Mangudi (Cooke et al. 2005); 36. Mangali/Luduwala (Willcox 1992); 37. Singh-Bhagwantpur (Vishnu-Mittre et al. 1984); 38. Ufalda (Fuller, unpublished data). 


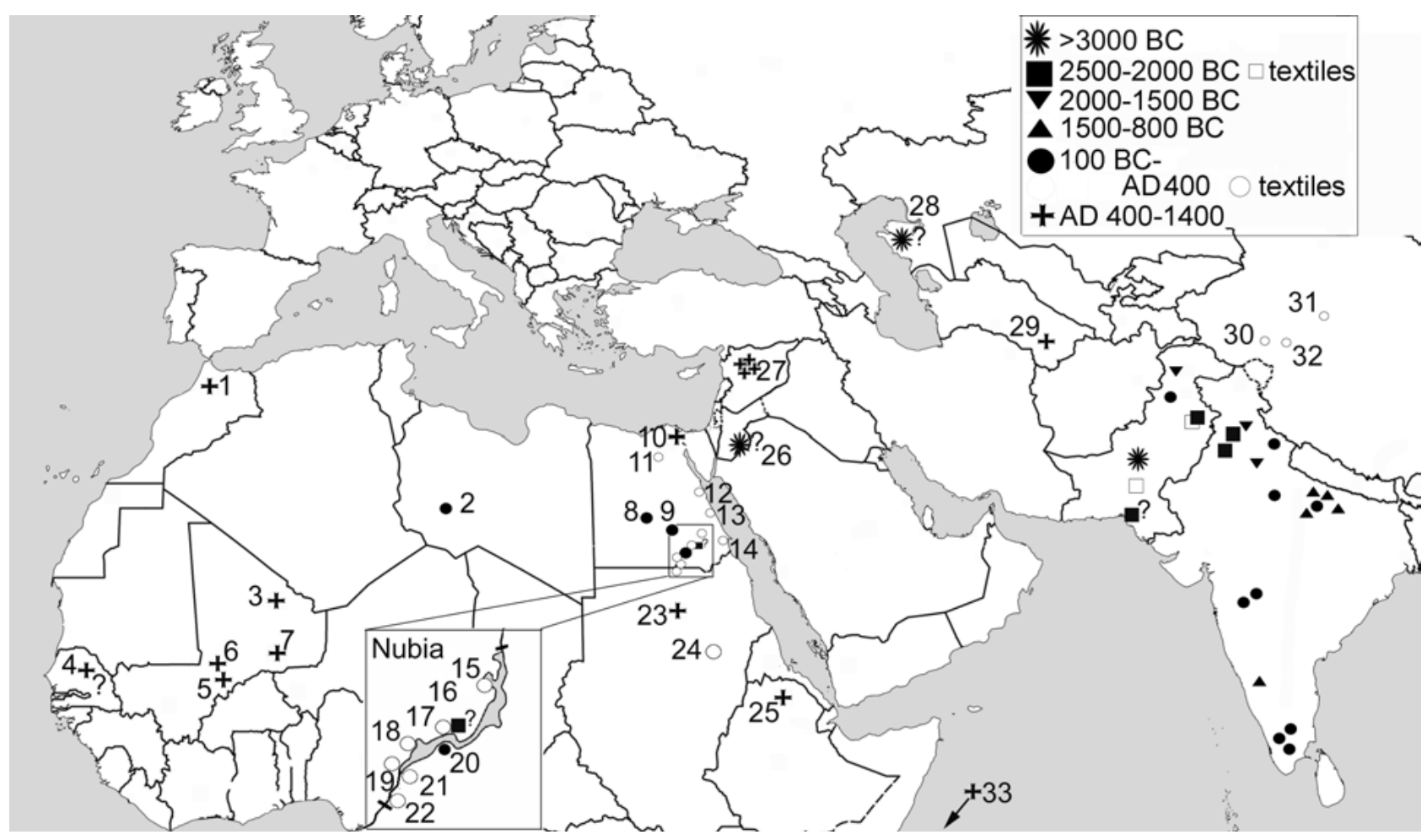

Fig. 12.33: The spread of cotton beyond South Asia: finds of seeds and textiles. Sites in India and Pakistan are unlabelled but represent those in Fig. 12.32 and Table 12.5. Other sites, with citations, are labelled as follows, with approximate dates indicated and nature of evidence if not seed remains. Question marks indicate uncertain evidence in terms of identifications, dating or indications of textile use. 1. Volubilis, AD 780-1000 (Fuller, unpublished data; cf. Pelling 2005); 2. Jarma, C. AD 200 (Pelling 2005); 3. Essouk (Murray and Nixon 2006); 4. Ogo, pollen, AD 1100-1200 (Chavane 1986); 5. Tellem burial caves, Bandiagara escarpment, textiles, AD 1100-1500 (Marr 1978; Boland et al. 1991); 6. Dia, AD 1000-1600 (Murray 2004, 2007); 7. Gao, AD 1200-1500 (Fuller 2000); 8. Dakleh Oasis, AD 200-400 (Thanheiser 2002); 9. Khargeh Oasis, AD 300-400 (Clapham and Rowley-Conwy 2009); 10. Tinnis, pre-AD 1200 (Clapham and Rowley-Conwy 2009 ); 11. Karanis, thread, AD 300-500 (Wilson 1933); 12. Abu Sha'ar, textile, AD 300-700 (Bender-Jorgensen and Vogelsang-Eastwood 1991); 13. Quesir al-Qadim, textile (Eastwood 1982); 14. Berenike, textiles, AD 0-500 (Wild and Wild 1998, 2001, 2005); 15. Wadi Qitna, AD 300-400 (Strouhal 1984); 16. Afyeh, c. 3000 BC, seeds in dung (Chowdhury and Buth 1971: 2005); 17. Karanog, textiles, AD 100-300 (Griffith and Crowfoot 1934); 18. Arminna West, textiles, AD 200-500 (Fuller, unpublished data); 19. Ballanna, AD 0-500 (Mayer-Thurman and Williams 1979); 20. Qasr Ibrim, seeds, capsules, fibres and textiles, 25 BC-AD 1800 (Clapham and Rowley-Conwy 2009 ); 21. Qustul, AD 0-500 (Mayer-Thurman and Williams 1979); 22. Second cataract cemeteries, AD 100-500 (Bergman 1975); 23. Nauri, seeds, AD 1000-1400 (Fuller and Edwards 2001); 24. Meroe West cemetery, textiles (Griffith and Crowfoot 1934); 25. Axum, AD 400-800 (Boardman 1999); 26. Dhuweila, fibres in plaster, 4400-3000 BC (Betts et al. 1994); 27. Sheheil, AD 700-800, Guftan, AD 1000-1100, Medād, AD 1100-1200, Hrim, AD 1200-1300, charred seeds (Samuel 2001); 28. Maykop kurgan, textiles, 'cotton-like', 3700-3200 BC (Shishlina et al. 2003); 29. Merv, seeds, AD 300-500 (Nesbitt 1993, 1994); 30. Sampul (Mallory and Mair 2000: 155); 31. Ordek (Mallory and Mair 2000: 152); 32. Niya (Mallory and Mair 2000: 165); 33. Arrow pointing in direction of Pemba island sites, Tumbe, AD 600-1000, and Chwaka, AD 1100-1600 (Walshaw 2005). For additional recent finds, see Viot 2019. 
The quantity of cotton found at Paithan shows a marked increase over the lifespan of the site (Fig. 12.30), suggesting an increasing investment to cash-cropping and a probably local textile production.

Tree cotton is normally harvested in the summer. It is a crop that likes high temperatures but also requires sufficient water. It is also important that in its final stages, as the cotton bolls form, that it is kept dry and free of rain, or else fibres will become discoloured and may become mouldy. In much of India, cultivation can rely on the monsoon, but in the Indus region, it is likely that systems of irrigation were developed. It is therefore conceivable that the spread of this crop to other regions also involved irrigation.

The production of textiles is an important part of craft-production economies in two ways: firstly to do with craft and secondly with agriculture. In terms of craft, textiles are labour-intensive and time-consuming to produce. They require labour for spinning and weaving after the initial fibre processing, which itself involves several stages: dehusking, seed removal (ginning), cleaning and smoothing, bowing or carding to separate the fine fibres, which are then rolled and ready to be spun. Only then can weaving of the threads or yarn be done. Accounts of traditional cotton processing from different regions are similar, including those from ancient India (Schlingloff 1974). In recent centuries, much of this process has been aided by mechanical developments, but traditional ginning was a labour-intensive method involving a rolling pin (often metal) and a wooden board which was used to force out seeds. Bowing is done with a bow-like instrument in which a vibrating cord helps to loosen the separation of the fibres. The implication of all this is that cotton production requires both the expenditure of labour in cultivation, beyond subsistence requirements, and in the household, in processing, but with the result of a commodity by which wealth can be accumulated and fairly easily transported, or sequestered by elites. The production of textile crops implies additional surplus production beyond what is required to feed families and communities. It is therefore necessarily production for trade, as fields of textile crops produce fibre far beyond what individual households are likely to use or need. In addition, it seems unlikely that all farming households that produced cotton crops would have also had the time and skill necessary to process raw cotton through to finished textiles, and this implies the trade of cotton to craftspeople. While it is conceivable that cotton might be grown on a small, garden scale for household needs, such production would be unlikely to produce recurrent finds in archaeobotanical samples from an urban excavation. Thus, we can conclude that there is likely to have been production for consumption above the household level. Craft crops such as cotton therefore constitute important evidence of early 'cash-cropping' (sensu Sherratt 1999).

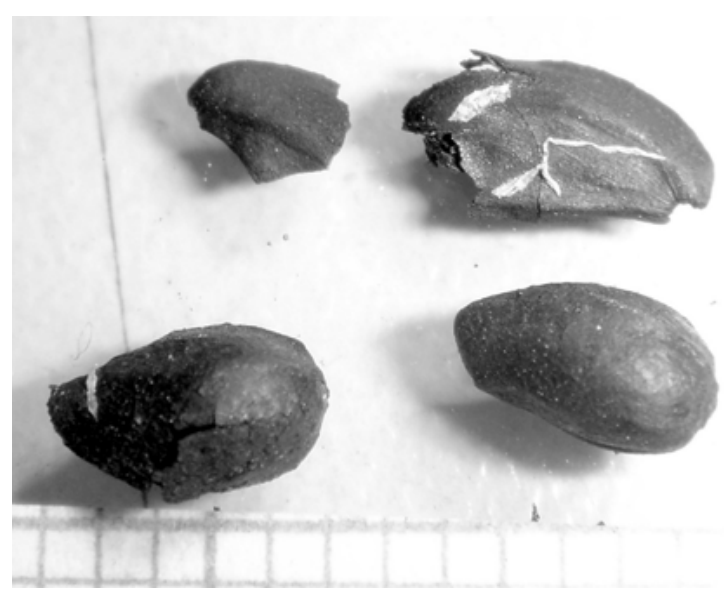

Fig. 12.34: Safflower (Carthamus tinctorius) from context 841.

That cotton was an important trade commodity of peninsular India in Early Historic times is implied by evidence from Roman importation of cotton cloth, including specifically from Paithan. Importation is indicated archaeologically by cotton textile finds at the Roman-era port of Berenike on the Red Sea coast of Egypt, which are inferred to have come from India on the basis of Z-spun threads; these finds dominate the archaeological textile record at the port (Wild and Wild $1998,2001,2005,2008)$. Cotton is also indicated as an import from India in Papyrus Vinod from Egypt (Casson 1990; Sidebotham 1991). Importation is also discussed in ancient Roman texts, including the Periplus Maris Erythraei, a 1st century AD Roman mariner's travel guide, written in Greek, probably in Egypt, which is associated with several sites in the Deccan. The site of Ter (reached overland from Paithan) is specifically named, as are Minnagara and Ujjain to the north of Paithan (Wild and Wild 2008; see Casson 1989). While Paithan was not specifically named as a source of cotton cloth, the archaeobotanical evidence suggests that it was part of a broader Indian geography of cotton production. The distribution of archaeological finds, whether in north-eastern Africa orCentral Asia, is predominantly from the Roman period (the Chinese Han period) (Fig. 12.33), testifying to the widespread trade in cotton during the Indian Early Historic period. 
Flax/linseed (Linum usitatissimum) is present in one sample. This species originated in the Near East and is widely cultivated for its edible oily seeds, as well as for its fibres. Divergent varieties have been developed for each of these specialized functions (Zohary and Hopf 2000). The seed oil is important for human consumption but is not easy to store once extracted from the seeds. Extracted from the seeds, the oil goes rancid but has other uses such as a lighting fuel or lubricant. Identifying Linum archaeologically is fairly straightforward, although congeneric wild species, which are widespread in Eurasia, may be difficult to distinguish definitively. In South India, for example, there is an indigenous L. mysurense (Saldanha 1996), but seeds of this species are expected to be much smaller.

Within India, the spread of Linum correlates with that of cotton, moving east and south of the Harappan zone in post-Harappan/Chalcolithic times, especially towards the latter part of that period (Fig. 12.32). This correlation suggests that Linum moved as a fibre crop, although oilseed varieties are likely to have also been present. The meagre evidence of this species at Paithan should not be taken as evidence that it was not present in the region, given the strong biases against seeds of this species surviving charring, although it is probably safe to conclude that this was in much less frequent use as an edible oilseed than sesame.

As discussed in relation to cotton, the spread of flax as a fibre crop implies a level of 'cash-crop' production and agricultural production beyond the basic surplus level. It is also a labour-intensive species to process. Processing plants for fibres involves rippling and retting (soaking with partial fermentation of stems), followed by pounding and combing to separate the internal (bast) fibres (for a synopsis, see McCorriston 1997: 522-524), after which spinning and weaving are possible. Unlike cotton, which had an international export market, linen may have been for more local use.

Safflower (Carthamus tinctorius) (Fig. 12.34) is used for its edible, oily seeds as well as its colourful flowers and pollen, which can be used in dying as well as in cooking. Safflower is a thistle-like winter annual, producing yellow, orange or red flowers (capitulum). Due to its large taproot, it tolerates dry conditions and is thus suitable for cultivation during the dry winters of South Asia. It produces a cypsela with a fibrous shell, within which is an edible oily kernel, like that in sunflower seeds. Like the main winter cereals and pulses, safflower has its origins in the Near East, but early finds suggest domestication rather late, perhaps as late as the end of the 5th or 4th millennium BC (Zohary and Hopf 2000). By the end of the 4th millennium BC, it had spread in India, as it has been found in quantity in a jar from an early level at Balathal in Rajasthan (Misra and Mohanty 2001). During the 2nd millennium $\mathrm{BC}$, it had become widespread in South Asia, with finds reported from Daimabad and Nevasa during the Malwa period (Kajale 1991), and several late 2nd millennium or early 1st millennium BC sites in the middle Ganges, including Imlidh-Khurd (Period II), Narhan, Waina (Period II), Senuwar (Period II) and Raja-Nala-Ka-Tila (Period II) (Saraswat et al. 1994; Saraswat 2004, 2005). Its archaeological distribution therefore parallels that of flax and cotton.

At Paithan, safflower is represented by a few fragments in Period 1 and two well-preserved fruits from an unphased sample.

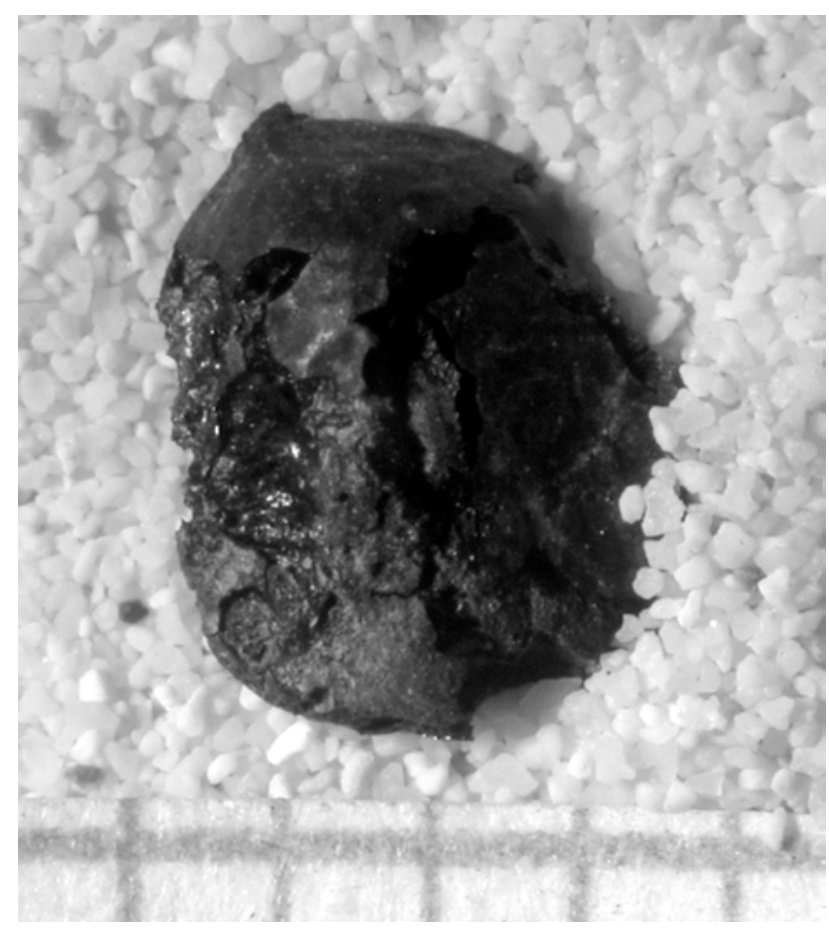

Fig. 12.35: Lone specimen, poorly preserved, of possible hemp (cf. Cannabis sativa) from context 1128.

Hemp, Cannabis (Fig. 12.35), is a highly polymorphic group of plants, which have been widely spread through cultivation and naturalization. Traditional taxonomy groups all of these as a single variable species as all forms are interfertile (Small and Cronquist 1976; Zhou and Bathelomew 2003). Plants are monoeious, producing either male or female flowers. Hemp is the distinctive thick-stemmed and large-seeded form that have been selected as fibre-producing and also have large, 
edible oily seeds. By contrast, a much more herbaceous form, with much smaller seeds, is typically cultivated as a drug plant with higher concentrations of the psychotomimetic compound, especially in female flowers, conventionally called Cannabis sativa ssp. indica, or $C$. indica Lamarck. Hillig (2005) recognizes three species: a west Eurasian C. sativa sensu stricto, which included fibre of oilseed landraces from Central Asia, West Asia, Europe and northeast Asia; $C$. indica, including all of the various drug cultivars, feral populations in South Asia, which are common in the Himalayas, and Chinese fibre cultivars; and the wild species Cannabis ruderalis. Although criteria for separating these species have not yet been developed for charred seeds, we expect the $C$. indica type to have been present, with its main uses for the drug, some use for its edible oily seeds and perhaps as a minor fibre source, much as is true in recent times (Watt 1889-1893; Pandey and Chanda 1996). It is a winter crop.

The few finds in South Asia are from the 2nd millennium BC, when it was probably introduced from Central Asia (cf. Fuller 2006a: 38). Phytoliths of Cannabis have been reported from Harappa (Fuller and Madella 2001: 338; Madella 2003), from the Late Harappan period (after 2000 BC). Charcoal evidence and charred seeds were found at Chalcolithic levels at Senuwar, 1300-600 вс (Saraswat 2004). The single specimen from Paithan, which is probable Cannabis, is therefore worthy of note. As oily seeds, there are major preservation biases against this species.

\section{The potential of archaeobotanical weeds}

Most of these species probably entered the archaeological record as part of crop-processing waste, as weedy contaminants are a normal part of any harvest (Hillman 1984; Reddy 1997, 2003; Stevens 2003; Harvey and Fuller 2005). Some species might also have entered the site with fuel, such as remains of fodder or grazed plant in dung fuel, although this is regarded generally as a less likely scenario in this case (see Fuller et al. 2014; Fuller 2003c). Therefore, weeds provide a record of the ecology of arable fields, which in turn may provide insights into the nature of agriculture in the past. Unfortunately, this is confounded by two issues: lack of species-level resolution in identification and uncertainty about which crops particular weeds are to be associated with. Some weeds most likely came onto the site with rice, such as sedges (Cyperaceae) and Ischaemum (cf. Galinato et al. 1999) (Fig. 12.36), while

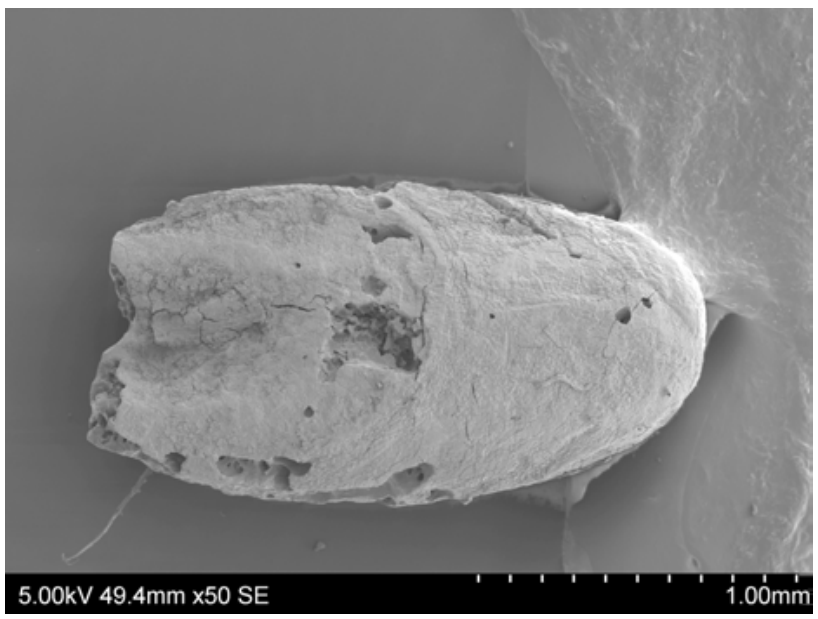

Fig. 12.36: Weedy grass, wrinklegrass (Ischaemum rugosum) from context 1116, dorsal view.

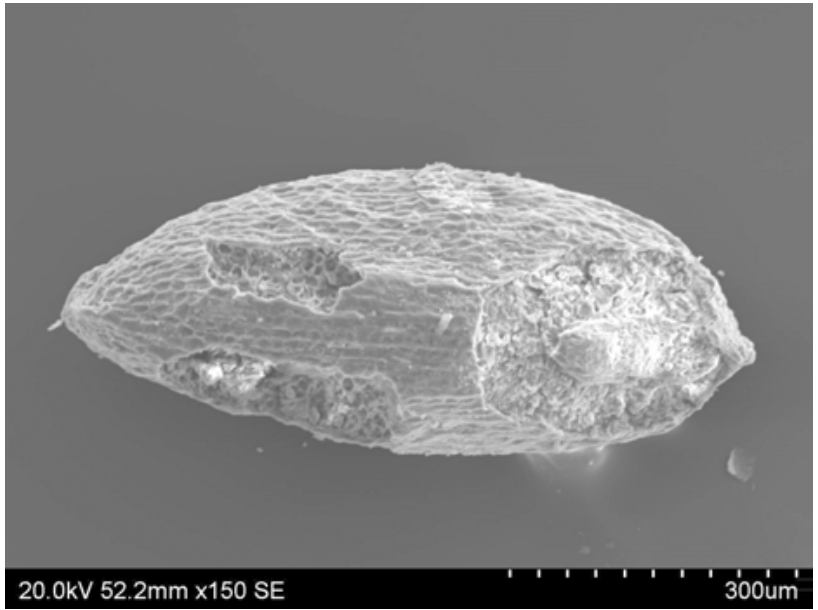

Fig. 12.37: Weedy grass, Indian goosegrass (Eleusine indica) from context 721, dorsal view.

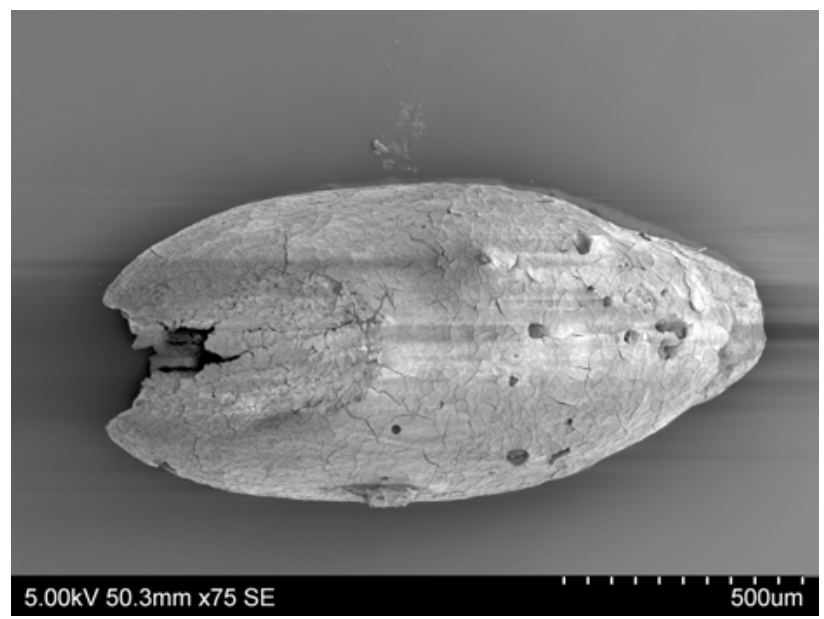

Fig. 12.38: Weedy grass, fingergrass (Digitaria sp.) from context 1116, dorsal view. 
others are more plausibly millet crop weeds, including the carpetweeds (discussed below) and Rubiaceae, as well as grasses such as Eleusine indica (Fig. 12.37), Digitaria (Fig. 12.38) and Urochloa. Other weed species may cut across several crops.

Another potential use of weed data is for inferring aspects of crop-processing, as weed seeds of particular size and weight characteristics are systematically removed from crop-processing at different stages. Once again, confounding factors include the large diversity of crops at Paithan, which may not have all been treated the same way. Nevertheless, one trend is clearly evident which is towards increasing quantities of weeds, from less than $2 \%$ relative frequency (18\% ubiquity) in Period 1, to $12 \%$ (and 62\%) in Period 2, to $23 \%$ (and 82\%) in Period 3. The total number of weed species, however, does not change (43 taxa). These data strongly suggest that more routine crop-processing stages are being carried out on site in Periods 2 and 3 compared to Period 1. It is also notable that in the two later periods there is a greater range of small-seeded weeds, such as Digitaria, Eragrostis, Urochloa and the Aizooaceae species. We expect many weed seeds, especially small seeds, to be removed early in the crop-processing sequence, i.e. through winnowing. The absence of this from the site during Period 1 could imply a more centralized organization of agricultural labour during this period, with larger workgroups available for processing in the fields immediately after harvest and fewer stages of processing carried out on site in domestic contexts on a day-to-day basis (see discussion of reasoning in Stevens 2003; Harvey and Fuller 2005; Fuller et al. 2014). It may also be the case that this change relates to the move away from an emphasis on kodo millet towards a more diversified cropping system. It may be that agricultural diversification and intensification were linked with an increasing emphasis on smaller, household units of productions.

Three recurrent and recognizable weeds in the family Aizooaceae are singled out for discussion together with a Rubaiceae type as these have been widely found in South Asian archaeobotany and it should now be possible to identify them accurately to species and to consider their significance. In the discussion some ethnographic uses are also mentioned, although it should be stressed that such uses are unlikely to have resulted in recurrent exposure to fire and archaeological recovery. Nevertheless, the presence of the species raises the possibility of multivarious uses in the past.

\section{Carpetweeds}

Three species of carpet weeds (family Aizooaceae) recur in the Paithan assemblage: Zaleya decandra, Trianthema portulacastrum and Trianthema triquetra (Fig. 12.39). Zaleya cf. decandra (L.) Burm. f. (syn. Trianthema decan$d r a)$ is a widely encountered seed type. It is a curled discoidal seed with an ornamented surface, which is typical of several major Caryophyllid families. As with many Aizooaceae, the seed coat ornamentation tends to be represented by wavy ridges that are concentric with the curl of the seed. In this case, they are represented by short, round rugouse ridges. Archaeobotanical examples identified to this species were illustrated by Vishnu-Mittre (1990) at Surkotada (also Chanchala 1994: pl. 1.20) and were also reported throughout the sequence at Rojdi, but in large quantities only from the Late Harappan Phase C (Weber 1991: 96). These seeds are commonly encountered in Southern Neolithic material (Fuller 1999). Comparable reference material is illustrated from a congeneric species by Kirkbride et al. (2006). This appears to be the same species identified as 'Portulaca cf oleracea' at Inamgaon (Kajale 1988: 818, fig. 27), and possibly also at other sites. The large hilum of Portulaca is, however, missing, as are the distinctive beads of the surface decoration, suggesting earlier misattribution of Zaleya specimens. This is a common weed in the open, dry areas of the inner Deccan that flowers after the monsoons, with reported seed sets in October-November or during the winter (Tadulingam and Venatanarayana 1985; Singh et al. 2001). Its distribution and archaeobotanical finds imply an association with millets. Common names include Belekomme or Gaijasoppe (Kannada), Tella-Galijeru (Telugu), Vellai Sharanai (Tamil) and Gadabani (Hindi) (Saldanha 1984; Tadulingam and Venatanarayana 1985; Ambasta et al. 1986). Some medicinal uses are reported for its roots, while the leaves have served as a famine food (Ambasta et al. 1986).

Trianthema portulacastrum L. (syn. T. monogyna L.) has plump curled seeds, with narrow beaks near the hilum and wider, somewhat square, ends. From the square end radiate faint wavy ridges, which are periodically discontinuous (cf. Noda et al. 1985). This species is also known from Chalcolithic and Iron Age sites in the Ganges basin, e.g. Narhan (Saraswat et al. 1994), Hulaskhera (Chanchala 1992) and later Early Historic sites, e.g. Manji (Chanchala 2000-2001). This species has not been noted in the Southern Neolithic assemblage and may be later addition to the peninsular weed flora. It is reported from Rojdi but only from the Late Harappan Phase C (Weber 1991: 95). Today this is a widespread and 'aggressive' weed of cultivation in India and elsewhere (Tadulingam and Venatanaray- 
ana 1985; Singh et al. 2001). The seeds are readily spread through animal dung. Nevertheless, it has some medicinal uses, can be fodder and is useful as a green manure (Ambasta et al. 1986). Its common names include Pundharoighentuli or Ghol (Marathi), Lal-sabuni (Hindi), Santhi (Gujarati), Ambatimadu or Galjeru (Telugu), Muchchugoni or Pasale-soppu (Kannada) and Shaaranaj (Tamil).

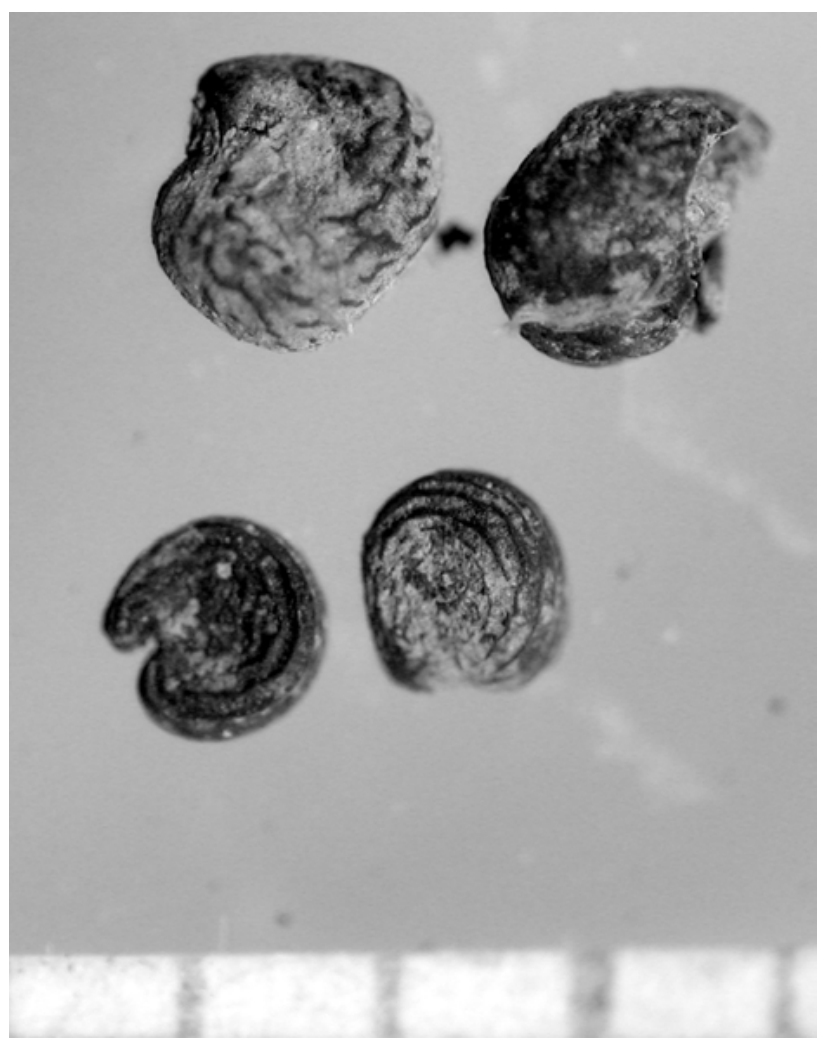

Fig. 12.39: Two species of carpetweeds (Aizooaceae) from context 933: Trianthema portulacastrum (above) and Trianthema triquetra (below), lateral views.

\section{Trianthema triquetra Willd. Ex Rottl}

These seeds are smaller and more flattened than either of the previous two species and have distinctive concentric ridges that run as uninterrupted rings around the seeds (cf. Kirkbride et al. 2006). These occurred occasionally in Southern Neolithic samples, as the author has examined, and are also reported from Late Harappan Rojdi Phase C (Weber 1991: 96) and the Early Historic period at Shirkapur (cf. Chanchala 1994: pl. 2.16). The species is also reported from the Early Historic Punjab at Sanghol (Pokharia and Saraswat 1999), but not in early Chalcolithic levels (Saraswat 1996-1997). It is reported as occasional in scrubland and moist soils, but favouring saline sandy soils
(Saldanha 1984; Tadulingam and Venatanarayana 1985; Ambasta et al. 1986; Singh et al. 2001). It is not regarded as a significant weed under regular cultivation (i.e. regular tillage), being more common on field edges (Tadulingam and Venatanarayana 1985), and it may be poisonous to livestock (Ambasta et al. 1986). It normally seeds from September to November. Local names include Naye-soppu (Kannada), Kukkapalakoora (Telugu), Siru-Sharanai (Tamil) and Pathar-phor (Rajasthani).

Borreria/Spermacoce (Rubiaceae) (Fig. 12.40) consists of small mericarps in which seeds are assymetrical, ovoid and one smooth convex back opposite a linear indentation in which a tubular attachment is present. These might be compared with miniature elongate coffee beans. This type is well represented in Southern Neolithic samples (Fuller 1999: C39) and occurs throughout the sequence at Harappan Rojdi (Weber 1991: 66). The widespread weed Spermacoce articularis L. f. (syn. Borreria hispida (L.) K. Schum.) is the most likely species, although this has not yet been confirmed against reference material, and two other species from the genus are reported from Maharashtra (Singh et al. 2001). These 'buttonweeds' are all low $(<30 \mathrm{~cm})$ to prostrate annual herbs that fruit at the end of the monsoon and are reported from light soils (Tadulingam and Venatanarayana 1985; Singh et al. 2001). This type is a likely millet weed; it is also traditionally used as fodder and the seeds and the leaves have medicinal uses (Ambasta et al. 1986). Common names include Ghanti-chi-bhaji (Maharati), Guthari (Hindi), Madana-budama (Telugu), Natha-churi (Tamil) and Madanabudu-maegiddah (Kannada).

Caryophyllaceae/Molluginaceae types are small curled discoidal seeds with distinct warted surfaces and small beaks above the hilum. They are rounder than the typical temperate Silene or Stellaria but a precise match is not yet available from reference material or seed atlases. This same type is known from the Southern Neolithic (Fuller 1999: C37). Another Caryophyllaceae or perhaps Molluginaceae type has distinct radiating ridges (Fig. 12.41) and should be identifiable when reference material is available. The situation is similar with the seeds of a mallow (cf. Malva sp.) (Fig. 12.42), and further comparative work is needed on seeds of this group from India, although several taxa are known as weeds. These latter weeds highlight the pressing need to develop a more comprehensive reference collection of wild herbaceous plants from peninsular India. 

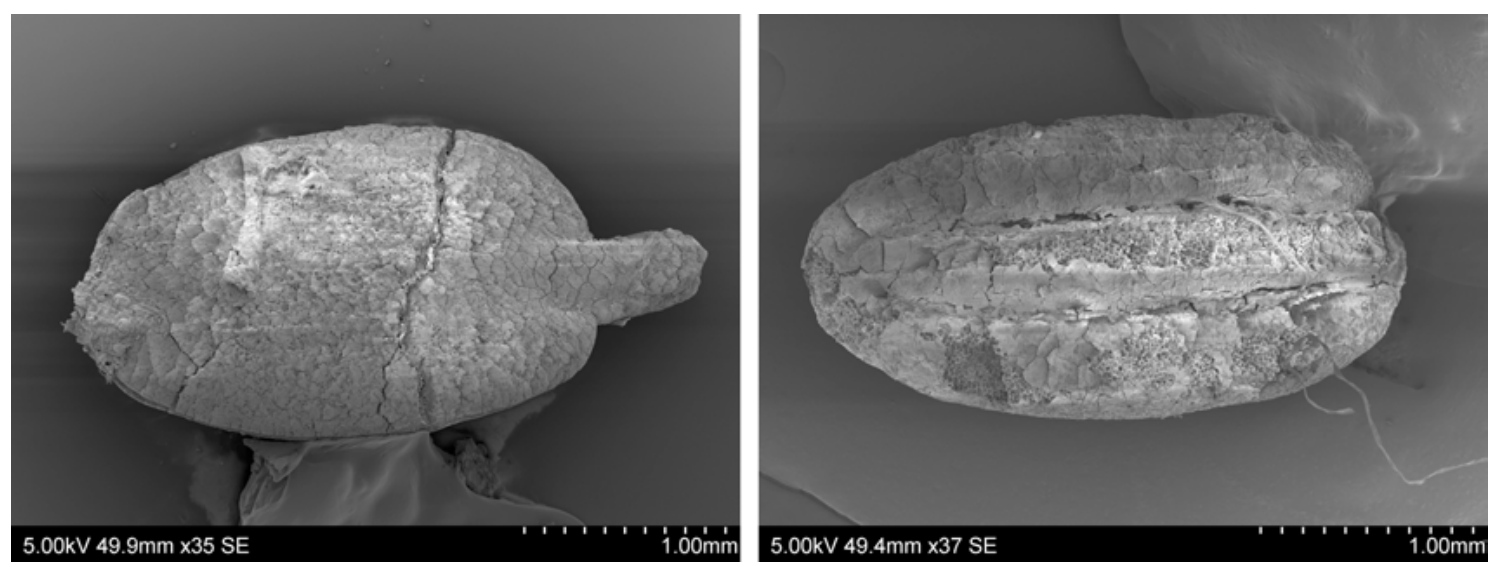

Fig. 12.40: Buttonweed mericarp (Borreira/Spermacoce) from context 1116: dorsal (left) and ventral view (right).

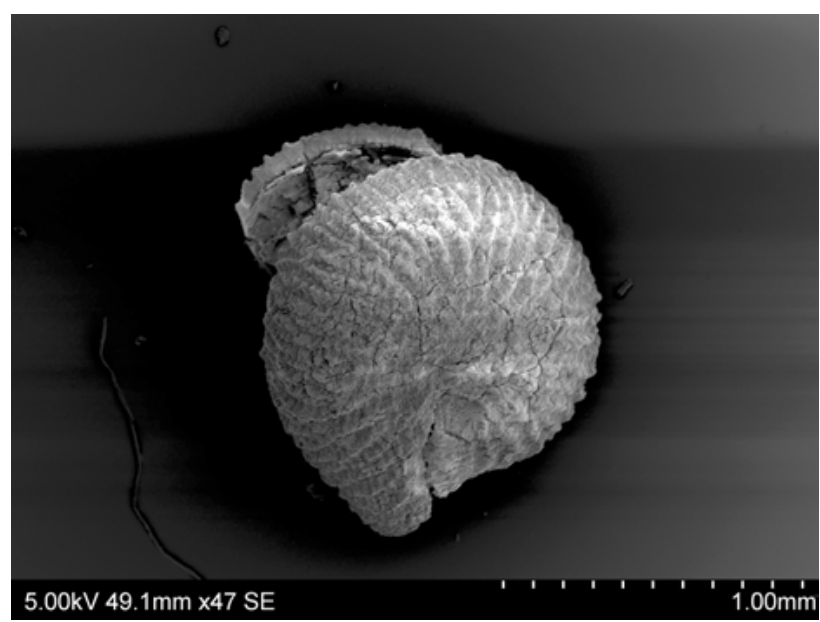

Fig. 12.41: Indeterminate weed type of Caryophyllaceae/Molluginaceae type from context 721 , lateral view.

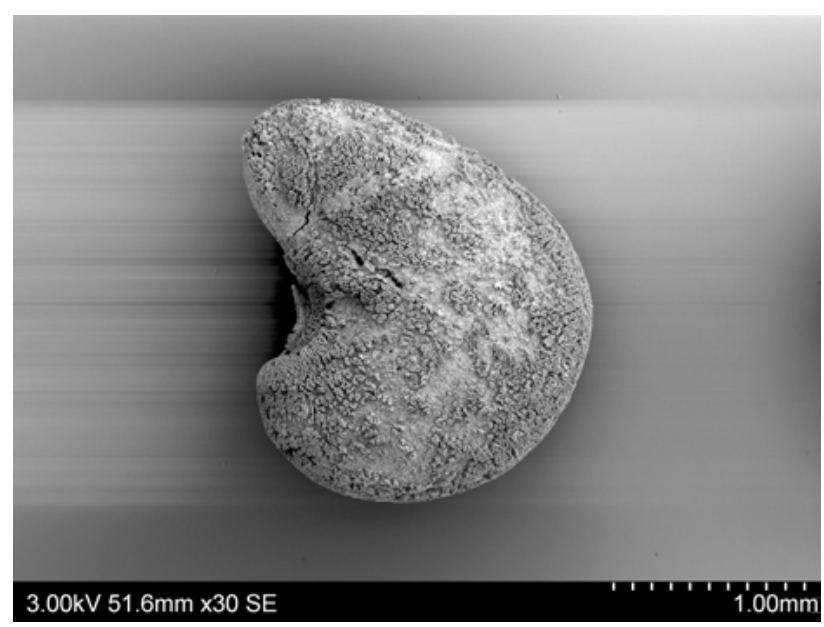

Fig. 12.42: Weedy mallow type seed (Malvaceae, cf. Malva), lateral view.

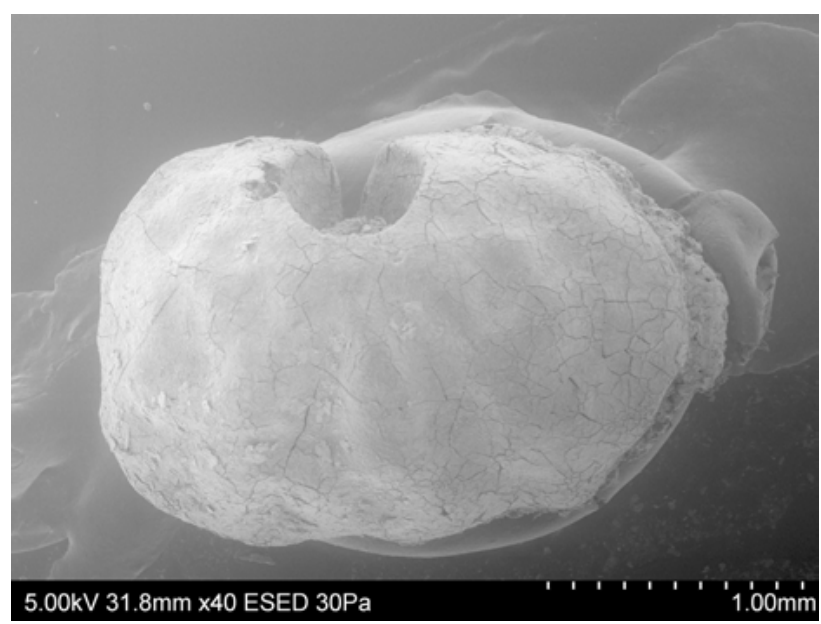

Fig. 12.43: Weedy dayflower seed (Commelina cf. benghalensis) from context 486 , dorsal view.

An additional weed type of note is the dayflower (Commelina cf. benghalensis) (Fig. 12.43). This species is common today as a weed of both irrigated and rainfed rice (Galinato et al. 1999). This species is reported as an occasional weed in the Neolithic and Chalcolithic Ganges, presumably of rainfed rice, but became increasingly common in Iron Ageand Early Historic times probably with the increase in irrigated rice (see Fuller and Qin 2009: table 2). A very similar type, however, has also been found in Southern Neolithic samples, suggesting that this may also be a weed of millets (Fuller 1999: fig. C4,B).

\section{Concluding remarks}

The Paithan excavations have provided a rich archive of plant use from the Early Historic to Medieval periods. This represents the botanically richest archaeological 
assemblage to date from the peninsular region. This is a result of routine sampling and flotation as part of the excavations but is also a product of the diversified plant economy practiced by the ancient inhabitants of the Godavari. Paithan has contributed important evidence on the history of several major crops. As should be evident from the discussion above, there are many issues which require further investigation and further evidence, and therefore, more programs of archaeobotanical sampling and laboratory investigation are needed on more sites. The staple cereals appear to have been millets, well adapted to the semi-arid savannah zone of peninsular India, and in particular native millets, of which kodo millet was pre-eminent in the Satavahana period. By the Early Medieval period, the African crops, sorghum and pearl millet had risen in importance together with foxtail millet (Setaria italica), but the South Indian native Brachiaria ramosa remained in cultivation. Rice was consistently present, but in relatively low amounts, suggesting that it may have been a high-status cereal. Another important crop throughout the sequence at Paithan was cotton. The presence of charred cotton seeds implies that processing of cotton bolls for fibre took place on site and that cotton was cultivated in the surrounding region. Thus, we have archaeobotanical evidence that Paithan was one of many Early Historic centres of cotton textile production for trade. The general importance of cotton cloth export from the Deccan is implied in Roman historical sources, as well as archaeological finds at Berenike on the Red Sea coast of Egypt (Wild and Wild 2008).

The patterns of change testified to through the site's occupation sequence suggest various strategies for increasing agricultural production, which in turn may imply a growing population. There is an unambiguous increase in the biodiversity of plant species, including a wider range of crops. There is also more emphasis on winter pulses through time. This implies both diversification of cropping strategies and probably cultivation of a wider range of soil types, including more marginal areas. In addition, it suggests increased double-cropping and reduction of the fallow periods between crops, i.e. true intensification (see Morrison 1994). It may be that agricultural diversification and intensification were linked with an increasing emphasis on smaller, household units of producers, as is suggested by the evidence for increased on-site processing of crops. 